\title{
Composting Possibilities for Sanitation Provision Ciudadela of Pachacutec/
}

\author{
Joseph Adrian Sauvé, B.Arch. \\ A thesis submitted to the faculty of Graduate Studies \\ in partial fulfillment of the requirements for the degree of
}

\section{MASTER OF ARCHITECTURE}

M.ARCH. (Professional)

Carleton University, Ottawa, Ontario, Canada

(C) 2007, Joseph Adrian Sauvé 
An informal slum community called Pachacutec, located on the urban fringe of Lima, Peru has several sanitation provision deficiencies that the Peruvian government has yet to and appears unable to address. A new sanitation approach using a composting facility and collection process can boost the proportion of the population with access to improved sanitation. In doing so, it should operate within the economic, technological and human resource capacity of the community, using profit incurred from compost and small trees sales to finance its services. As an alternative to ocean dumping in Peru, composting can also encourage the greenification of parks and schoolyards in addition to stopping the spread of pathogens that contribute to intestinal disease. This thesis will draw from local and international sources to demonstrate the potential for a pilot project initiative. If the proposed pilot is eventually constructed it will be a foundation for further research. 
1.0 Visible Design Context: Ciudadela Pachacutec 15

2.0 Proposal A: Composting for Single Family and Shared Group Plots 23

3.0 Proposal B: Compost Facility for Ciudadela Pachacutec 38

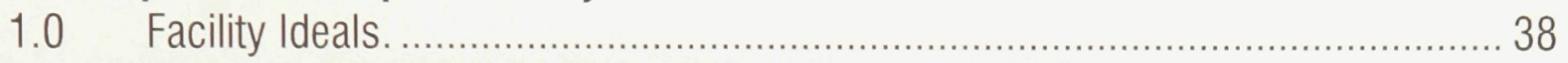

2.0 Compost Facility Plan of Implementation ……............................................... 39

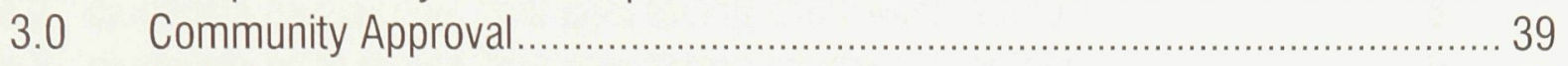

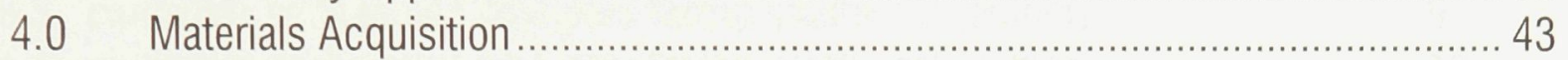

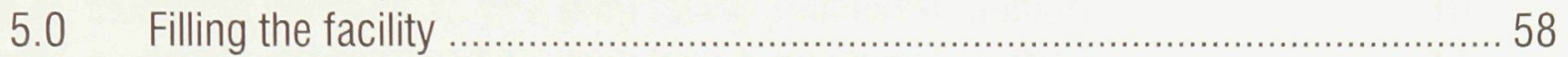

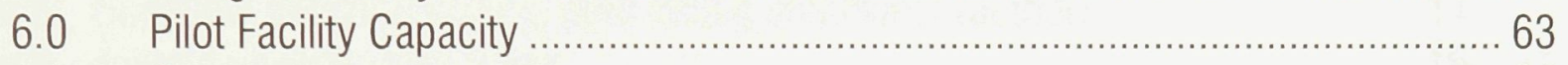

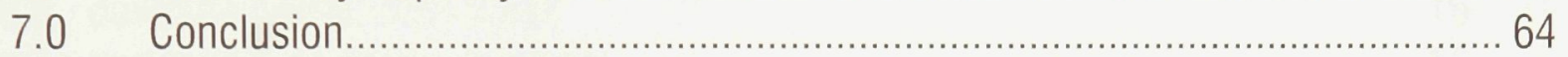

Appendix A. Invisible Design Context I: Protection of Health and Self-Mobilization 68

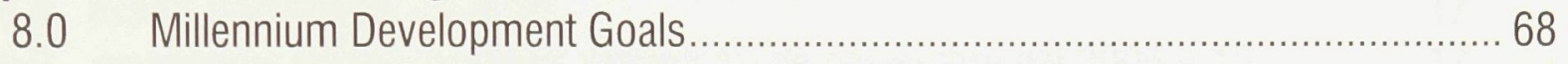

$9.0 \quad$ Agenda 21 and CSD-2

10.0 Water and Sanitation in the World's Cities ................................................ 73

11.0 Design Context lists: Transmission pathways, underlying and direct causes .... 76

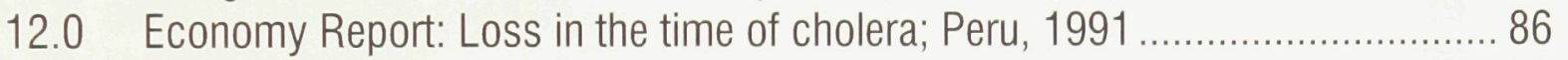

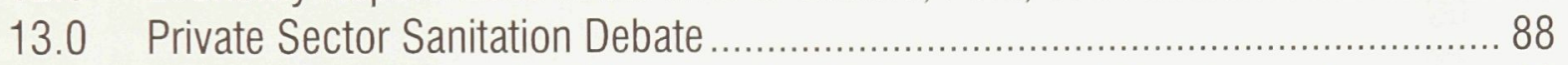

14.0 Participation: International Institute for Environment and Development ............. 89

Appendix B. Invisible Design Context II: Peru's National Sanitation Policies $\quad 91$

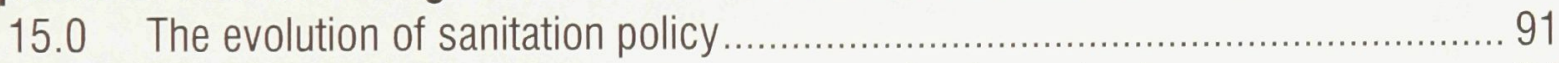

16.0 Local stake-holders, and regulation groups for the peri-urban. ...................... 94

17.0 Policy Driven Technological Gaps ............................................................. 96

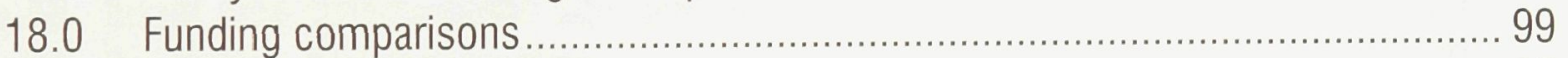

19.0 Issues with International Collaboration ...................................................... 99

20.0 Compost Provision and Peruvian Law...................................................... 101

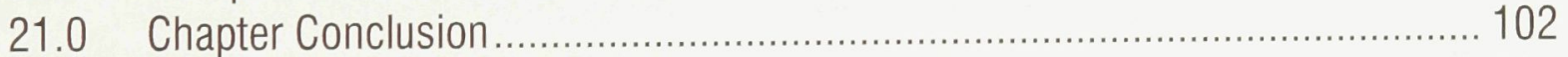

Appendix C. Building on Innovation: Technology and Potential 104

22.0 World Bank Technical Paper.................................................................. 104

23.0 Technical Options: World Bank and Joseph Jenkins .................................... 108

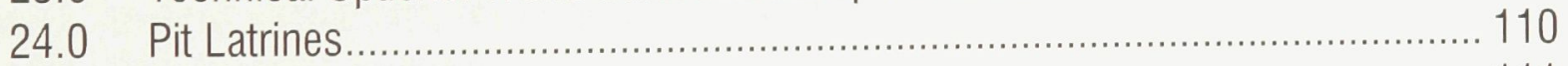

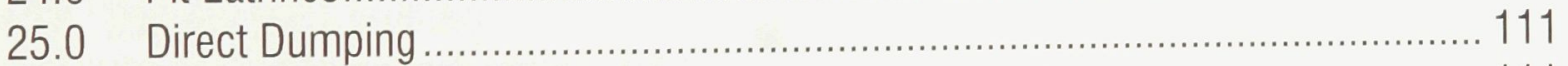

26.0 Large Scale Machine-Ventilated............................................................... 111

27.0 Simplified Self-Aerated Method for Sanitation............................................. 119

28.0 Composting Facility Cost Analysis .......................................................... 122

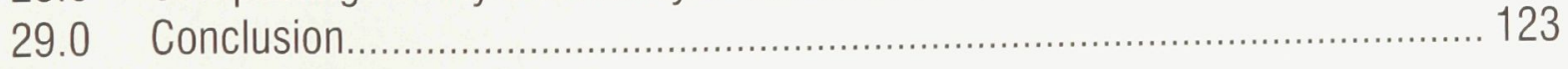


figure 1 ciudadela pachacutec lima peru facing southwest (author) 7

figure 2 ciudadela pachacutec lima peru facing southwest (author) 8

figure 3 ciudadela pachacutec lima peru facing southwest (author) 9

$\begin{array}{ll}\text { figure } 4 \text { ciudadela pachacutec lima peru facing southwest (author) } & 10\end{array}$

figure 5 ciudadela pachacutec lima peru facing southwest (author) 11

figure 6 downtown lima: mira flores 16

$\begin{array}{lll}\text { figure } 7 \text { san martin de porres (author) } & 16\end{array}$

figure 8 desert community (author) 17

figure 9 newspaper image: aja lima, martes 15 de noviembre del 2005 p.16 17

figure 10 children's games at community center (author) 18

$\begin{array}{ll}\text { figure } 11 \text { garden in the desert (author) } & 18\end{array}$

$\begin{array}{ll}\text { figure } 12 \text { garden courtyards (author) } & 19\end{array}$

figure 13 illustration (author) 20

figure 14 illustration (author) 21

figure 16 northeast over independencia, lima. google earth inc. september 2005. 23

figure 17 mary's house below hogar communitario (author) 24

figure 18 hogar communitario (author) 25

figure 19 new hogar communitario site looking west (author) 29

figure 20 hogar new communitario site (author) 29

figure 21 illustration diagram (author) 30

figure 26 drawing of compost bin diagram for buckets 1 of 4 (author) 34

figure 27 drawing of compost bin diagram for buckets 2 of 4 (author) 35

figure 28 drawing of compost bin diagram for buckets 3 of 4 (author) 36

figure 29 drawing of compost bin diagram for buckets 4 of 4 (author) 37

figure 30 plano de lima metropolitana, toribio anyarin in jante (altered by author) 40

figure 31 map of pachacutec found in police commissioners office in pachacutec 41

figure 32 flat bed truck (author) 43

figure 33 drawing of formwork and crossbar (author) 44

figure 34 drawing of formwork and poles (author) $\quad 45$

figure 35 drawing of formwork and beam (author) 46 
figure 36 drawing of formwork t-joint (author) 47

figure 37 drawing of completed 't' with sweeping figures (author) 50

figure 38 drawing of archimedes screw (author) 51

figure 39 drawing of platform (author) 52

figure 40 drawing of platform storage (author) 52

figure 41 drawing of toilet (author) 53

figure 42 drawing of improved toilet design (author) 55

figure 43 toilet construction from donated wood pallets, mitch's garage (author) 56

figure 44 toilet construction from donated wood pallets, mitch's garage (author) 56

figure 46 improved wood pallet toilet closed (construction and photo by author) 57

figure 45 improved toilet with open lid (construction and photo by author) 57

figure 47 drawing of completed row at full capacity (author) 59

figure 48 drawing of bucket cleaning process (author) 61

figure 49 drawing of unloading process (author) 61

figure 50 illustration composting facility panel (author) 65

figure 51 illustration composting facility panel (author) 66

figure 52 illustration composting facility panel (author) 67

figure 53 informal divide pachacutec at night (author) 84

figure 54 pachacutec street (author) 84

figure 55 bathroom addition (author) $\quad 85$

figure 56 boys and girls pit latrines (author) 85

figure 57 pit latrine (author) 86

figure 58 pit latrine (author) $\quad 86$

figure 59 source: evaluation report, p.64. 95

figure 60 table source: evaluation report p.52. 100

figure 61 envirolet toilet: envirolet.com $\quad 115$

figure 62 source: humanure handbook- composting toilet systems p. 87-88 117

figure 63 source: humanure handbook- composting toilet systems p. 102-108 118

figure 64 source: humanure handbook- composting toilet systems p. 102-108 119

figure 66 pathogen destruction chart, humanure handbook, p.152 120

figure 67 humanure handbook -third edition p.225. 122 
History has shown us very clearly that one cannot constructively transform a society from the outside. All genuine transformations have been initiated from within the society, even though in many cases the genesis for such transformations lay in the cross fertilization of ideas and experiences from different countries.

Rajni Khothari, Poverty: Human Consciousness and the Amnesia of Development

Development without self help is an impossibility, but people whose surroundings are ugly and barren are apt to be unproductive and dispirited. This is not the idle speculation of a do-gooder. Any factory manager knows its truth...the human spirit is our most precious resource. Its ecology is our greatest challenge.

William R. Polk: Forward for Hassan Fathy, Architecture for the Poor

There are many examples in the world where the high costs of environmental degradation are plainly seen with hindsight but were not quantified at a time when something could have been done to prevent them. The valuation of productive soils in the future may be much greater than we now can quantify and, with hindsight, composting may eventually look more attractive.

Letitia A. Obeng and Frederick W. Wright: Co-composting of domestic solid and Human Wastes

Article 7 of the Political Constitution of 1993 [of Peru] stipulates that everyone has a right to the protection of their health, the family environment and the community, as well as the obligation to contribute to the promotion and defense thereof.

Constitución Poliica del Perú

What fecophobes may not understand is that those of us who aren't fecophobes understand the human nutrient cycle and the importance of recycling organic materials...I'm simply suggesting that we begin considering new approaches to the age-old problem of what to do with human excrement.

Joseph Jenkins: The Humanure Handbook 


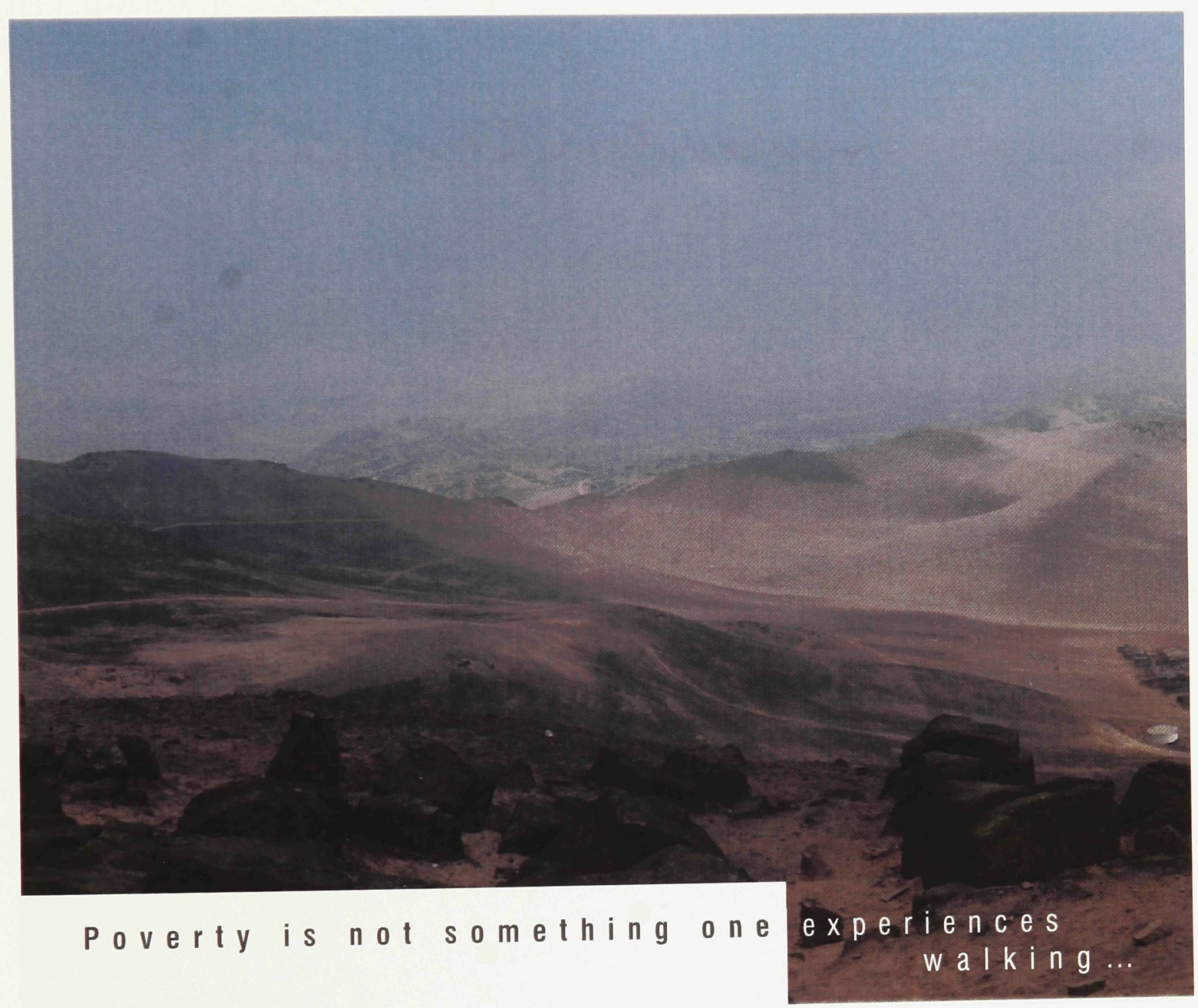

Figure 1 


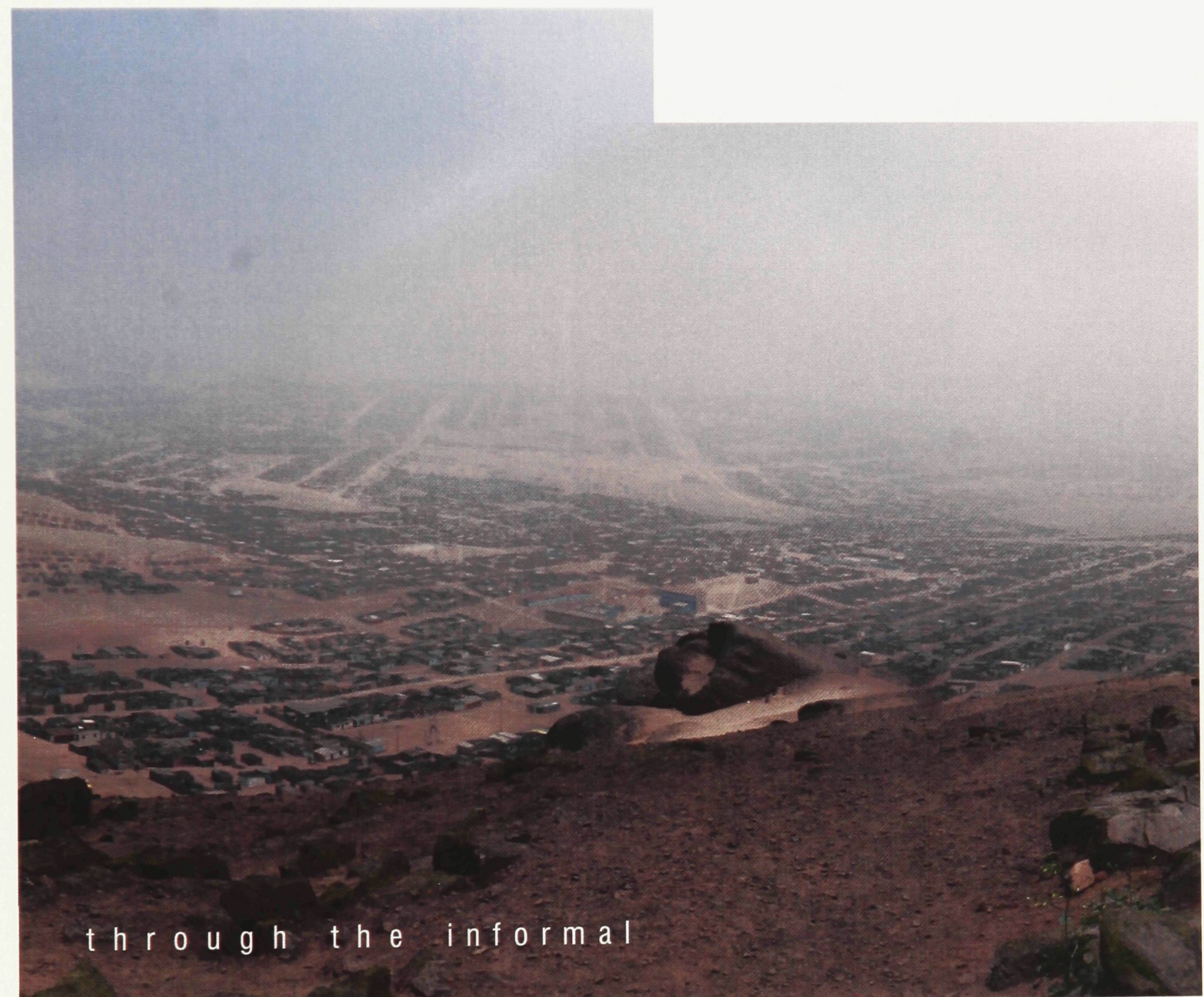

Figure? 


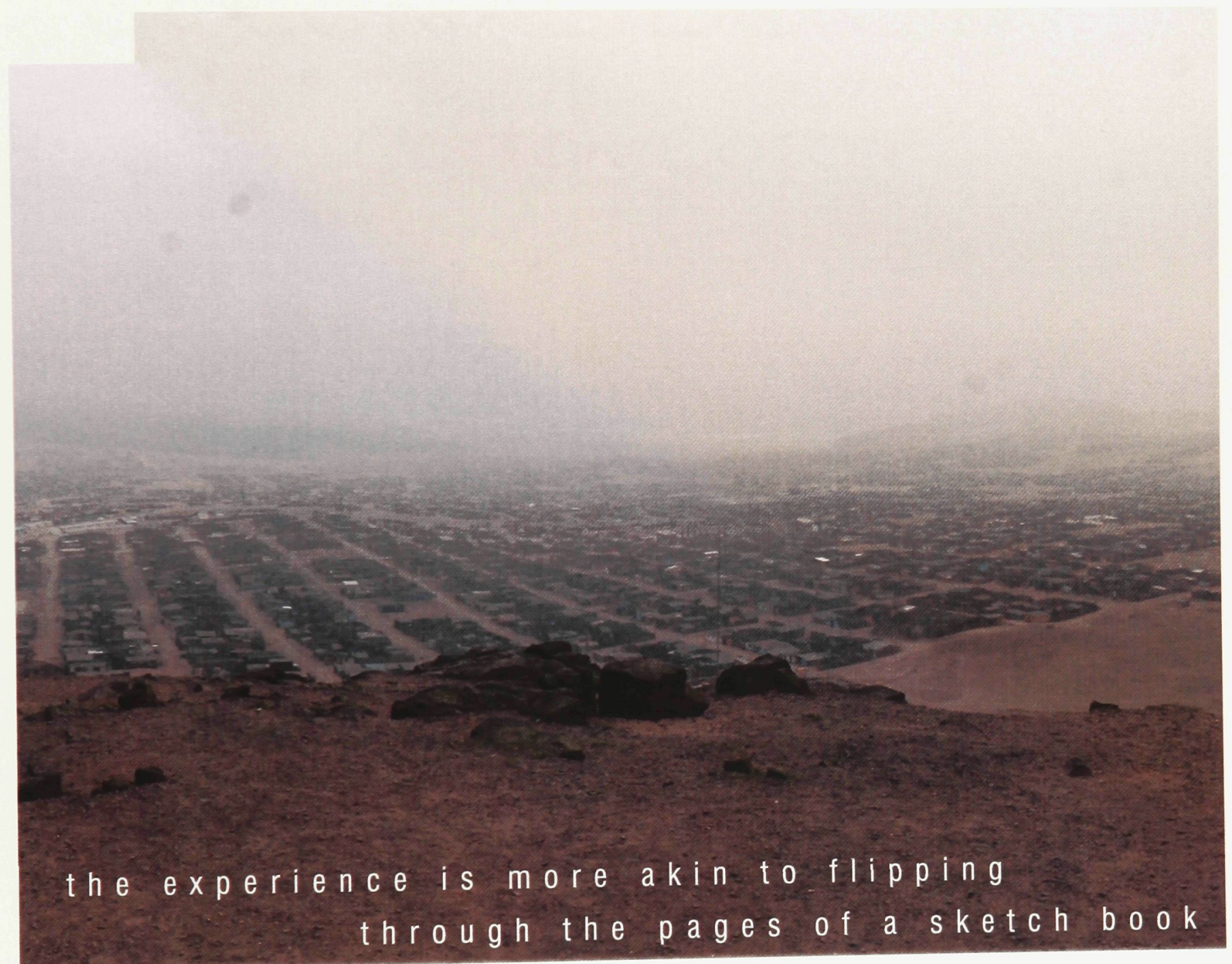

Figure 3 


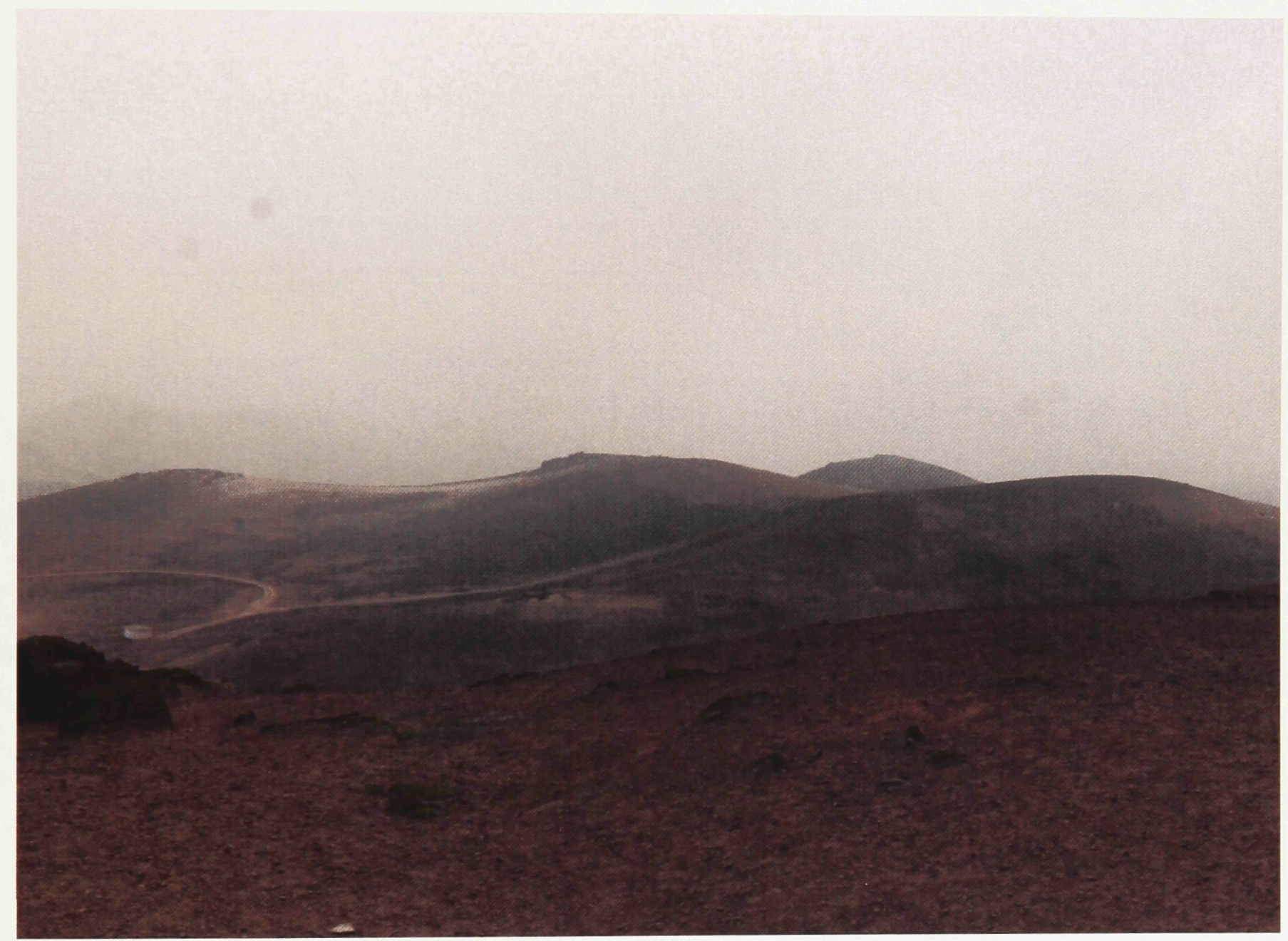

the ideas are unrefined and uninitiated

Figure 4

facing southwest october 2005 


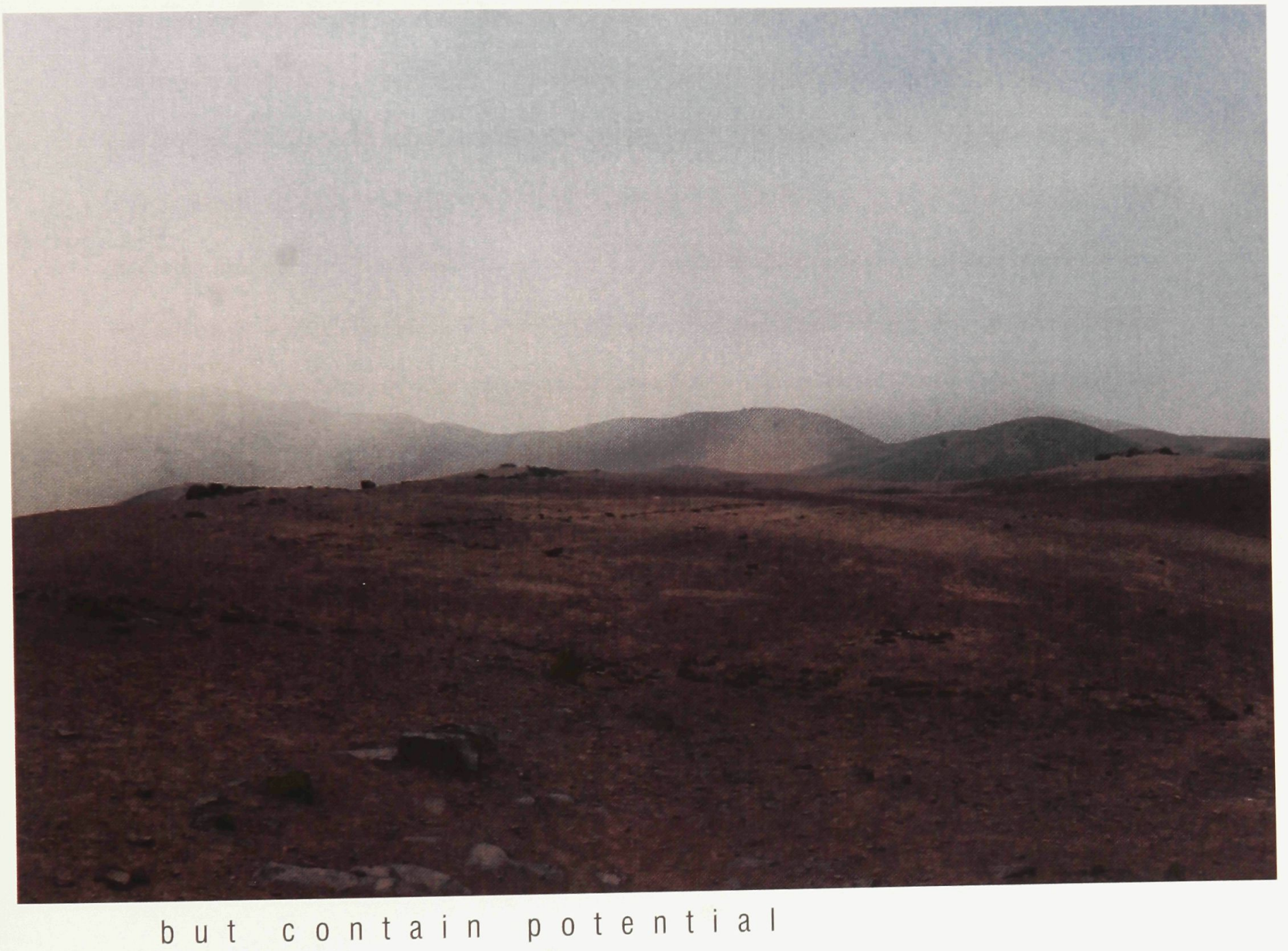

Figure 5 
As designers, we respond to the contextual opportunities in our built environment with a motive and a method to improve upon it. Urbanization due to population growth has declined in most 'developed' parts of the world and aiding initial development is more efficient than renovating built space, thus the greatest opportunities for urbanization currently lie in the rapidly expanding cities of the 'developing' world. Far from utopia, unplanned urbanization is turning our world into 'a planet of slums'. There are two central mechanisms for change to facilitate improvement: global population growth and mass migration to urban centers. Without determined design initiatives to guide urban expansion, fifty years from now these will subside to a predicted cool down period. Improvement is slowest in cities that have stopped growing, thus one can predict there is strong potential for large slums to remain in a state of poor construction. Meeting sanitation in slums is one of the greatest opportunities for improvement.

Informal communities of so-called 'trapped capital', or what economist Hernando De Soto terms 'extra-legal settlements' ${ }^{2}$ have grown from Peru's institutional inability to keep pace with the global trend of urbanization. Lima is currently the $14^{\text {th }}$ largest urban center in the world, and still growing ${ }^{3}$. Because one-third of Lima's population of nine million is illegally squatting, and because mass migration to the urban core is increasing, it is clear at this point that Lima has neither the institutional strength nor regulatory capacity to provide adequate sanitation for its informal groups. It is also clear that improvised sanitation and the accumulation of pit latrines is a growing threat to the health, environment, economy and spirit of informal settlements. If a design solution is to survive the challenges of economy and a lack of regulation, it requires responding to

\footnotetext{
${ }^{1}$ Davis, P.1.

${ }^{2}$ Desoto, P.28.

${ }^{3}$ http://www.graphicmaps.com/geoquiz/thelist.htm, P.1.
} 
the social, cultural, and community opportunities, taking advantage of the capacity for self-mobilization.

The history of this circumstance takes root in the Fifties, Sixties and Seventies, when the government tried to dissuade migrants from legally integrating into the core. By the Eighties, they had realized that this would not stem the tide of migration and began to develop strategies for legal integration. The main strategy developed was to offer informal groups conditional property rights. The government provided an ultimatum; they challenged an invaded area to self organize and prove a strong community structure, a lack of crime and a dedication to take care of its weakest. Through a series of written applications, over the course of ten years many informal groups submitted. Areas which could then meet the criteria were provided with not only property rights, but the installation of street lighting and electricity grids.

Due to the value of such an offer, a growth of formally represented community groups resulted, reducing the informal population from about 50\% in 1960 to about 33\% in $2005 .{ }^{4}$ Residents with land title soon utilized their housing as collateral for legal loan applications. Many other benefits emerged, including the development of small businesses and the availability of private health care. Previously viewed as invaders, residents with land title also gained the security to invest in their property. Slowly the informal thatch and metal shanties will be replaced with concrete frame and clay brick homes- as is already the case for the rest of the city.

Yet there remain many deficiencies within this plan, amongst which sanitation continues to be overlooked. In 2000 it was reported by the WHO (World Health Organization) that 1,191,000 people in Lima still had no access to the city sewer system and only $74.3 \%$ of its population was connected to the water supply network. To identify an opportunity for improvement, the present study required the experience of living

\footnotetext{
${ }^{4}$ Desoto, P.15.
} 
within the community of Pachaqutec - and travel to an additional twelve neighboring communities with similar economic struggles - to study sanitation over the course of four weeks. ${ }^{5}$ As a compliment to working with a local NGO called Aldeas Infantilies SOS Del Peru, who have had a long history on the site, intensive research was conducted into the visible and invisible site factors using several texts produced by the United Nations, the World Bank, and the Government of Peru. Additionally, through the analysis of literature on the safe use of personalized waterless composting toilet systems, ${ }^{6}$ the design of a larger composting facility began. One of these sources in particular, entitled the Humanure Handbook, acts as a basis for our community made design solution.

The thesis will begin with an introduction of the visible design context using photography and a description of Lima to introduce the site. Two main proposals will follow as a proposal to address the sanitation problem, which include a series of steps for a pilot project introduction and an outline of a specific construction process for this facility. This thesis will then unfold in Appendix $A, B$ and $C$ to prove that such a design is possible, desired by the community, and appropriate as an approach. Appendix A and B will draw from recognized sanitation authorities, the context of disease and the forces behind inaction identified by the UN. Appendix $\mathrm{C}$ will explore the technical merit and sanitation alternatives identified by the World Bank and the Humanure Handbook specifically.

This thesis is an initial design step, in a long procession of steps toward constructing a research facility. Above all, it will act to introduce the possibility of serving the needs of sanitation through compost, critically addressing the need for contextual and community specific design.

\footnotetext{
${ }^{5}$ Studies conducted in several communities occurred in October 2005.

6 "Compost is the stabilized and sanitized product of composting; compost is largely decomposed material and is in the process of humification (curing). Compost has little resemblance in physical form to the original material from which it is made." Humanure Handbook, P. 27.
} 


\subsection{Visible Design Context: Ciudadela Pachacutec}

The desert floor lies beneath the streets in Miraflores, in the downtown core of Lima (figure 6). Covered by grasses, sidewalks, shops, and skyscrapers, recent construction looks no different from new areas of Los Angeles or San Diego on the California coast. Buildings are built on fast track schedules and construction is commonly contained to city approved construction zones.

Further from downtown, in districts like San Martin De Porres, the production is unlike anything North America has seen. Building is collective here, owner-constructed, all put together with the same materials, and built on slower schedules. In San Martin De Porres, everything is perpetually under construction (figure 7). Protruding through lower spaces of finished plaster and paint, a rough layer of clay brick and concrete spawn a forest of reinforcing bars above pedestrian filled streets. Dusty patches of ground are chased by expanding gardens. Paved roads roll out like carpets. San Martin De Porres is a recently settled area, changing everywhere and all at once, representing a middle age typology of the developing city. Its growth is generally vertical at this stage and committed to the infrastructure of its improvised past.

Outside the urban boundaries lies a third typology, the urban typology of fresh beginnings (figure 1-5, 8-11). This typology has boundaries that trail off to dust, expanding north and along the ocean coast. Here in places like Pachacutec, the dessert floor is uncovered, ubiquitous and inseparable from all things. In some areas, a few hidden courtyards that lie behind brick walls are the only exceptions to the arid dessert hills (figure 12). Where the streets are dusty and the housing is unfinished, the garden courtyards act as an escape. Gardens placed within these desert hills are spaces of imagination. Most are built for children, not royalty, or for rich families. The dust is covered to foster an environment for learning and playing in recognition of the priority for increased spirit in these communities. 


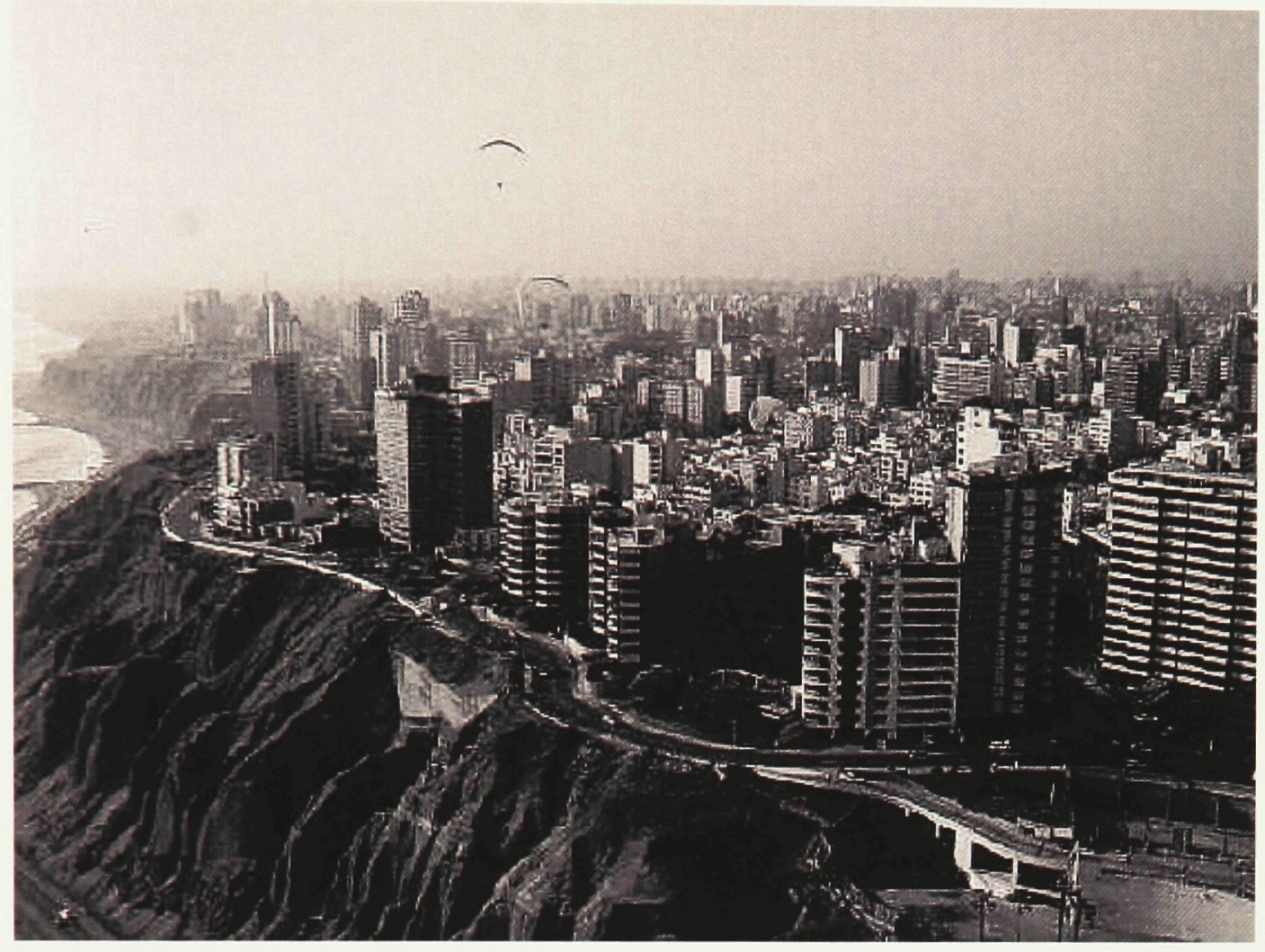

Downtown Lima: Mira Flores $\quad$ Figure 6

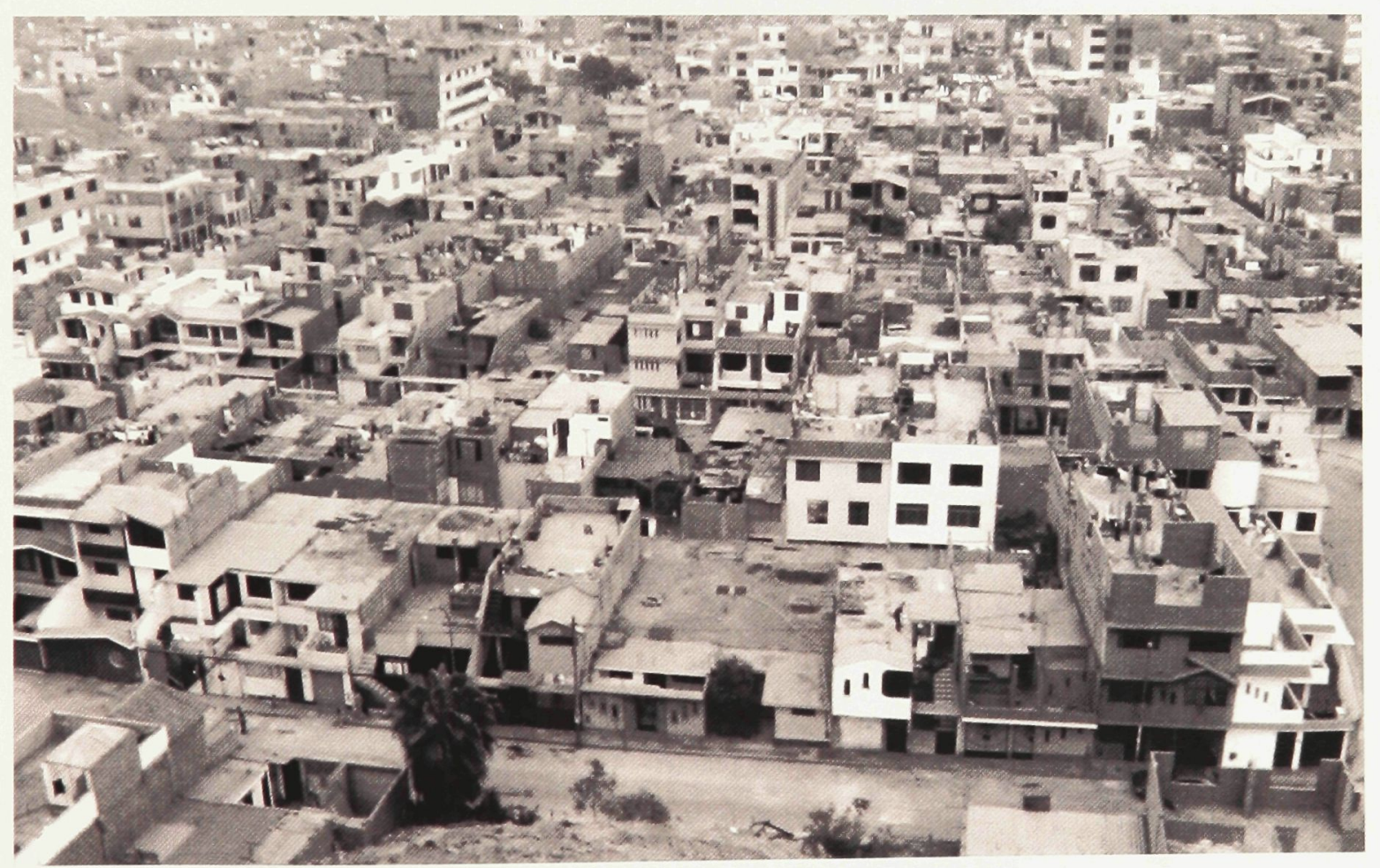

San Martin De Porres (Author)

Figure 7 


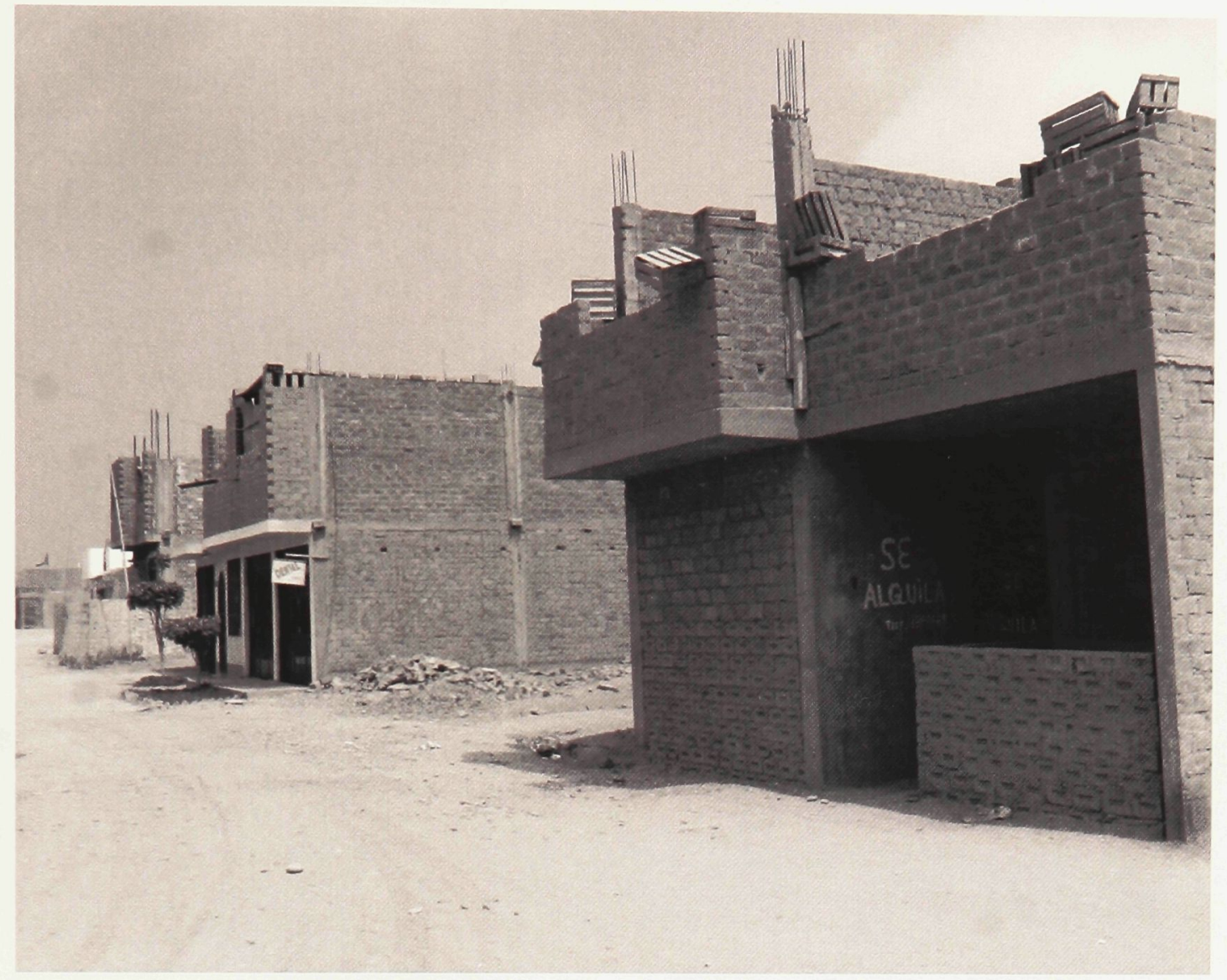

Desert Community (Author) Figure 8

Newspaper Image Source:

AJA Lima, martes 15 de noviembre del 2005 P.16.

Figure 9

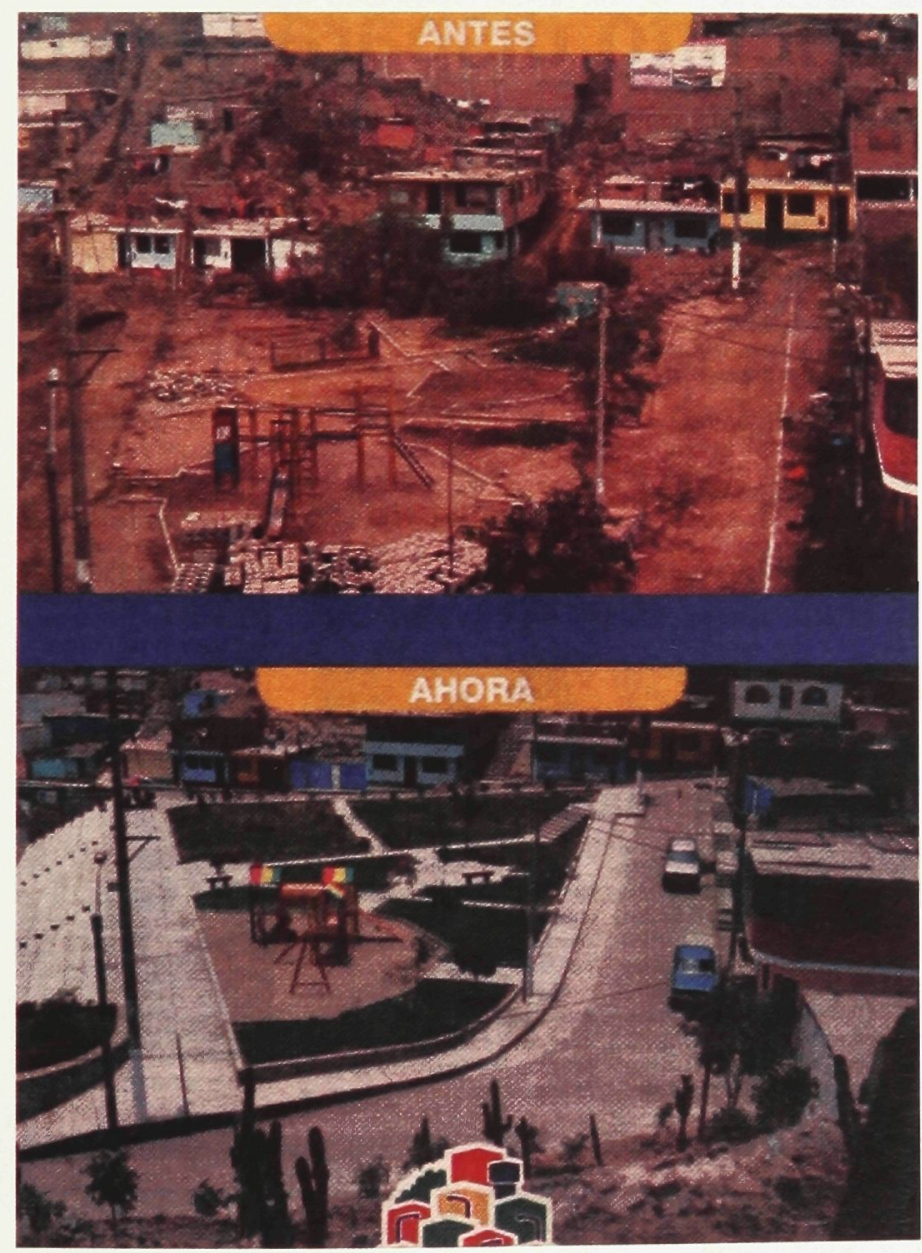




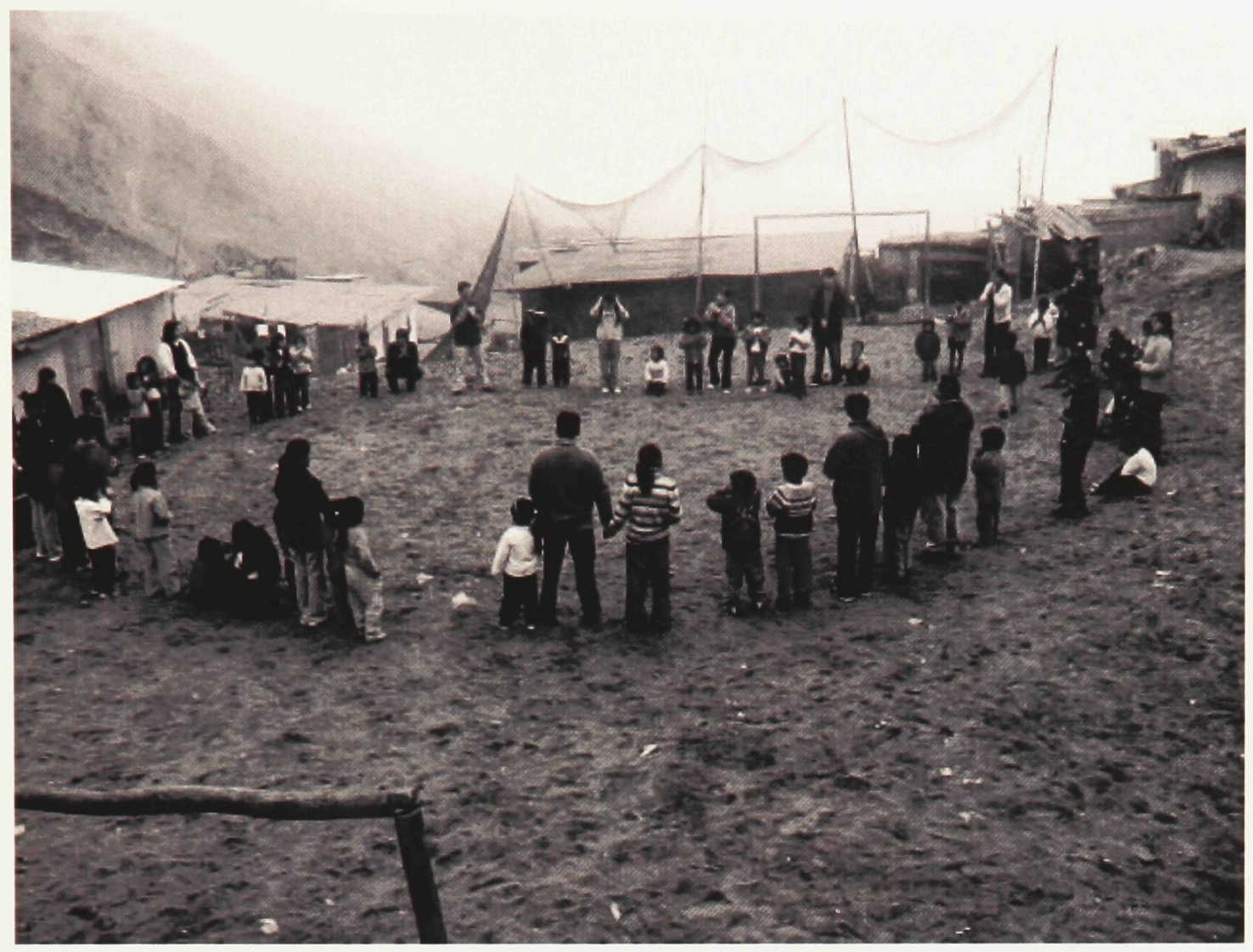

Children's Games at Community Center (Author)

Figure 10

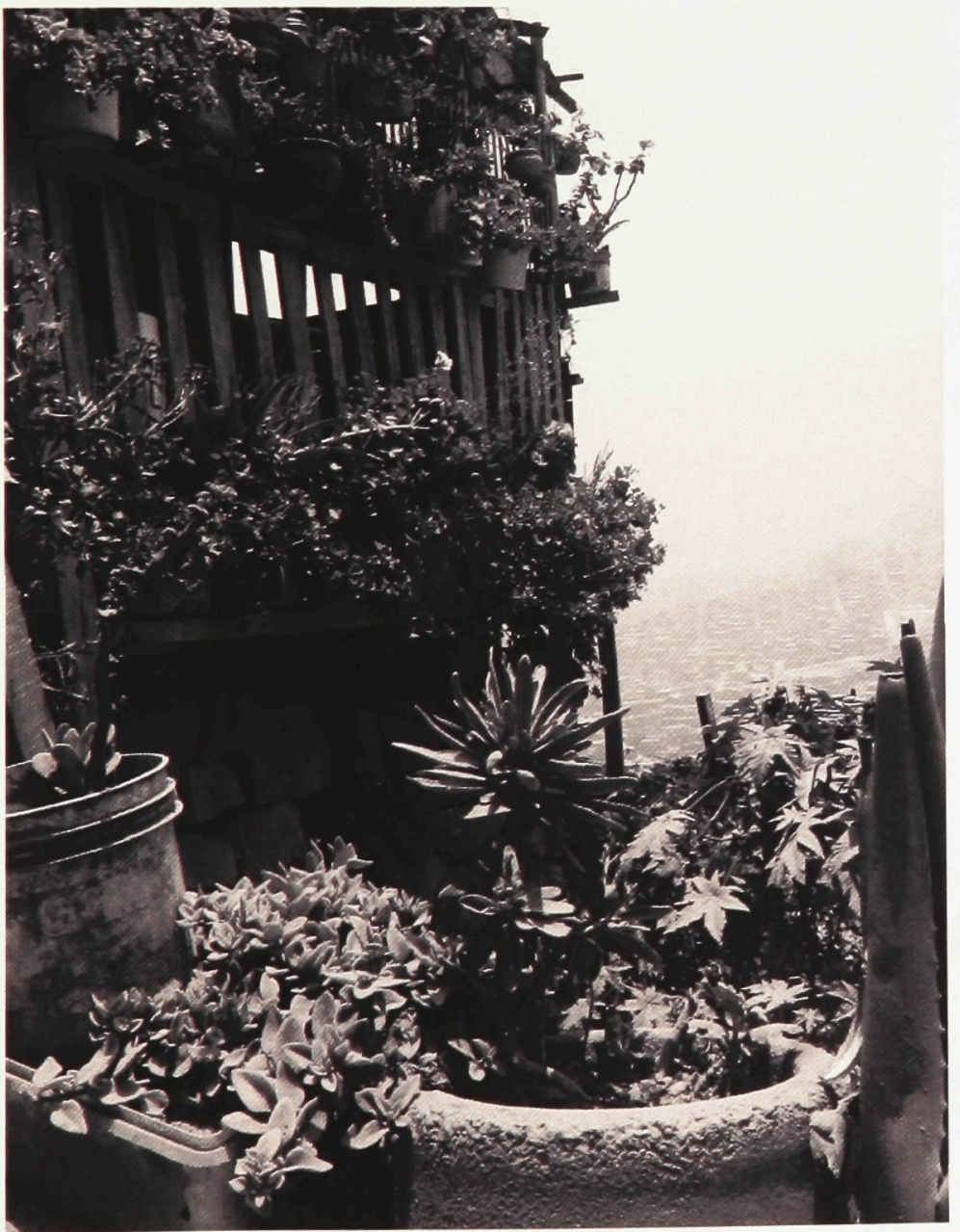

On close inspection, the greatest difference between an inspiring space and a frightening space is the beauty of strategically used resources. Waste is dispiriting. Using grey water to irrigate plants utilizes water that was carried from far.

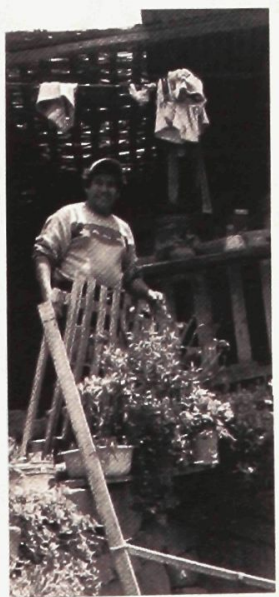


Just one tree in a desert neighborhood can signify reuse.

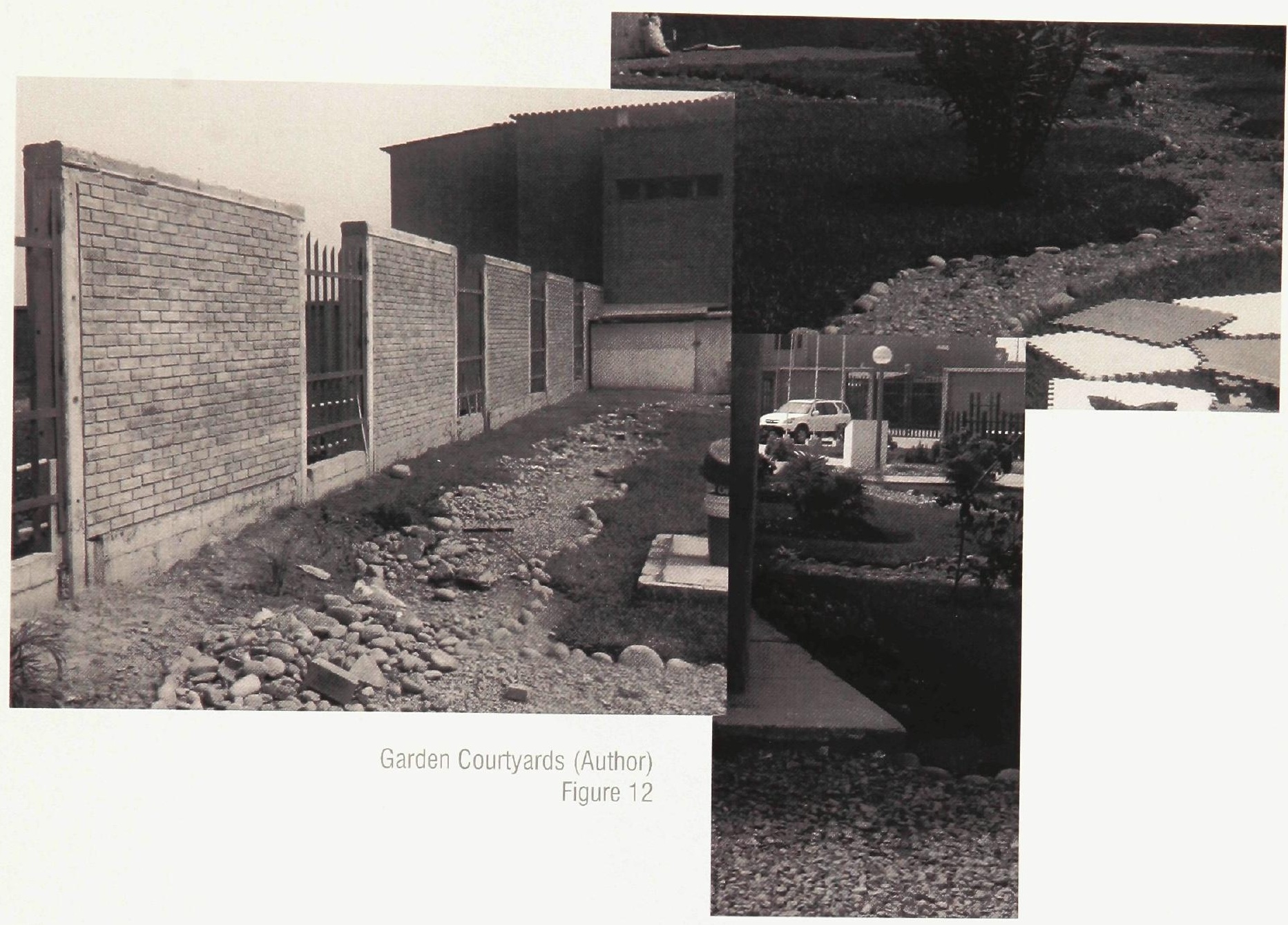

A small amount of compost can dramatically change a community's ability to strategize its resources to cover the sand where waste water is available. ${ }^{7}$ Compost in addition to adding nitrogen and nutrients retains water allowing for productive soil where it is added. Walking through Pachacutec, a couple of small trees are visible where residents have added fertilizer to the sand (figure 13-15).

\footnotetext{
${ }^{7}$ Of all the informal area, one particular man in Wascar, had the nicest garden, his garden was a pocket of green in landscape of brown.
} 


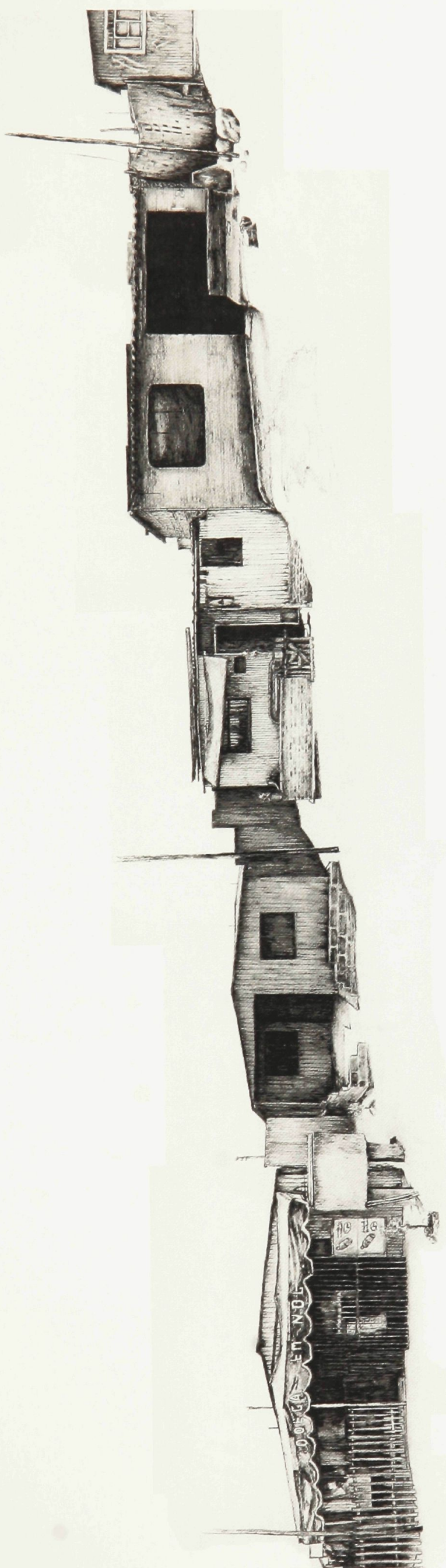

illustration by author Figure 13 


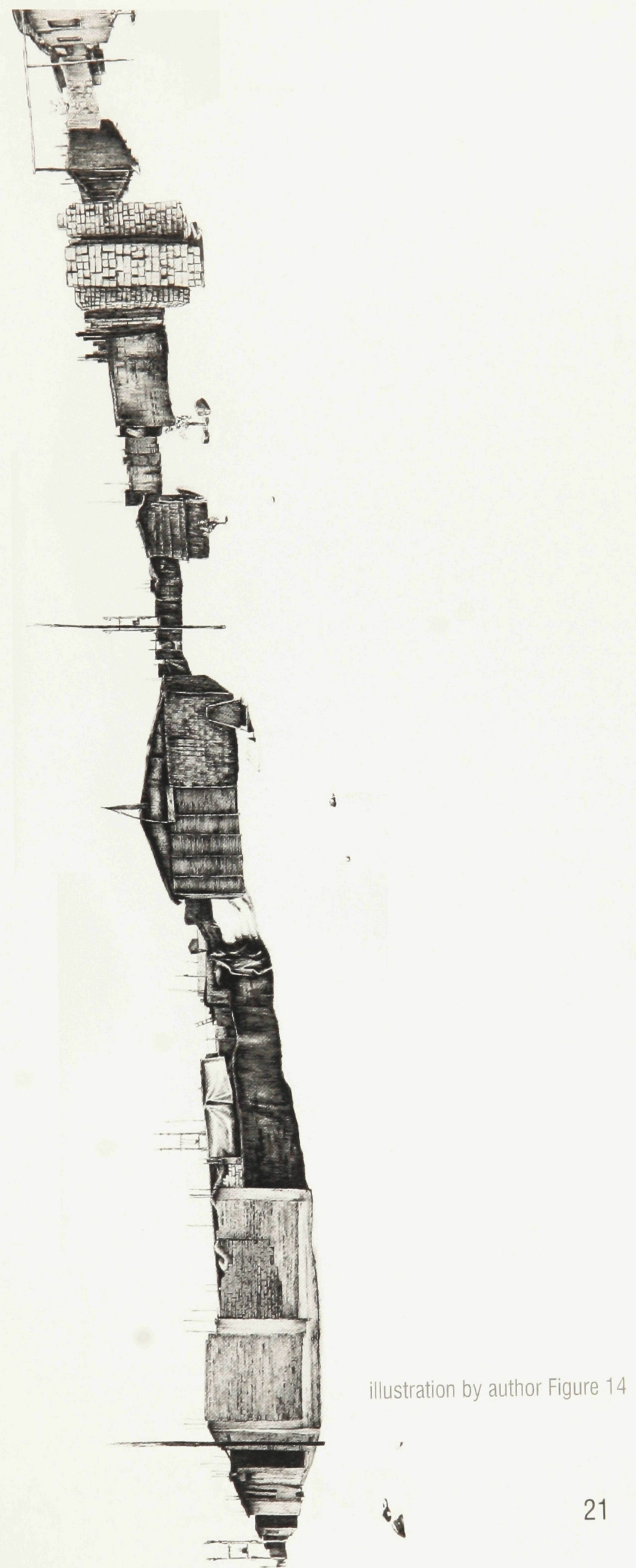




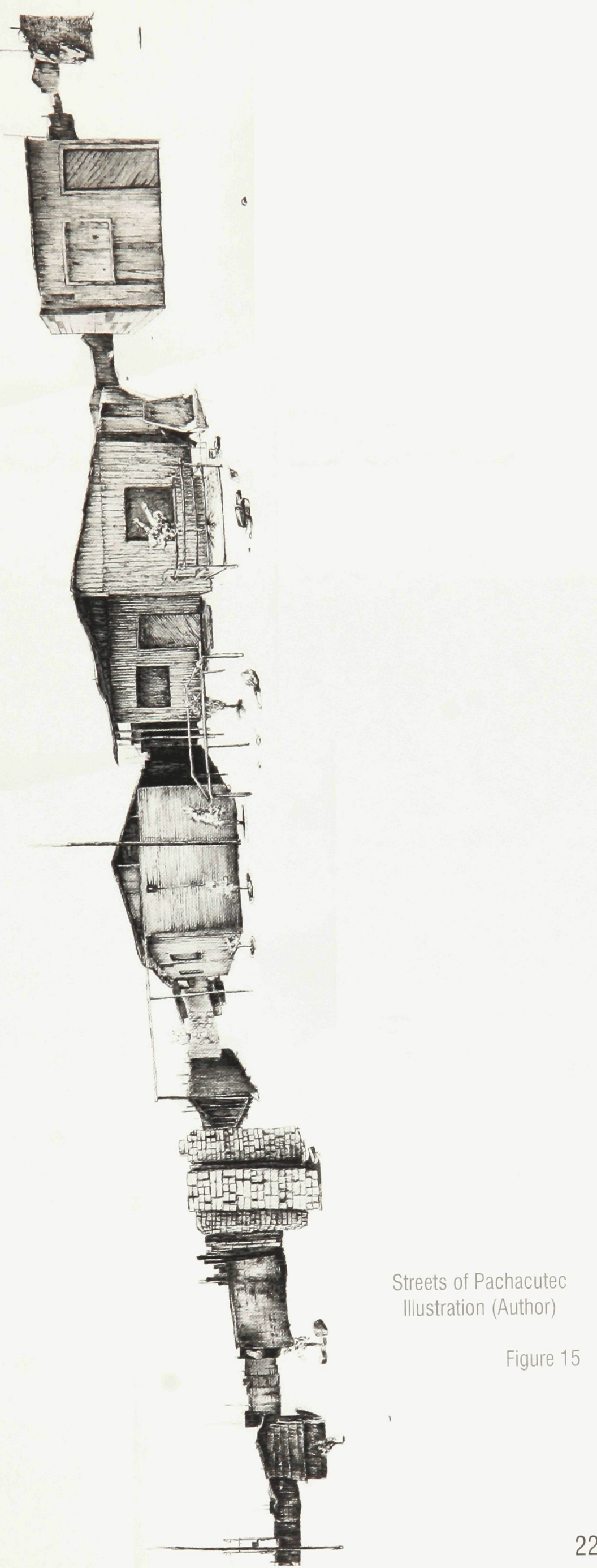




\subsection{Proposal A: Composting for Single Family and Shared Group Plots}

The research for this thesis involved first-hand experience living and working in informal settlements on the peri-urban fringe of Peru's capital city of Lima. Each day, over the course of a month in October 2005, between two and three informal sites could be visited. With the help of Aldeas Infantilies SOS del Peru acting as a guide to public transit, bus service would typically account for about two thirds of the trip and it was often necessary to ascend large hills on foot in order to reach the informally squatted areas.

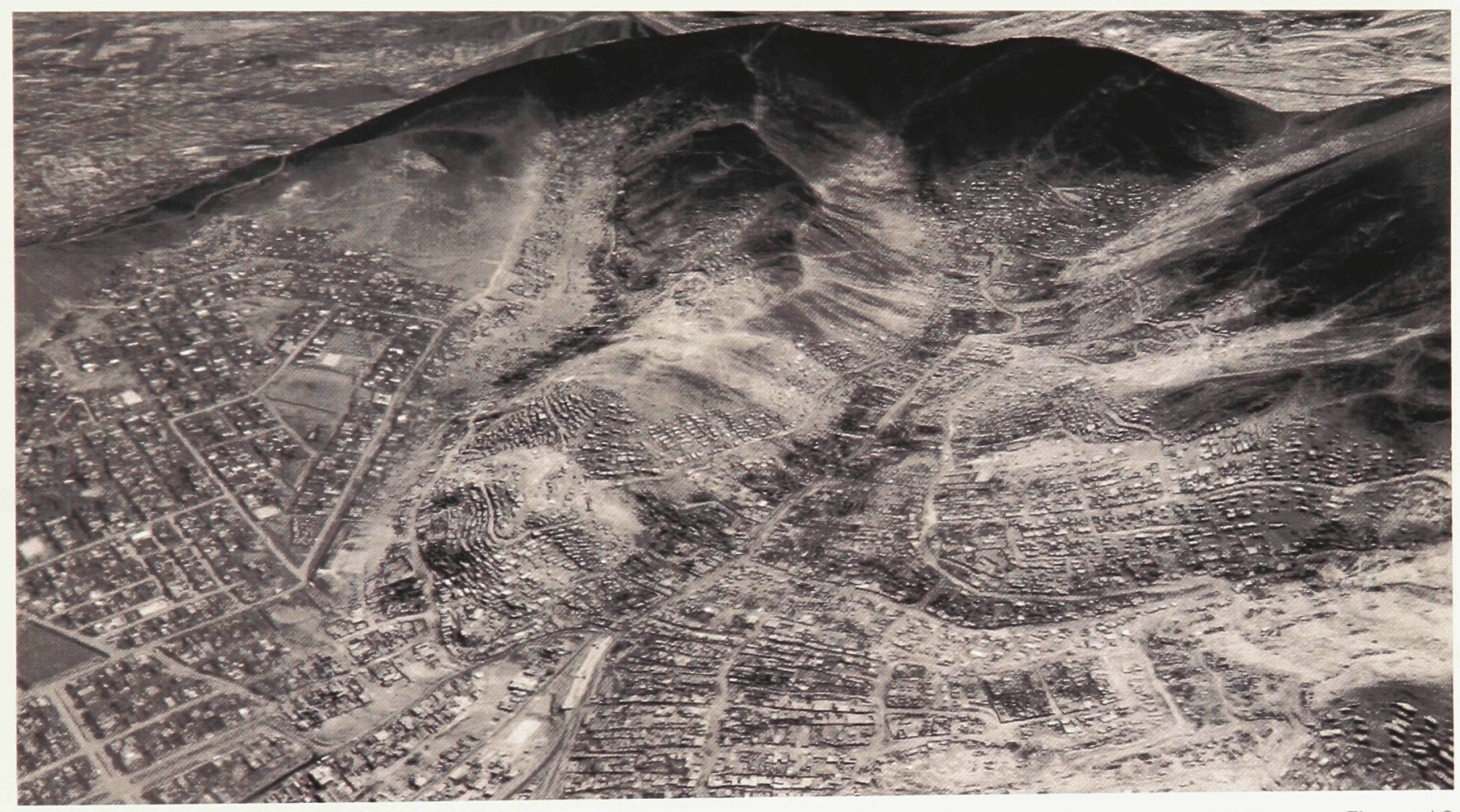

NorthEast over Independencia, Lima. Google Earth Inc. September 2005. Figure 16

Formally planned portions of Lima can be seen to the left side of figure 16, and to the right side, becoming less developed as one nears the tops of the hills, are the smaller shanty structures referred to as informal housing.

Throughout the trip, it became obvious that sanitation was the most important challenge to meet. The terrain however, posed a large problem to meeting sanitation 
using just one approach. It became clear that, however accommodating a single design might be, there were always informal dwellings higher up and harder to reach than the average population.

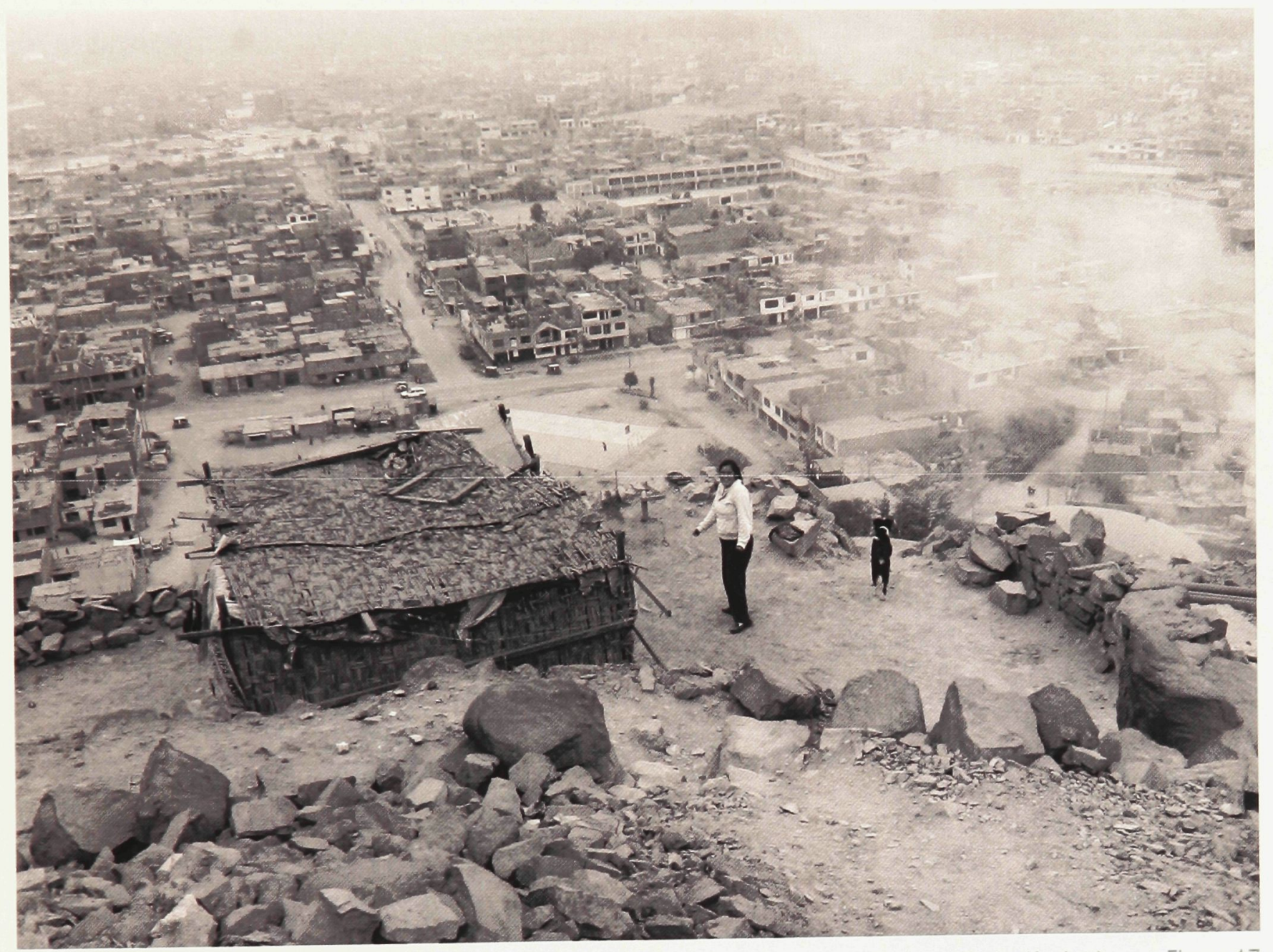

Mary's House below Hogar Communitario (Author)

Figure 17

Mary for example, pictured here beside one of her dogs, did not have a proper path which made just visiting fairly difficult. ${ }^{8}$ For dwellings such as hers, a separate and more autonomous proposal was created and geared towards more isolated dwellings that would be difficult to integrate into a community based system.

${ }^{8}$ Mary is the caretaker at Hogar Communitario Sagrado Corazon de Jesus, an Aldeas Infantilies Facility 
Using a series of bins constructed of wood pallets, a regulated compost pile can take on the role of sanitation in these hard to reach places. The Humanure Handbook outlines a general strategy that is fitting for this site. This book includes the scientific proofs that explain the necessary environment in which owner-constructed selfprovision is possible. Beyond Mary's site instead of handing out copies of the Humanure Handbook, (255 page English text) or holding a training camps for education in these areas, the best opportunity seemed to be designing a working example in a community center that would received attention and daily tours.

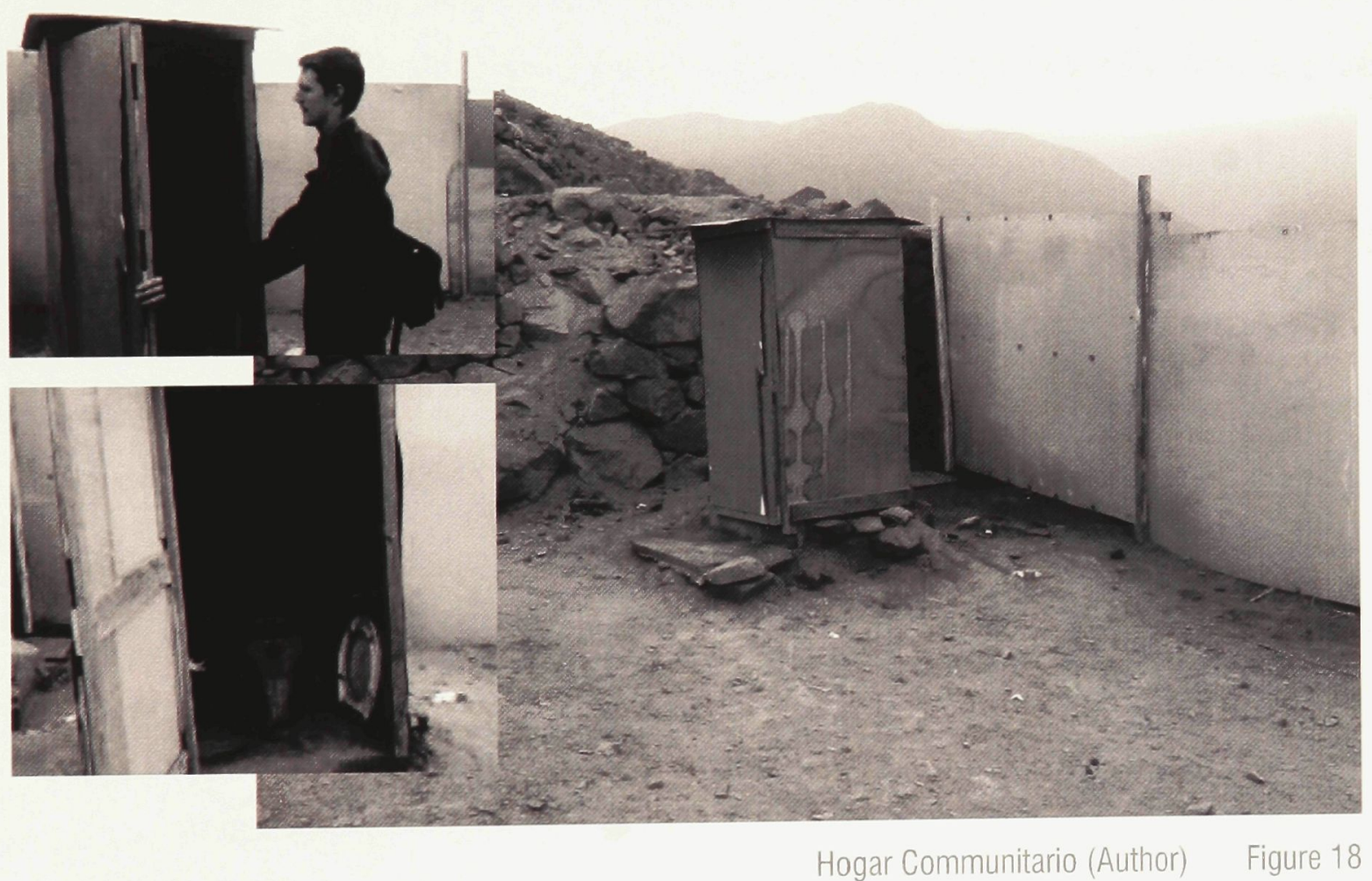


In addition to being an informal settler, conveniently Mary is also the caretaker for the Communitario Sagrado Corazon de Jesus in Hogar, one of the many kitchen and classroom facilities for orphan children organized by Aldeas Infantilies. Mary has donated her property, the larger portion of her land, to this community center. Aldeas has helped to hire local doctors, dentists, kitchen staff and mothers in an effort to supplement the diets, health and education of the local children. Both Mary and the children use the pit latrine in figure 18 and it is the only toilet in the facility. The Hogar Communitario may improve in time as it receives more funding from the community. The facility charges a small fee per child (excluding orphans) to fund the project and uses additional profits to make improvements to the property in line with the general model for communiatrio facilities of the area.

Aligning the context, surplus and needs, with locally purchasable products and using the NGO's institutional organization to exemplify the initiative, a composting system was designed for a communitario like the one where Mary works. Because hers was so isolated it was felt that a design initiative should be directed towards a larger facility so that is what was done. It was clear that a chance to spread the compost approach into the greater community existed through such a site because these facilities are often the center of community interaction.

Historically in these communities most people using pit latrines built dwellings on the cheapest pieces of land to avoid the threat of relocation. Informal housing is commonly constructed on steep slopes where trucks can not drive and these dwellings are built above the gravity dependant water cisterns like Mary's house. Without water pressure, water has to be transported by hand. Such conditions are not favorable for permanent septic systems in cases where a tank would require sanitation trucks to 
empty waste and water consuming toilets are too water intensive for these locations. ${ }^{9}$ Water based systems are also permanent and commit the residents to participate in the direct ocean dumping that the majority of Lima contributes to which creates an entire additional set of economic and health related ramifications.

These communities have obvious small scale needs that are common to informal areas: Human feces cannot compost in pits because of a lack of oxygen and the difficulty of trying to manage it. Sitting stagnate the pits are a collective community problem. Insects act to spread disease, the latrines are not conducive to cleanliness and the smell during summer months is especially unbearable. If chemically treated the pits poison the land over time, which limits land use and degrades the investment that was made into properties. Fertilizer is also a valued resource that is difficult to obtain and because the sand on most properties is incapable of retaining water, waste water has no where to go, but instead evaporates in the sun. The potential for more sustenance farming would also be possible if compost is made available to the community. Fertilizer, if produced on a household scale may, even be sold in the market as income and finally introducing vegetation into the community has spirit related benefits that both keep the dust down and make the communities more hospitable to children.

Feces is most commonly wasted in these informal settlements. It is typically buried, dumped in the ocean, burned, or eaten by animals. Termite wood is another problematic surplus. Termites are common throughout the desert, where piles of old wood accumulate. Most of this wood is infected with termites because it is not chemically treated, and can thus be used as a carbon rich composting resource. Paper products are another surplus that can add carbon which will help to decompose the nitrogen rich excreta. Also by reducing organic waste, such as chicken bones and food

\footnotetext{
${ }^{9}$ Water toilets would also be adding to the roughly 7 million people who contribute to the long term problem of human waste being dumped directly into the ocean.
} 
scraps, household garbage can be used, which will reduce garbage problems. Most garbage is dumped down hillsides where birds and rats and dogs scavenge the food scraps because of its organic qualities.

Part of the challenge to balance the surplus' with the needs was finding local resources that could be purchased to construct a compost system. Wood pallets, suggested in the Humanure Handbook are an economically feasible building material appropriate for making compost bins because they allow air to pass freely. In a city without trees, wooden pallets are typically stripped apart by local carpenters, who use the wood to make hardwood furniture. Used in their complete form and not requiring much assemble Joseph Jenkins, the author of the Humanure Handbook recommends them over other materials.

In a place where most people work three jobs, education is best absorbed through witnessing functioning examples where residents need not trust anyone to pass the information down. The goal was to create some standards of sanitation within the communitarios of Aldeas first. Aldeas is foremost a respected institution. Because the communitarios are run by locals and sought after by the communities this approach was found desirable and seemed like the best place to start a project.

Conveniently, Aldeas had received a parcel of land for a new communitario in Hogar that was on a larger piece of land then Mary's and they requested a tentative design for a kitchen and classroom facility for 40 children requiring only a general strategy. They were open to a range of suggestions. Because the community was to construct the communitario and because the materials were to be scavenged or donated, the community leaders needed nothing more than an organizational plan.

The idea of the facility was to construct compost bins along the east side of the building. The compost produced after two years, (when completely sanitized) could be used to plant flower gardens, two specifically on either side of the kitchen. The waste 
water from the washing area could then be used for irrigation. Eventually, if a lot of compost was produced, the product could be sold at a store, so an extension to the caretakers house was drawn.

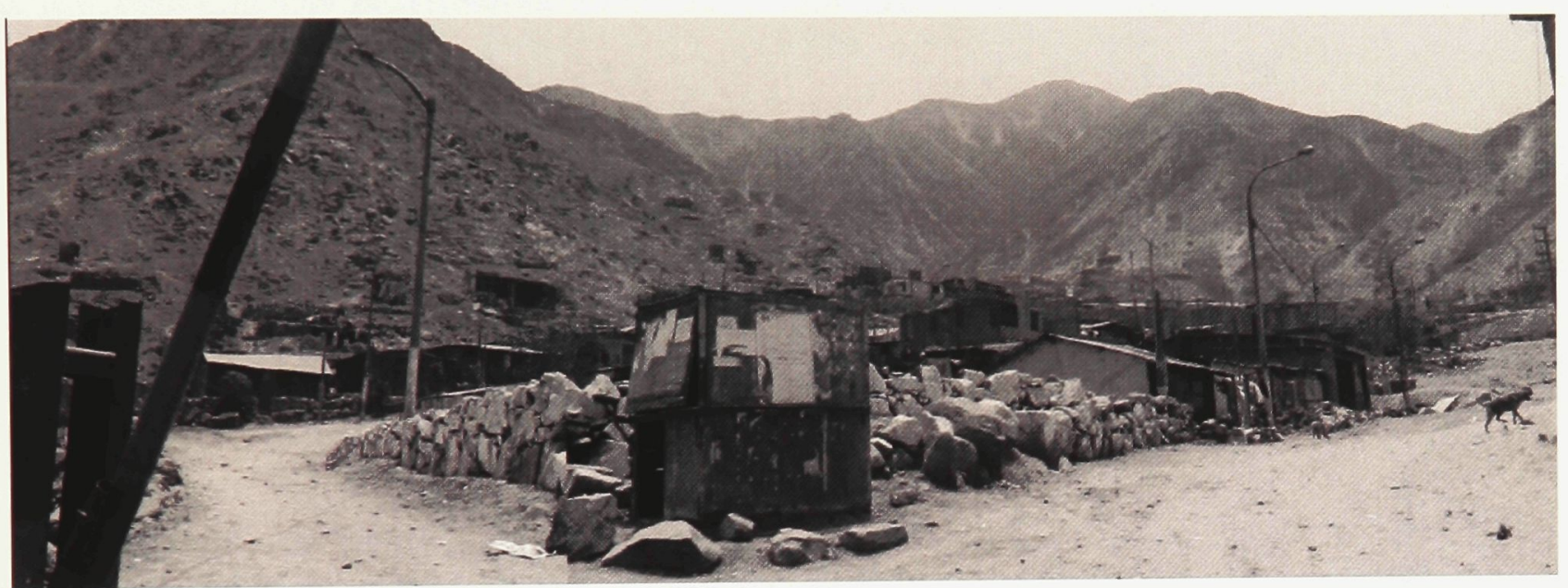

New Hogar Communitario Site Looking west (Author)

Figure 19

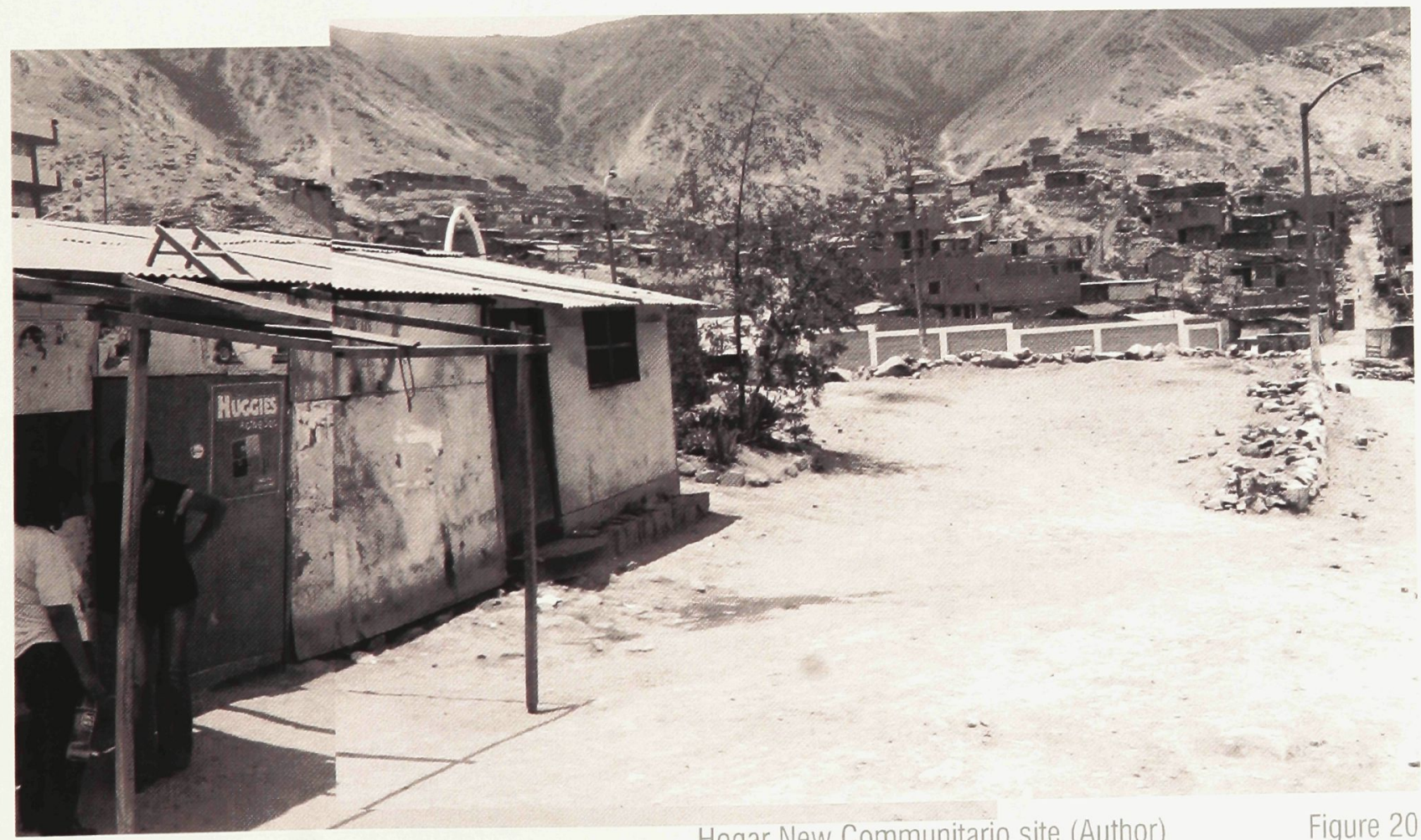




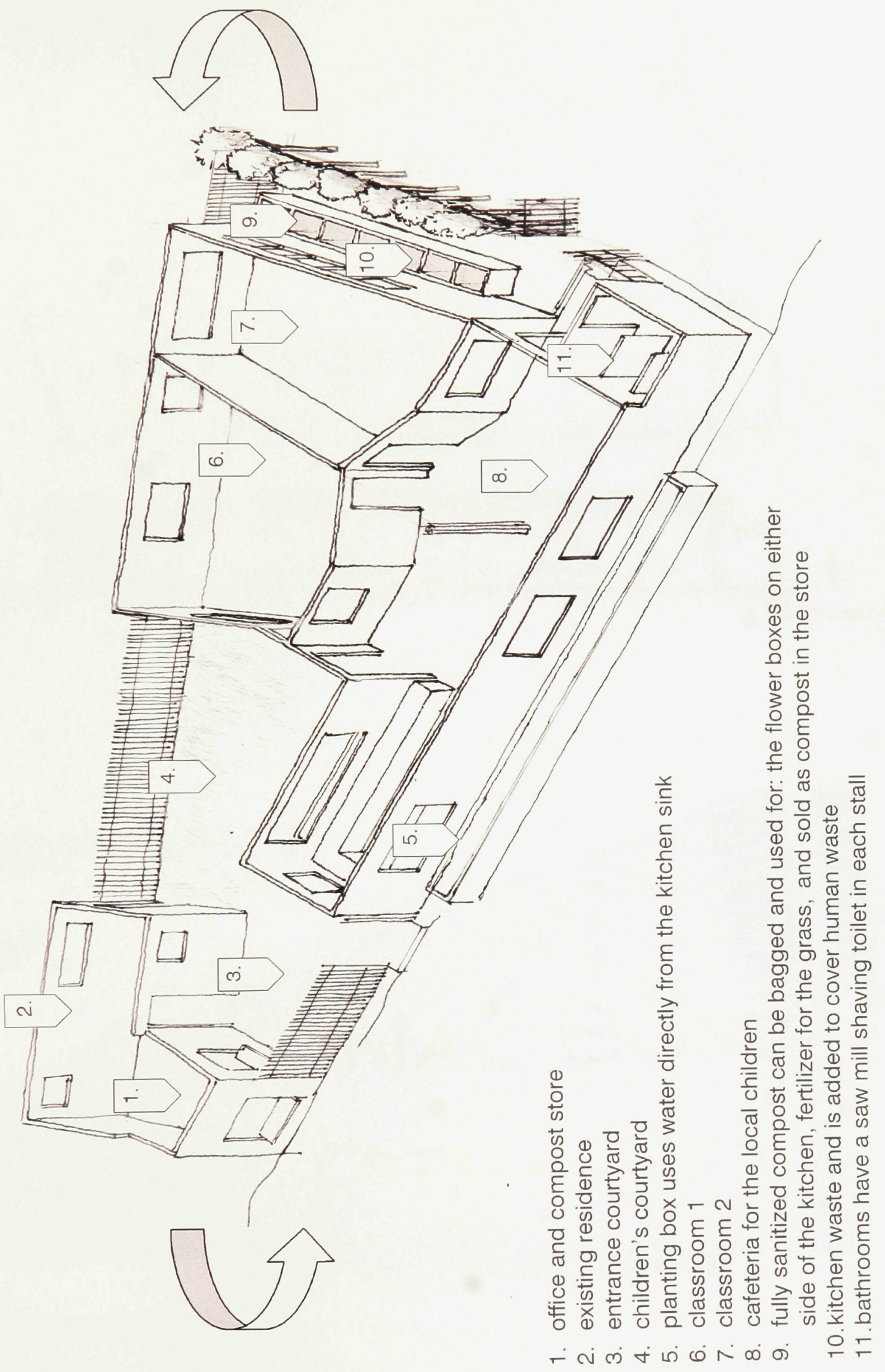

Illustration Diagram (Author) Figure 21 

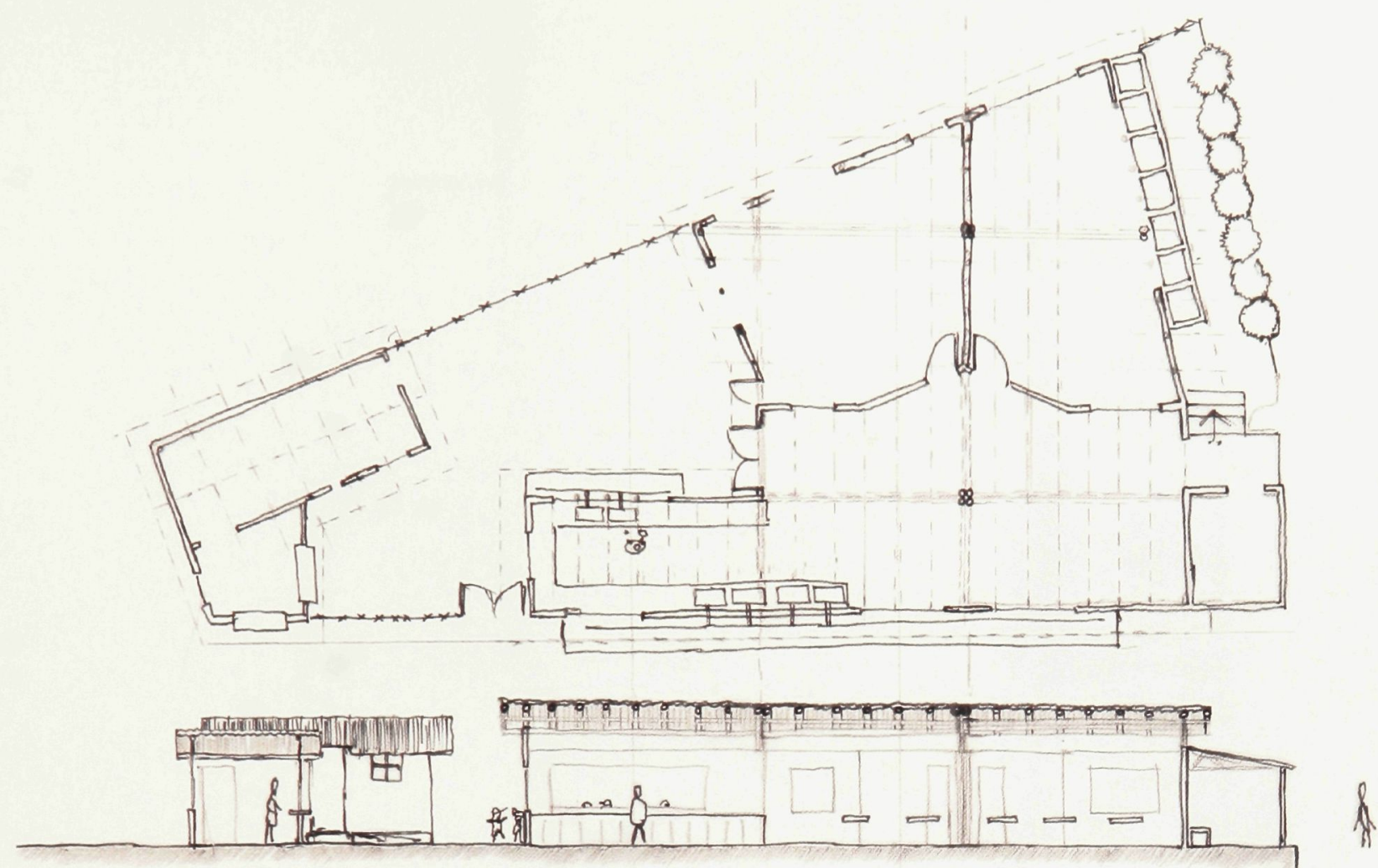

Hogar New Communitario Plan (Author)

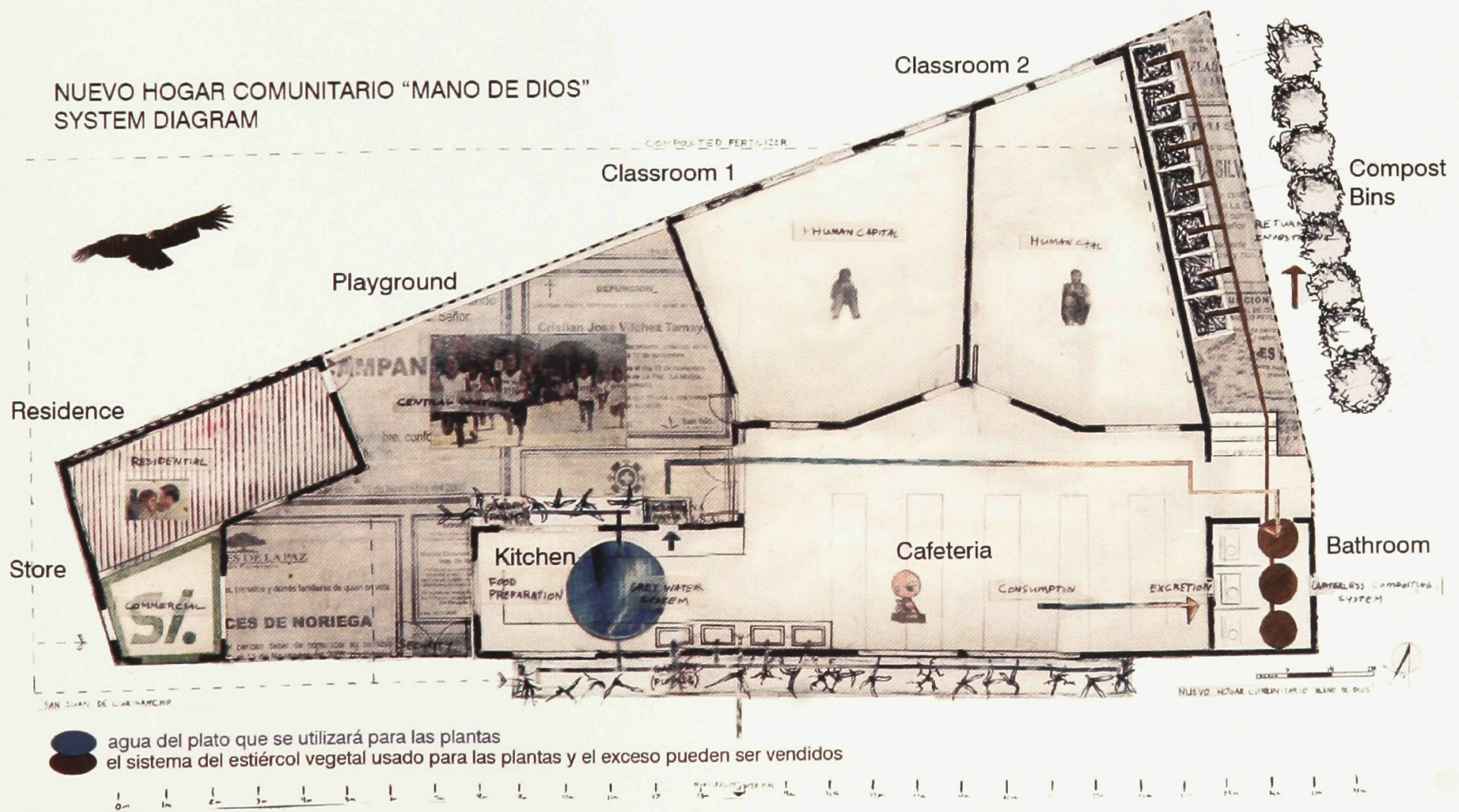



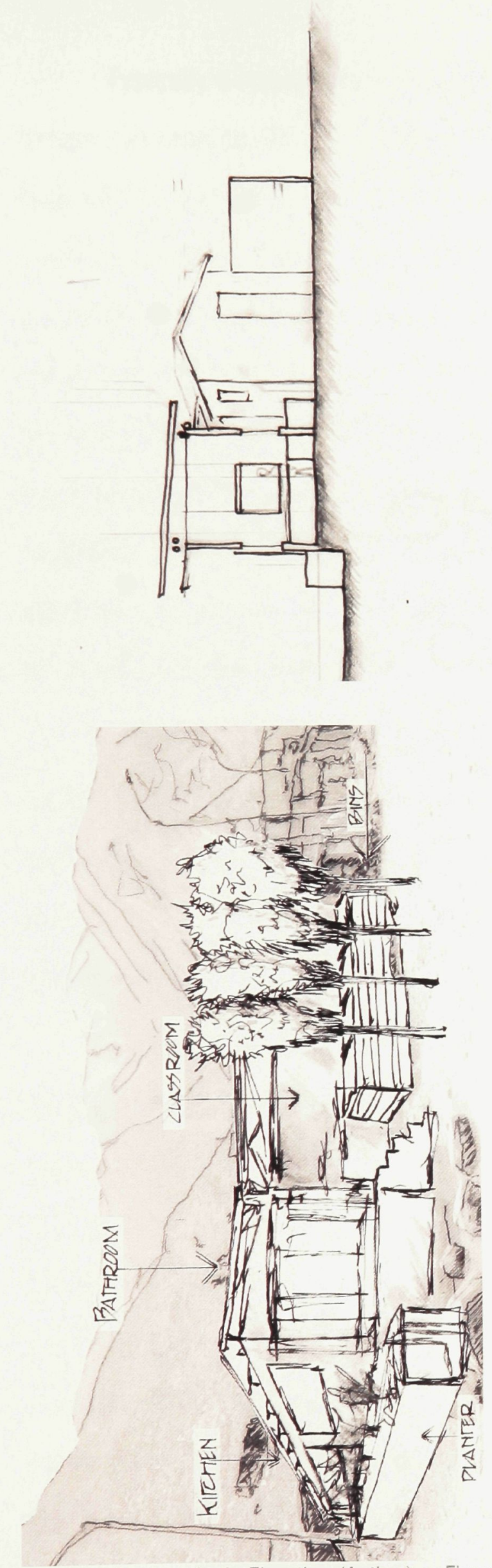

Hogar New Communitario Elevation (Author) Figure 24
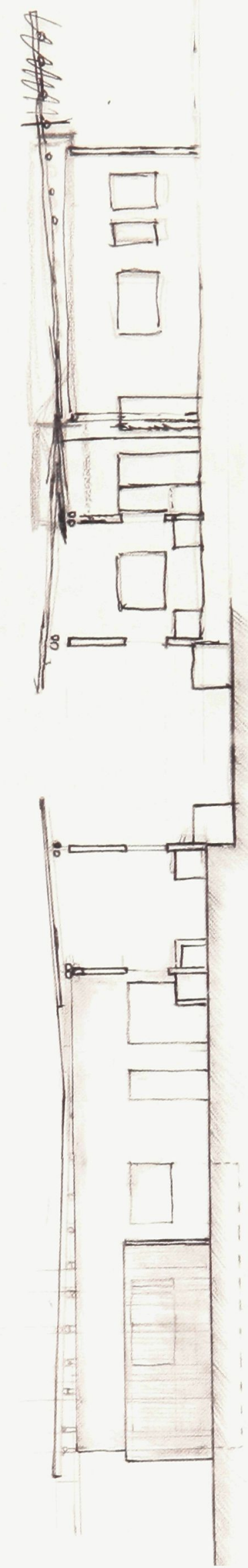

Hogar New Communitario Section (Author) Figure 25 
Typically a household bin system may have trouble producing a decent enough compost product to sell in the market. In the case of this proposal, because there is a large kitchen that produces vegetation waste, and because there is a high volume of children, a healthy compost was possible without buying many ingredients. The main advantage of introducing bins into the Aldeas facility was the institutional ties it had to the greater city. If the process could work here, Aldeas staff would be able to document the technology and pass it to other communitarios. The caretaker in this circumstance could also be monitored by the NGO staff to ensure regulation. Instead of building a rectangular structure, which was common to almost all other communitarios, the site permitted a bit of flexibility and materials are so minimal anyways it seemed like a waste to not play with the form at all.

The problem with using the communitario as the only model for introducing compost to the larger community was the specificity information gap. Because residents could not be bothered with all the science and were too busy to read pamphlets it became obvious that Jenkin's system needed to be reduced into a single diagrammatic image accompanied by only minor text.

Because the 5 gallon pail was the only material in the system that would not be readily available and because buckets were cheap to purchase in bulk, the design solution offered was to print the condensed drawing directly onto the buckets themselves for distribution. If the buckets where printed and accepted as gifts from Aldeas staff, they would act to cheaply distribute the information for residents to construct their own toilets and compost bins. When the municipality constructed concrete steps that led up the steeping slopes they painted the steps bright yellow to demonstrate support, regardless of the informal status of residents. For this reason, if the municipality will fund the bucket initiative, the plastic is to be bright yellow as well. 

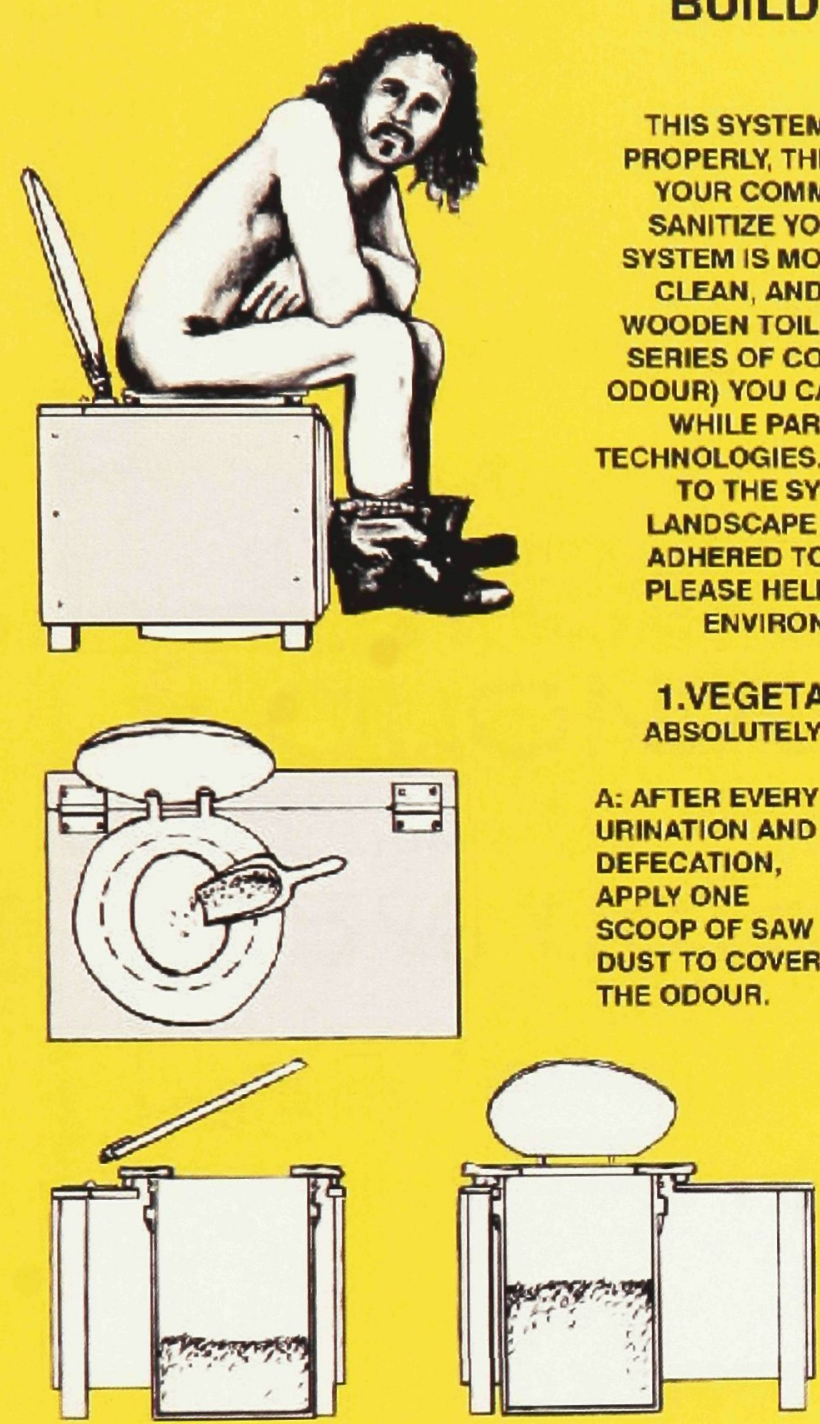

\section{TOILET CONSTRUCTION}

a) TRACE THE QUCKET RIM TO MAKE A HOLE. (TOP PIECE)

b) BUILD THE BOX TO THE CORRECT HEIGHT SO THAT THE BUCKET PRDTRUDES THROUGH THE HOLE 1CM

c) ATTACH THE TOILET SEAT, SO THAT THE WEIGHT OF SITTING IS SUPPORTED BY THE BUCKET ITSELF

THE SEAT TABS (SHOWN ABOVE, AROUND DOTTED LINE) MAY NEED ADJUSTMENT. THE BOX CAN BE MADE IN A VARIETY OF WAYS: THIS HINGED DESIGN ALLOWS FOR EASY REMOVAL. ANY BOX MUST PREVENT THE BUCKET FROM TIPPING DURING USE.
A: AFTER EVEAY URINATION AND DEFECATION, APPLY ONE SCOOP OF SAW DUST TO COVER THE ODOUR.

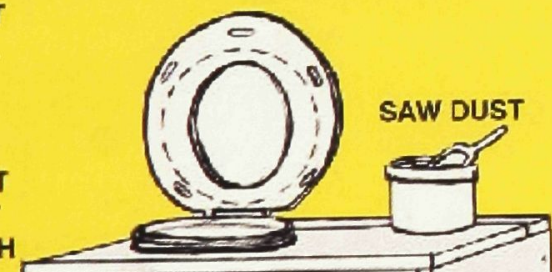

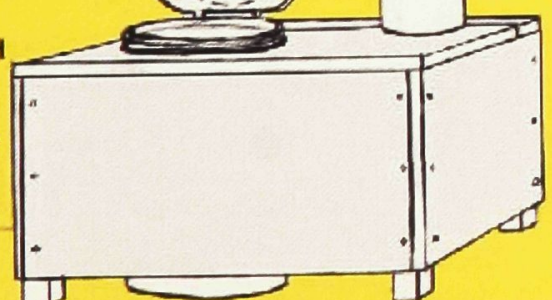

THIS SYSTEM IS DESIGNED TO SAFELY MANAGE HUMAN WASTE. IF USED PROPERLY, THE FOLLOWING COMPOST PROCESS WILL REDUCE ODOUR IN YOUR COMMUNITY AND DESTROY HARMFUL PATHOGENS HELPING TO SANITIZE YOUR HOME. COMPARED TO PIT LATRINES, THIS WATERLESS SYSTEM IS MORE ECONOMICAL, MORE COMFORTABLE TO USE, EASIER TO CLEAN, AND DOES NOT REQUIRE DIGGING PITS. BY CONSTRUCTING A WOODEN TOILET AND USING THIS PAIL TO TRANSPORT YOUR WASTE TO A SERIES OF COMPOST BINS (USING A COVER MATERIAL TO ELIMINATE THE ODOUR) YOU CAN PREVENT OCEAN DUMPING, OR GROUND CONTAMINATION WHILE PARTICIPATING IN ONE OF THE WORLDS MOST SUSTAINABLE TECHNOLOGIES. THE RESULTANT COMPOST PRODUCED IS AN ADDED BENEFIT TO THE SYSTEM WHICH CAN BE USED FOR FLOWER GARDENS AND LANDSCAPE PROJECTS. IF THE FOLLOWING STANDARDS ARE STRICTLY ADHERED TO, THE COMPOST MAY ALSO BE A PRODUCT YOU CAN SELL. PLEASE HELP TO FOSTER A SAFER, GREENER AND MORE SUSTAINABLE ENVIRONMENT FOR YOURSELF, YOUA NEIGBOURS AND FUTURE GENERATIONS.

1.VEGETATION 2.TIME 3.OXYGEN 4. SELF HEATING ARE ABSOLUTELY NECESSARY FOR A SUCCESSFUL COMPOSTING PROCESS.

B: PATIENTLY WAIT FOR THE BUCKET TO FILL: FORMING A BIOMASS NECESSARY FOR A SELF HEATING PROCESS. (THIS HELPS DESTROY BACTERIA.)

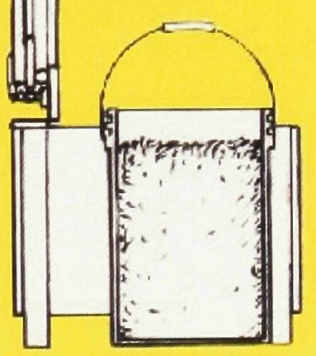

C: PREPARE A NEST OF VEGETATION IN A BIN AND EMPTY THE BIOMASS ONTO IT.

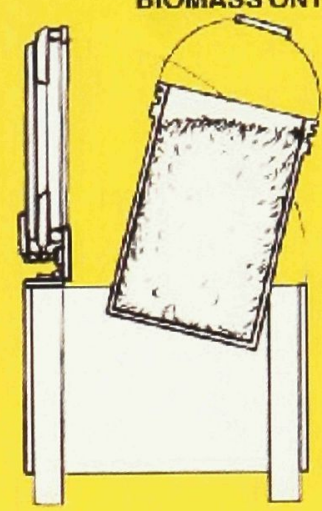

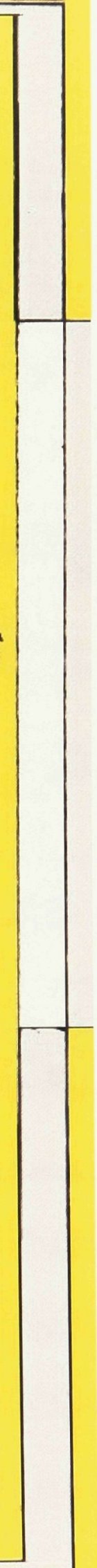




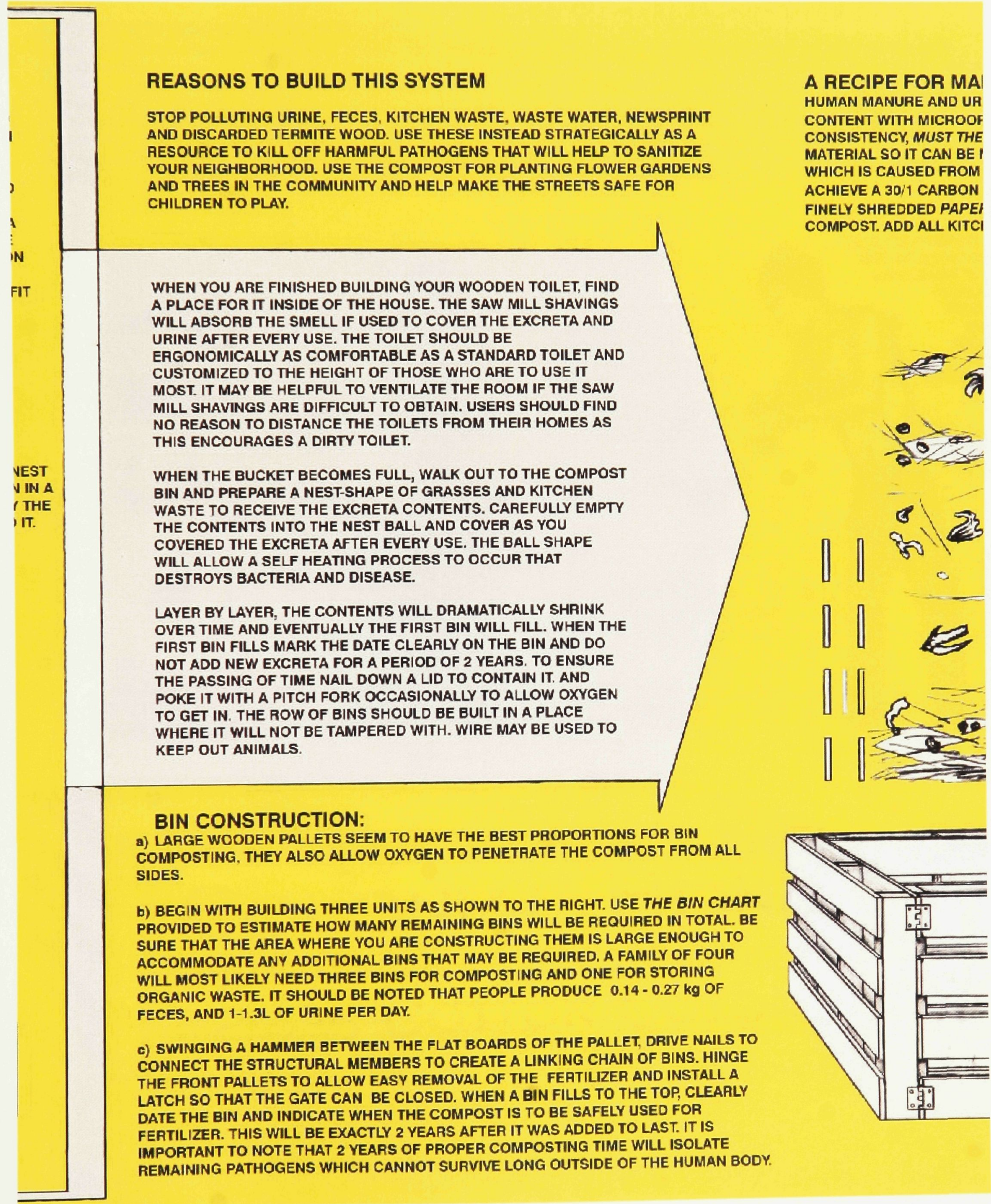




\section{A RECIPE FOR MAKING GREAT FERTILIZER}

HUMAN MANURE AND URINE ALONE WILL NOT COMPOST: THEY CONTAIN TOO MUCH NITROGEN RICH CONTENT; AND NOT ENOUGH CARBON RICH CONTENT WITH MICROORGANISMS. 1. PLANT EY-PRODUCTS SUCH AS HAY, STRAW, WEEDS, OR EVEN PAPER PRODUCTS, IF GROUND TO THE PROPER CONSISTENCY, MUST THEREFORE BE ADDED TO MAKE GOOD FERTILIZER. IT IS VERY IMPORTANT TO OBTAIN AND STORE ENOUGH OF THIS TYPE OF MATERIAL SO IT CAN BE MIXED AS NEEDED. A GOOD MIXTURE OF PLANT WAIST AND MANURE (CARBON TO NITROGEN 30/1) WILL STOP THE ODOUR WHICH IS CAUSED FROM AN ABUNDANCE OF NITROGEN RICH WASTE.MANURE MIX IN EACH BUCKET HAS A 10/1 CARBON TO NITROGEN RATIO, TO ACHIEVE A 30/1 CARBON TO NITROGEN RATIO, MIX ONE BUCKET HUMAN MANURE, URINE, AND SAW MILL CHIPS, TO 3 PARTS HAY, STRAW, WEEDS, OR FINELY SHREDDED PAPER. 2. KITCHEN FOOD SCRAPS ARE NEUTRAL (GENERALLY 30:1), AND THEY PROVIDE MOISTURE AND WILL COMPLIMENT THE COMPOST. ADD ALL KITCHEN SCRAPS TO THE SYSTEM AS IS IT DESIGNED TO CONSUME ALL ORGANIC WASTE.

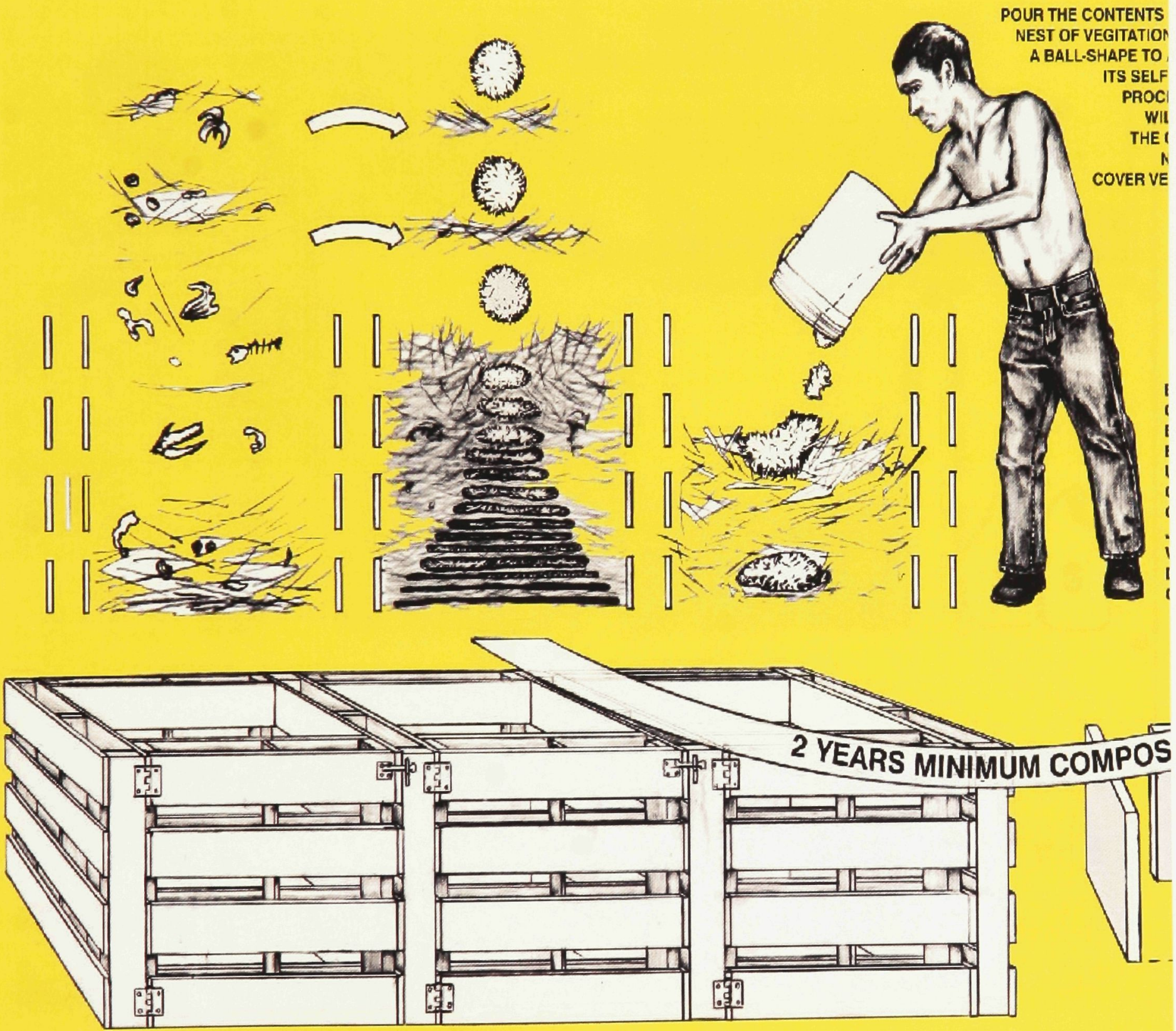


TENT, AND NOT ENOUGH CARBON RICH ER PRODUCTS, IF GROUND TO THE PROPER N AND STORE ENOUGH OF THIS TYPE OF O NITROGEN 30/1) WILL STOP THE ODOUR A 10/1 CARBON TO NITROGEN RATIO, TO ZHIPS, TO 3 PARTS HAY, STRAW, WEEDS, OR JE MOISTURE AND WILL COMPLIMENT THE STE. \begin{tabular}{l|l|l} 
THE BIN PLANT & MIN. & $\begin{array}{l}\text { NUMBER OF BINS MUST COLLECTIVELY } \\
\text { TAKE UP 24 MONTHS OF FILLING TIME } \\
\text { BEFORE THE FIRST ONE IS SAFE TO USE. }\end{array}$ \\
CHART & 24 MO.
\end{tabular} 3

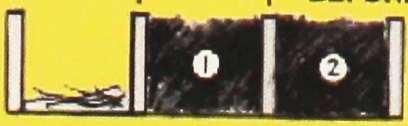

min 24 mo. 24 mo. $/$ ill

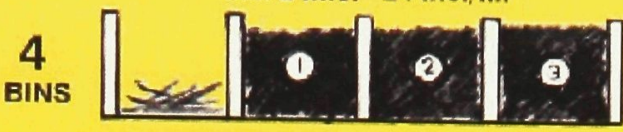

min 24 mo. $12 \mathrm{mo}$. $12 \mathrm{mo} / \mathrm{fill}$
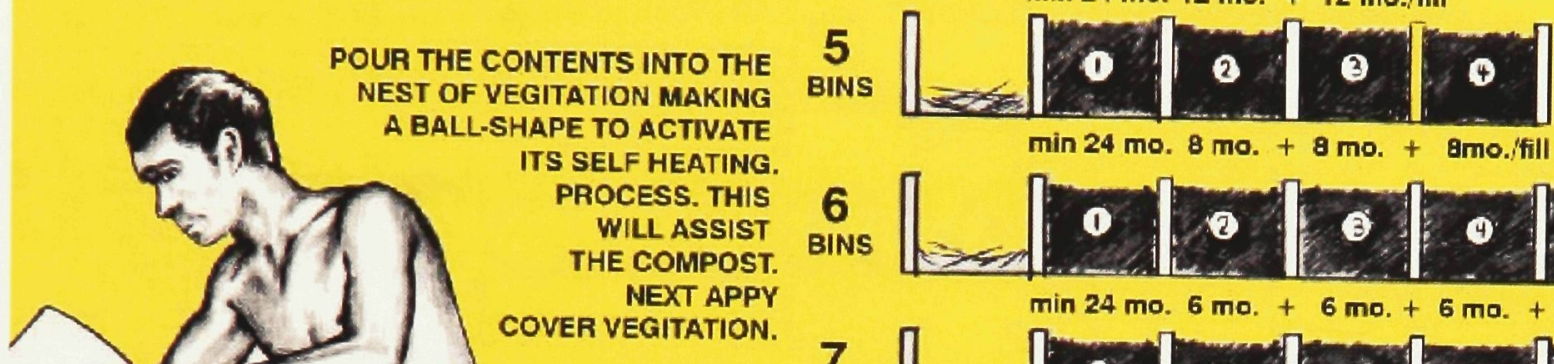

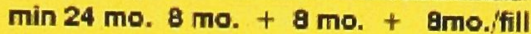

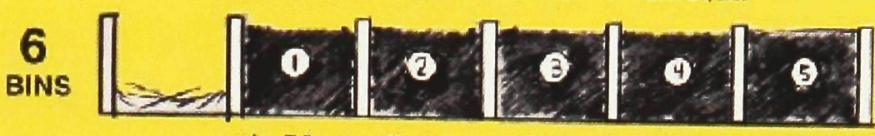

min 24 mo. 6 mo. +6 mo. +6 mo. +5 mo. fill
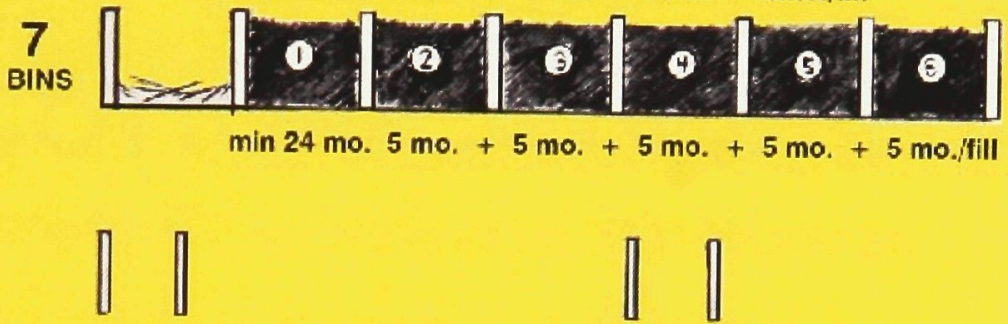

BE SURE TO

CLEAN THE

BUCKET AFTER

EACH DUMP

USING RUBBER

GLOVES AND

ORGANIC SOAP.

JUST DUMP THE

WASTE WATER

DIRECTLY ON THE

COMPOST AFTER<smiles>C=CC=C</smiles>

॥
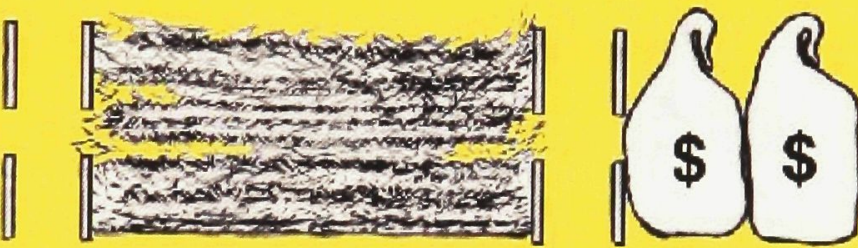

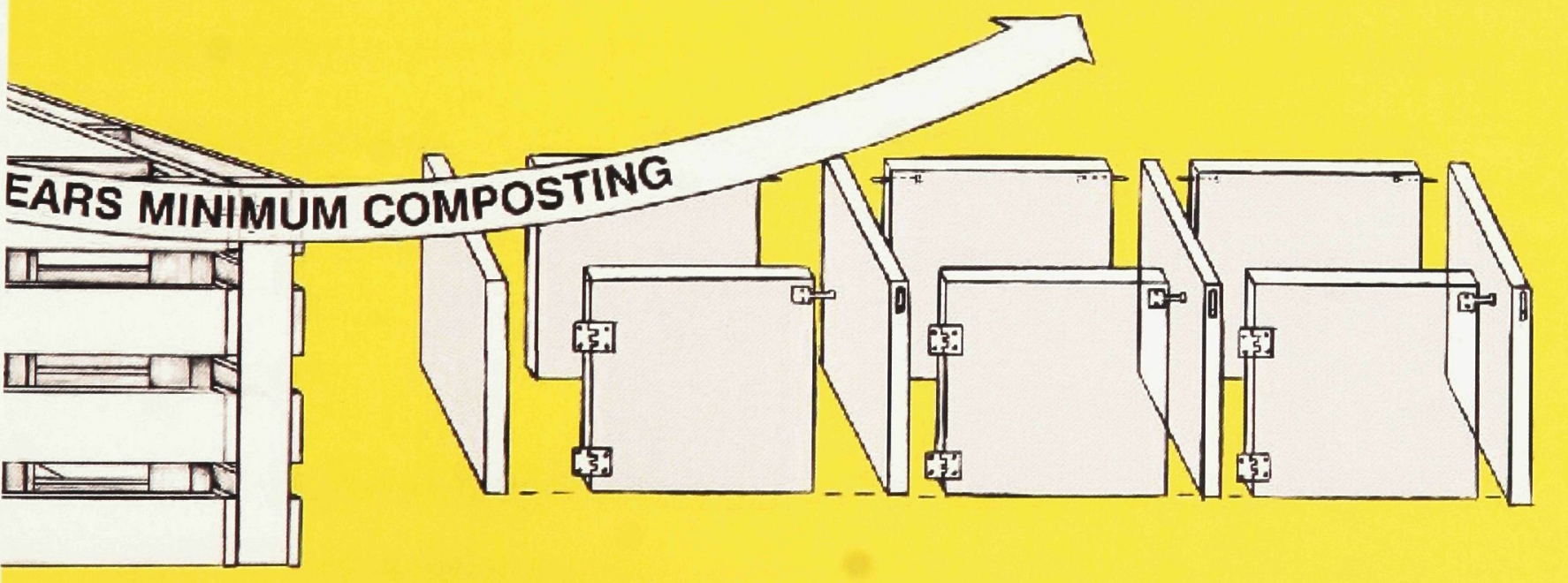

Drawing of Compost Bin Diagram For Buckets (Author) 4 of $4 \quad$ Figure 25 


\subsection{Proposal B: Compost Facility for Ciudadela Pachacutec}

Pachacutec is an 'informal' peri-urban desert community ${ }^{10}$. Unlike Hogar, which is located in the San Juan de Lurigancho District and lying close to the core of the city, Pachacutec is built at the urban blanket's outmost fringe along the ocean coast. In the same absence of regulated sanitation, its residents have also self-constructed thousands of pit latrines. Pachecutec however, is not built on an awkwardly sloping hillside. Only twenty years ago there was nothing there but empty desert. In another failed attempt to stop migrants from squatting in Lima's downtown the municipality built a portion of Pachacutec to lure urban squatters out. Not leaving the downtown, new countryside migrants quickly squatted in their place on the partial development and the whole area has built up resultantly. Migrants who have settled illegally in Pachacutec are accustomed to improvising the shelter and services they require in the absence of government provision. Because the community is not divided into pockets of dangerous terrain and because the people of pachacutec are determined to work through selfmobilization, it is possible to introduce a larger compost facility for this area. Due to the economy of scale, the bin system for small groups and independent residents had to be innovated into an easy to use large capacity assembly line model. This thesis will now present the approach, construction process and a detailed explanation of how this facility can be employed. ${ }^{11}$

1.0 Facility Ideals.

Designing a sanitation system in Pachacutec required meeting an ambitious target. The system had to be able to operate without regulatory government services, to

\footnotetext{
${ }^{10}$ Informal settlements consist of communities who exercise their rights to obtain land title through squatting.

${ }^{11}$ This large scale facility could potentially become a prototype for neighboring sites.
} 
serve a population that lacked formal property rights, designed to require little participation from the general public, to be built without complex machinery, using no piped infrastructure or foreign assembly, no expensive consultation, no electricity, no water and to do so without municipal funding.

Because the facility's greater intent was to hinder pollution, it also had to operate without creating waste. The final challenge was to design a facility that could operate in close proximity to the people it served.

2.0 Compost Facility Plan of Implementation

Although the intention was to fund the facility by paying back a loan through compost and small tree sales, the pilot project will require separate funding dedicated for the research and development of the system. Funding in the form of a research grant will help develop this thesis into a set of finalized construction documents complete with preliminary engineering approvals, lab testing, and the construction of a test mock up of parts to prove the compost will be productive and free of pathogens exiting the system. Although regulation may not be provided by government, approvals from the ministry of health and from the ministry of Environment of Peru must be obtained before the approach is brought to the community.

\subsection{Community Approval}

The community approvals process will be delicate. It is assumed that making a presentation to both the largest NGO working in the community and to the main university research groups, credibility will accumulate in the public eye. The largest NGO in Pachacutec is Aldeas Infantiles SOS del Peru, and the university research body is CENCA (Center for Social Research and Popular Education). 


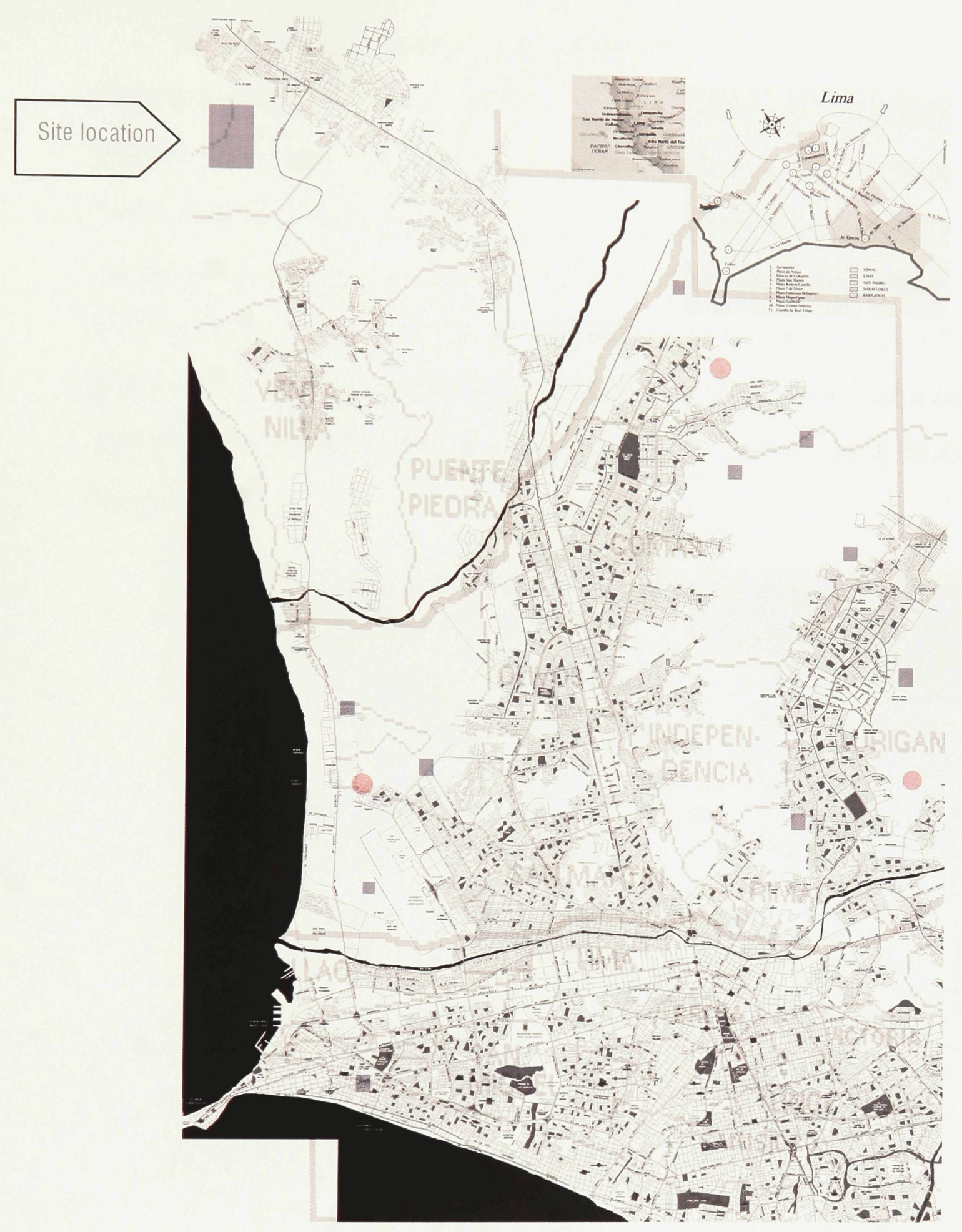

Plano De Lima Metropolitana, Toribio Anyarin in Jante (Altered by Author) Figure 26

After approval from these groups a preliminary presentation will be made before the community to obtain permission to start household interviews, introduce the project and begin the selection process to find 106 inhabitants to participate in the pilot. 
Intensive household interviews are required to both explain the intent and to inform to a strategy for finding community leaders. Electing three representative speakers from the popular participant vote will most likely be the best approach for a selection process. Based on a strategic location, a land assessment, ownership conditions, and the proximity to our participating group, a final site selection will occur for the placement of the facility. ${ }^{12}$ The site should have a continuous slope of ten degrees and be close to a service road. Because of prevailing winds that typically blow from the North; the site location should be on the southwestern edge of the main community. ${ }^{13}$

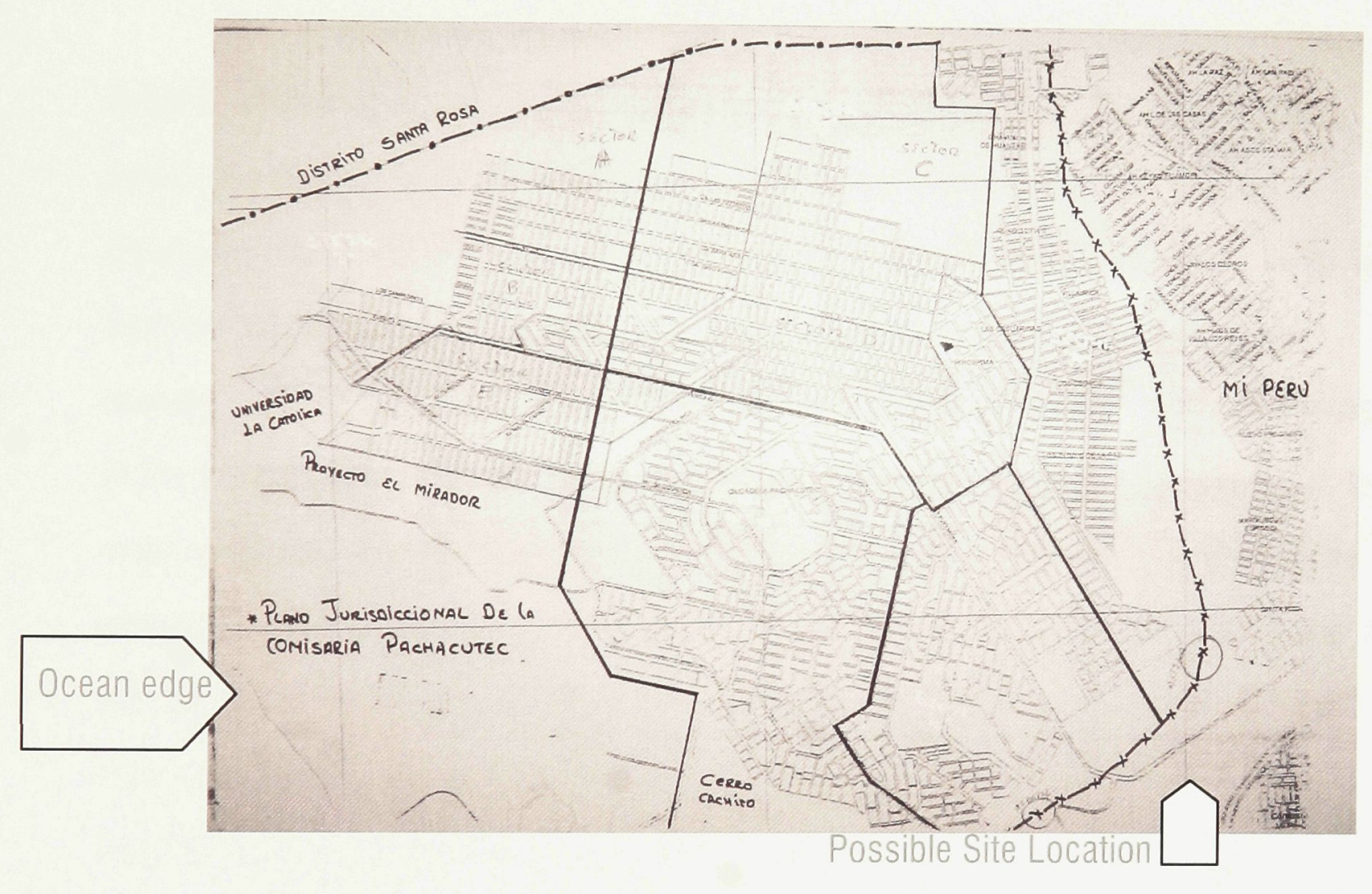

Map of Pachacutec found in Police Commissioners Office in Pachacutec

Figure 27

\footnotetext{
${ }^{12}$ Figure 31 is a map of greater Lima has shows epicenters of informal activity where our facility may also have application. Each of the blue squares represents an informal community visited. The red squares are Aldeas Centers.

${ }^{13}$ Figure 32 is a map that was found at Pachacutec's tiny Police Station and photographed on the wall of the Commissioners office in October 2005.
} 
An ideal facility location would be just west or east of Cerro Cachito, (figure 31) or in general proximity to this area. If it is too difficult to obtain land legally, it may be possible to have a tract of land dedicated on a conditional basis; similar to planned squatters rights (the pan requires approval by the municipal authority). This is similar to how Aldeas builds community centers as discussed in Proposal A. Playgrounds and parks in informal areas obtain land with such tentative agreements. When site selection is completed, a final engineering, earthquake and soils assessment is required. Finally, regarding community participation, a map will be required to determine the length of the collection route.

The hiring process will be the next step of implementation. Chosen from the elected community representatives, three full time and permanent positions will go to tender. Funding for these three employees will require start-up capital. The job description demands that each worker participate in general labour, be able to drive, be mechanically inclined, and should have experience with gardening and sustenance farming ${ }^{14}$ These three workers will assist with the removal of pit latrines, the installation of the new toilet systems and the clean up of the participant yards and streetscapes to some degree during the initiation phase. Workers will assist in the construction of the compost facility and be responsible for running the pilot after it is constructed. It was felt that full time employment would be more advantageous then hiring workers on a part time basis, both to secure consistent work and to act as an investment in the community. The selection of these three employees will require a vote from the participant community, and workers will undergo a probation period before selection.

\footnotetext{
${ }^{14}$ Such skills are common to informal residents.
} 


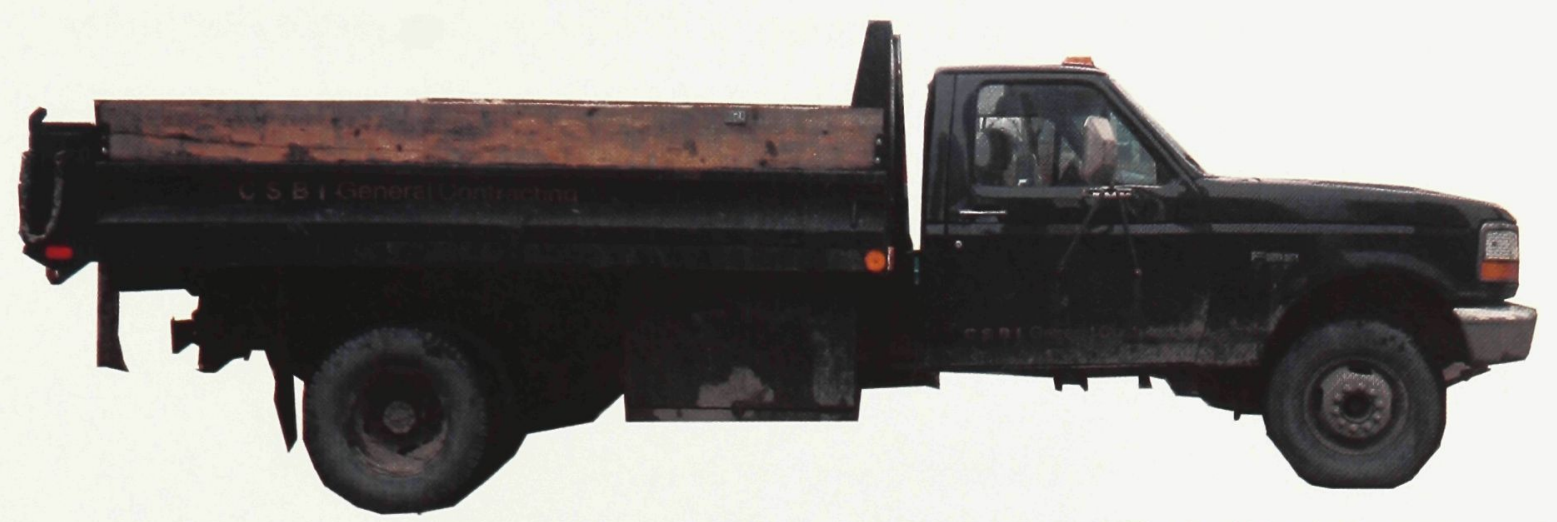

Flat Bed Truck (Author) Figure 28

Acquiring materials is the next step to constructing the project. A flatbed truck purchased within the community is necessary in order to obtain further materials. The truck should have two seats and removable cages around its bed on three sides. With the workers, the site and the truck at hand, local construction consultants will be required to approve the assembly process of the facility.

The actual assembly can be a community effort beyond the three laborers and the consultant, but the majority of the work should be manageable with four.

At this time, it will be important to meet with the local concrete women's group that operates in Pachacutec. ${ }^{15}$ Typically, the concrete women's group works in partnership with Aldeas, and other NGO's to ensure that investment does not go to funding groups outside the community. Because the facility site will be all sand and rock, most of the materials to produce the concrete will be available on site, with the exception of the cement mix and reinforcing bars (re-bars) that are also locally available. Because of these reasons, concrete is the best material choice for the heavy load bearing portions of the facility.

\footnotetext{
${ }^{15}$ The women's local concrete block company, was started with similar ideals to this compost facility. Setting up the company required using local resources, taking advantage of the community capacity.
} 
The commission of four sets of reusable formwork is the next step of construction. The formwork designs must receive approval from the women's concrete group before they go to tender to a local welder and resident repairperson. Using this formwork, concrete pieces produced in bulk will be used to assemble the facility as a kit of parts.

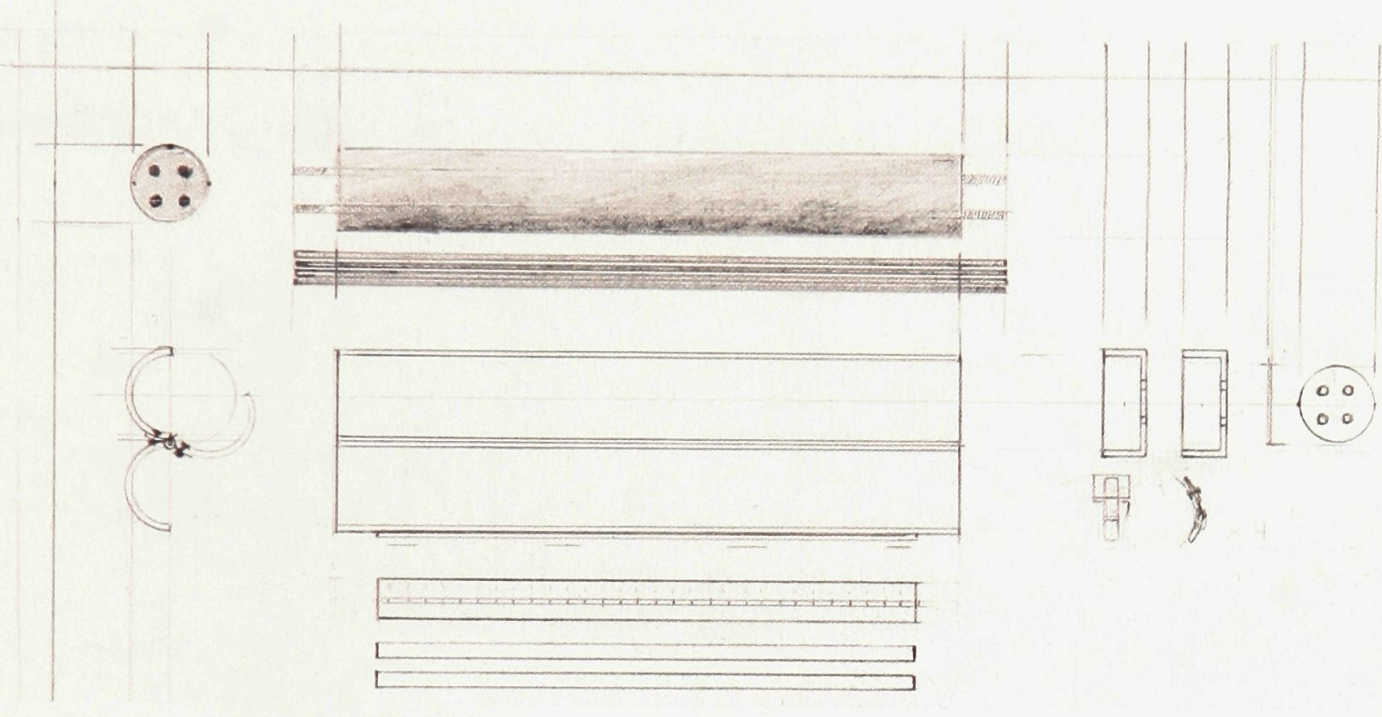

Drawing of Formwork and Crossbar (Author)

To take advantage of pre-made forms and for the sake of poetic justice, the formwork should be built using water based plumbing components. Slicing a section of lightweight PVC pipe in half and hinging it on one side will create the basis for an operable and reusable formwork assembly. Screwing small clips opposite the hinge will keep it closed. Standard pluming caps can act to contain the concrete and position the re-bar at the same time. First cut the rebar to size, and then thread both ends. By precisely drilling four holes in each end cap, protrude the re-bar through the first cap and use the nuts to position it. Then slide the cap and re-bar into the tube (which will be closed), tip sideways and fill to the top with concrete making sure to vibrate the assembly with rubber mallets to rid it of air bubbles. While the concrete is still wet, place the second cap on, push the rebar through the holes and apply the second set of nuts to adjust the rebar position. When the assembly is tightened, leave it to cure. This will produce a crisp concrete shape, (figure 33). 
In this proposal the measurements have been calculated as an initial gesture. Although these dimensions are subject to revision and further engineering assessment, the final approach should be similar in strategy, but hopefully easier to follow with simplified numbers. In the example here, the concrete cross bar piece is $1405 \mathrm{~mm}$ in length and $175 \mathrm{~mm}$ in diameter, with a reinforcing bar length of $1606 \mathrm{~mm}$ using a PVC pipe with an internal diameter of $175 \mathrm{~mm}$. The end caps with will have an internal diameter of $185 \mathrm{~mm}$ accounting for the thickness of the plastic.

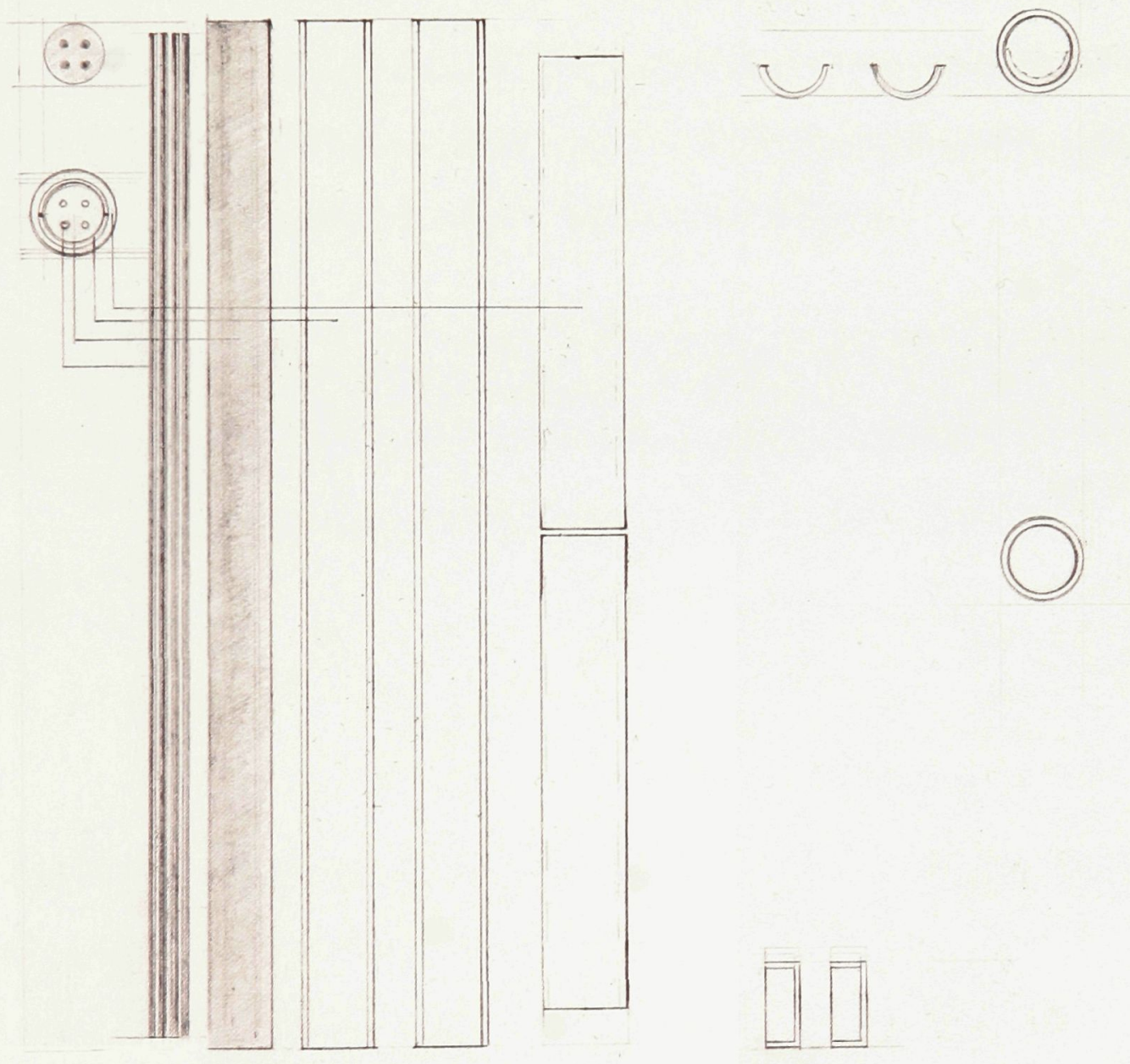


The larger structure will also require formwork for the taller poles. This can be achieved using two PVC pipes and a similar end cap approach, (figure 34). The main pipe can be cut across its longest dimension. The second and larger in diameter pipe will be divided lengthwise. Place one sleeve over the long sections, and add a cap to seal the first end. Stand the pipe up, add the second sleeve, fill the cavity with rebar, pour the concrete, cap the assembly and hammer out the bubbles. The plastic will allow for a long curing time and should produce a strong and polished shape. The length of the concrete pole was initially calculated to be $2950 \mathrm{~mm}$ with a diameter of $175 \mathrm{~mm}$. The long pipe sections are $2950 \mathrm{~mm}$ in length. The second pipe pieces should be $1366 \mathrm{~mm}$ in length, with an internal diameter of $185 \mathrm{~mm}$, which will be the same diameter dimension as the end caps that will cover the first two halves of the first pipe.

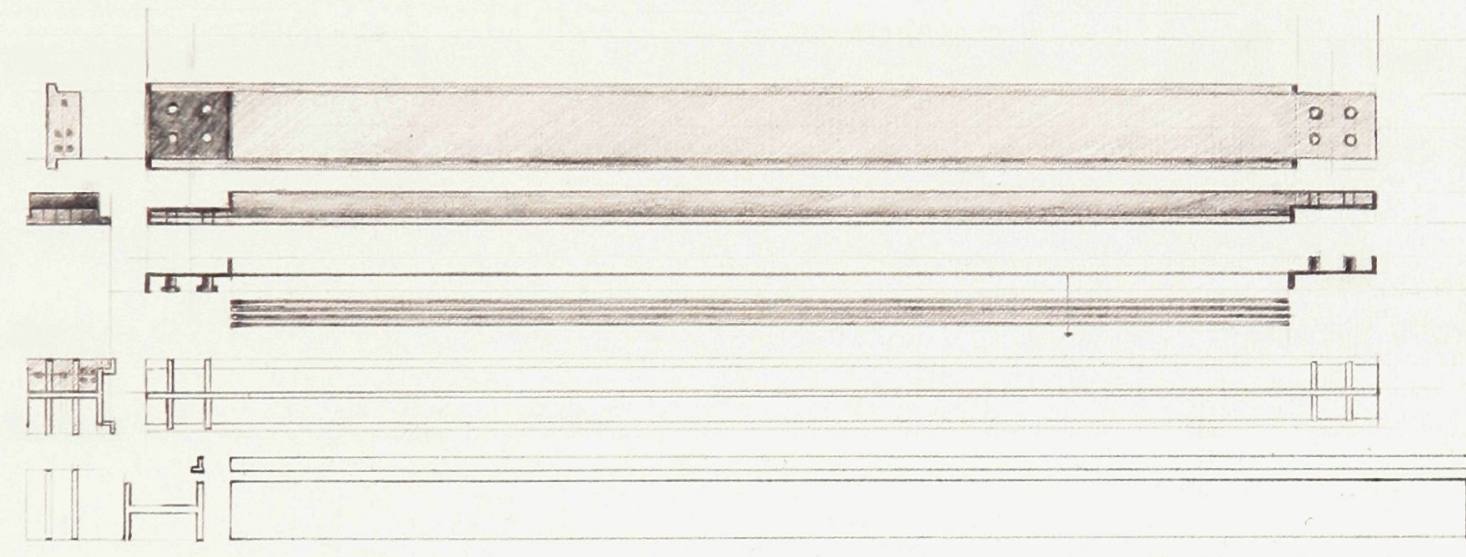

Drawing of Formwork and Beam (Author) Figure 31

The beams will require a harder form, (figure 35). Because we cannot afford steel beams we will use an oversized steel beam for formwork, to in turn produce many smaller concrete beams. We can then return the steel beam when the facility is complete. An estimated wide flange $3798 \mathrm{~mm}$ in length with a flange cavity of $211 \mathrm{~mm}$ by $86 \mathrm{~mm}$, in depth, would be ideal. This beam would need to be donated as a custom order from a factory. The idea is to use a clean and smooth surface for producing clean concrete beams that have overlapping joints. The rebar for the concrete beam can be 
attached to metal plates at each end to create a smooth and structured joint with holes to accept the threaded rods from the concrete cross bar during the larger assembly.

Laying the steel beam on its side, (figure 35), weld four small rebar pieces to the flange at each end of the beam. Since we are welding, both cavities might as well be prepared as a formwork surface. By welding steel tubes to the steel lap joint plates that will sit inside the finished concrete beam, we will be able to slide the beam on and off of the bars that have been welded to the wide flange. These tubes will serve as internal holes to fasten the beams to the cross bars when the facility is assembled. Tying the rebar to the lapping plates is made easier and consistent by placing them in the cavity first. Alternatively, the rebar can be attached to the plates outside the steel beam and stretched tight when placed on the wide flange before the concrete is poured. Rather then pouring concrete into a dirt form that would be very messy, the plastic and steel forms will allow for consistent pieces every time. If the plates and rebar are set up in the metal shop the women's group will only need to pour the concrete and ensure its consistency with slump tests. Used motor oil applied to the forms before pouring should help to keep the concrete from sticking.

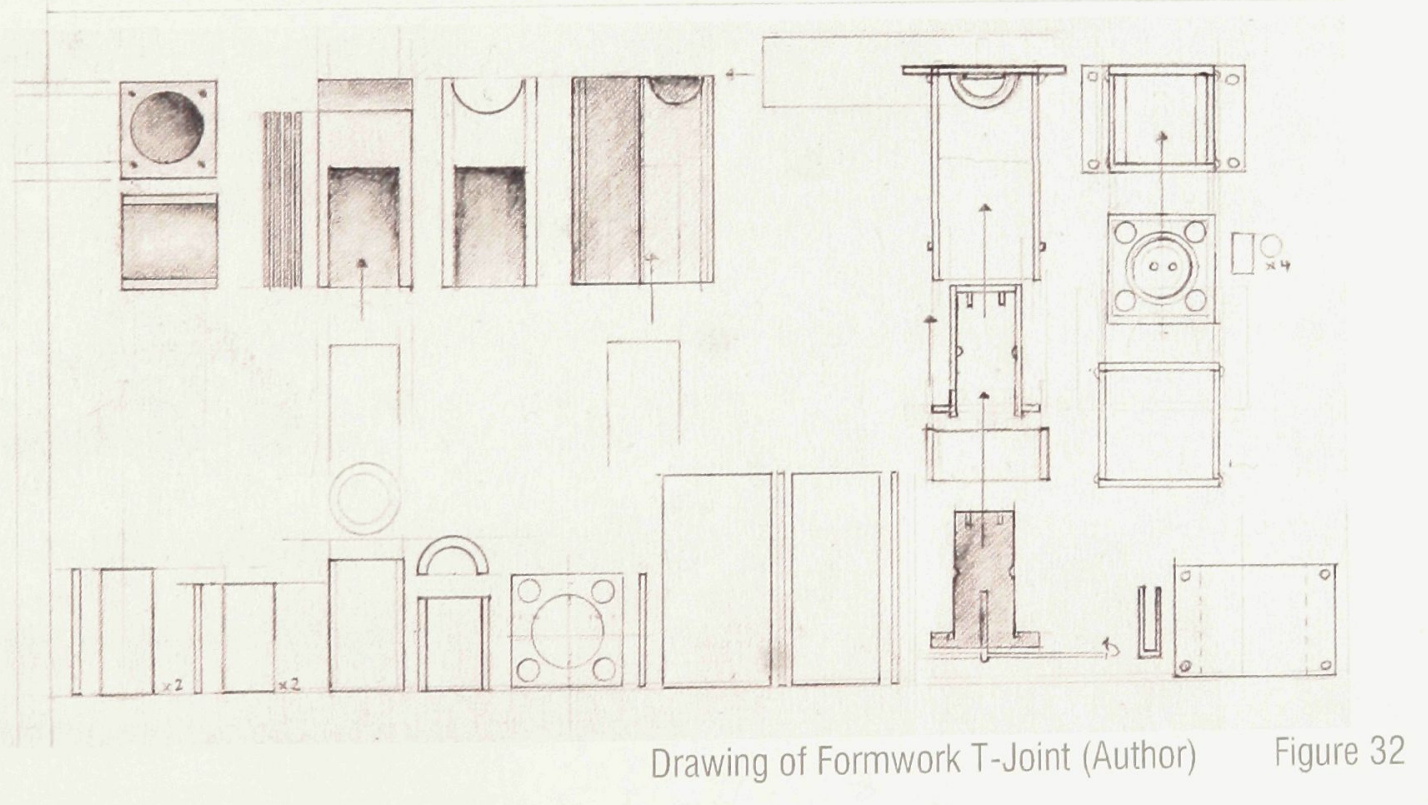


The next formwork piece is the most complex of all the formwork components (figure 36). Like a kind of keystone it connects the supporting structure and translates the load from the cross bar to the pole. The shape is a simple box with two tube cavities. One tube cavity at each end, the top tube cavity is perpendicular to the first with a concrete space between. Creating a junction piece will allow for a rubber disc between the pole and the cross bar which will help the system to be anti-seismic. Using a metal box and a tube with a $175 \mathrm{~mm}$ diameter, which imitates the pole and cross bar as a void, the cavities will receive their respective pieces when the form has cured and the facility is assembled.

The complexity of the formwork is justified by the benefit of being a kit of parts system. Like industrial formwork for making toy Lego, the form may be cumbersome to create, but once it is made it can mass produce simple and easy to assemble pieces. Because the women who produce concrete blocks do not typically pour large constructions on site, and because their facility is set up to repeat smaller pieces the economy of scale seems to match this type of approach. The concrete pieces can be transported from the facility using the truck, which will be about a five-minute drive. The larger poles can be placed into the footing holes directly off of the truck and slid into place. As the parts are small they can generally be lifted by our three workers. Using a twelve to one ratio chain pulley may make the process much easier, and we could always attach the steel wide flange beam to the truck to create a small hoist.

While the forms are being built, welders will be commissioned to purchase the small wheels and hired to weld structural arms that will be used to hang the compost.

The compost is designed to be hung from the concrete structure using two layers of nets for containment. These nets will be commissioned from the local fishermen to sew together in the same assembly line style as the concrete forms were made. Each compost bag will use and outside layer which is a structural fishnet and and 
inside layer is akin to a flour sac. This internal layer requires testing to ensure a balance between retaining moisture and allowing aeration. While the nets are sew together and the concrete forms under way, footing positions can be staked on the facility site.

Assembly of the first Row can now begin. Construction crews will begin preparing the ground surface to pour the footings. When pouring, builders will have to leave tolerances for adjustability. T's should be assembled and adjusted before the final footings are poured to anchor the poles. Sticks can be used to hold the structure in place until the footing is ready. A concrete shoe will be anchored, and the pole will sit in the shoe as a friction fit. The finite details of the footing need to be engineered to meet earthquakes requirements, (figure 37 ). 


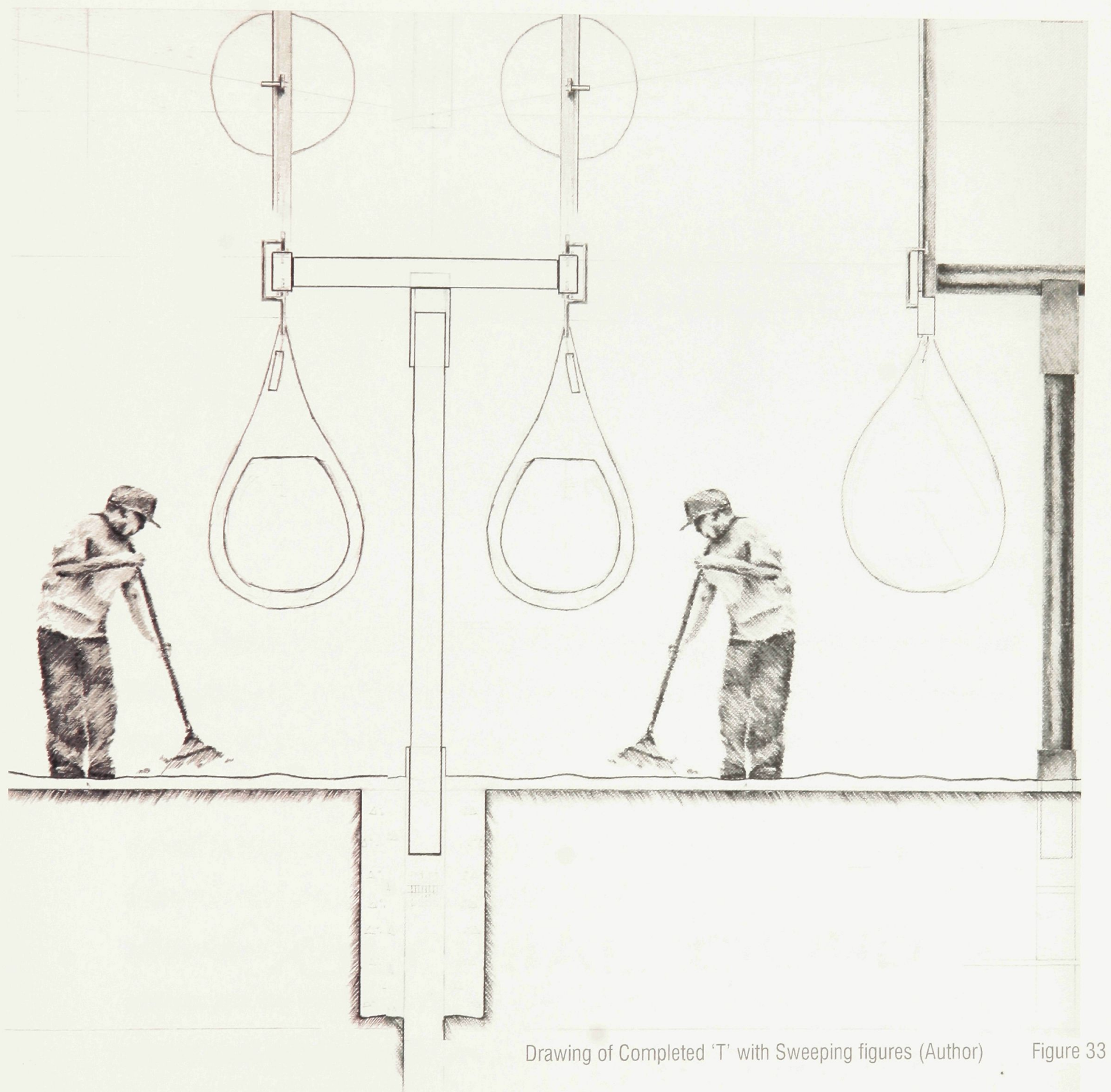


The final beams on each row will require a device, which has been termed "the Archimedes screw". 6 rows of concrete T's will be required for the pilot in total. These are built on a slope of ten degrees using gravity to power the system to move the line. The bags hang on steel arms similar to meat at a butchery moving at a rate of about one bag per week as the bags will be held in the system until their compost process is sanitized. The Archimedes screw functions to allow the removal of one bag at a time.

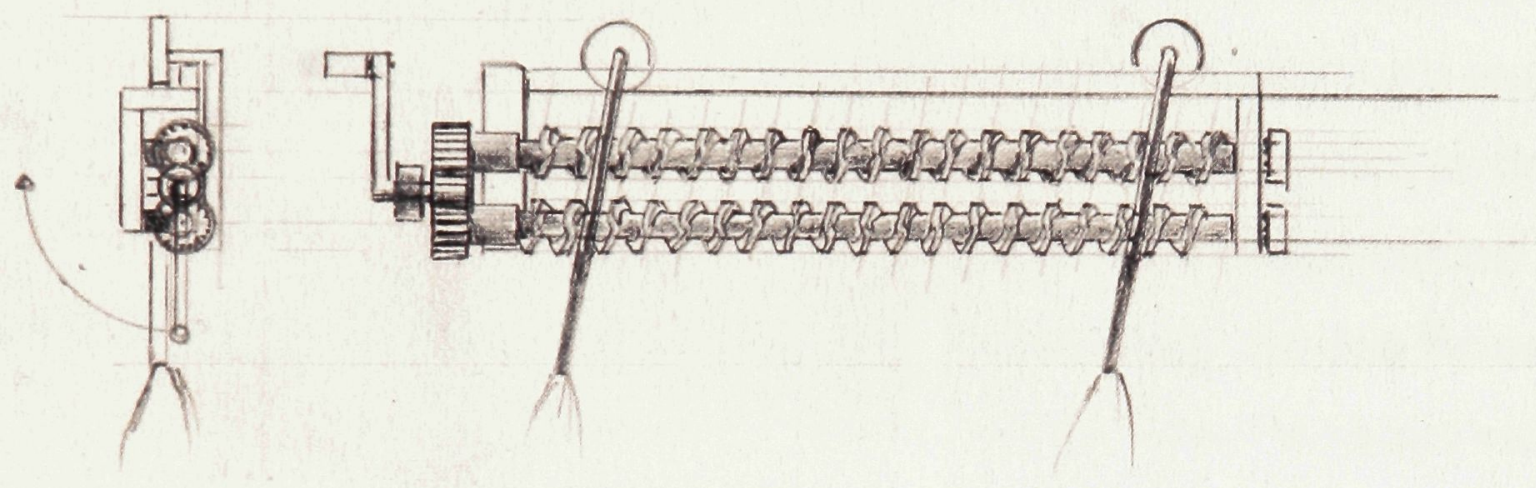

Turning the handle, turns the gear that turns the screws simultaneously. Because the hanging arms are fixed to the concrete beams because of a top and bottom ridge in the beam, the chain is allowed forward while resisting the force of the other bags, grabbing to bags at once. This screw system can be welded together using metal discs cut and bent and welded to a solid steel pole. The welding process for the screw is similar to making large drilling equipment. To stop the chain from moving, fixing the handle should be enough, due to the coefficient of friction of the interacting bars and screws, and the direction of force. A small hill, using sand or poured concrete on the ground could add more friction and help to prevent the bags from swinging out. 
When the construction of the pieces is complete for the first row and the footings are poured to anchor the shoes for the poles, it is time to begin constructing the concrete platform (figure 39).

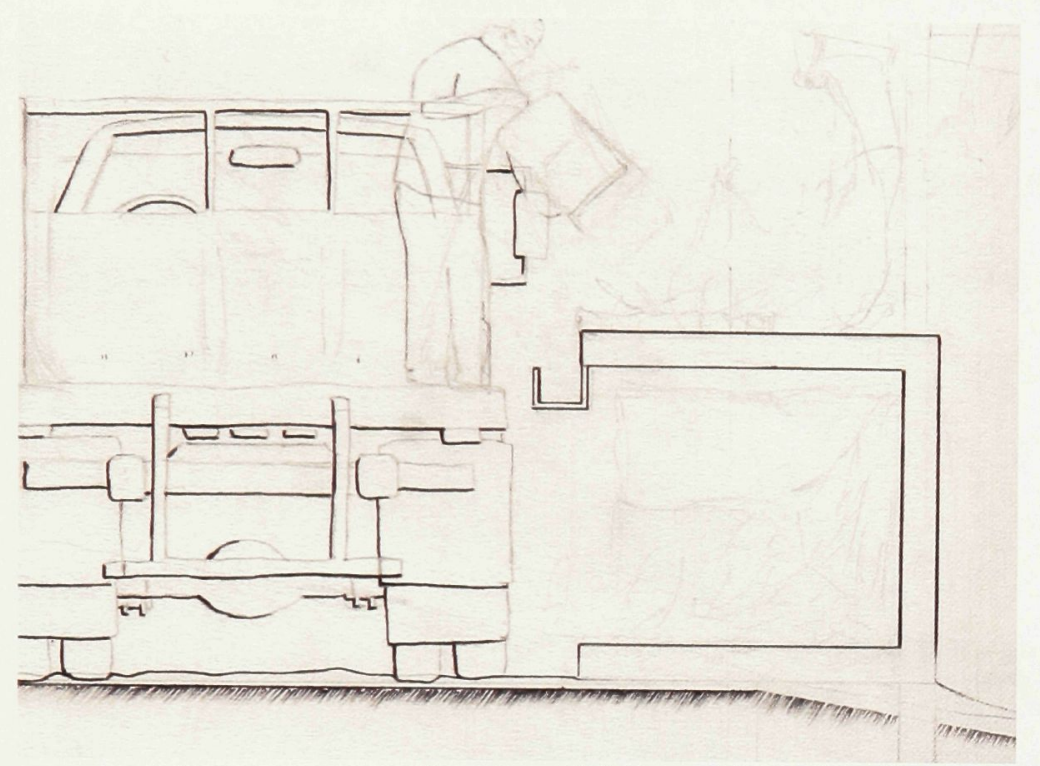

Drawing of Platform (Author) Figure 36

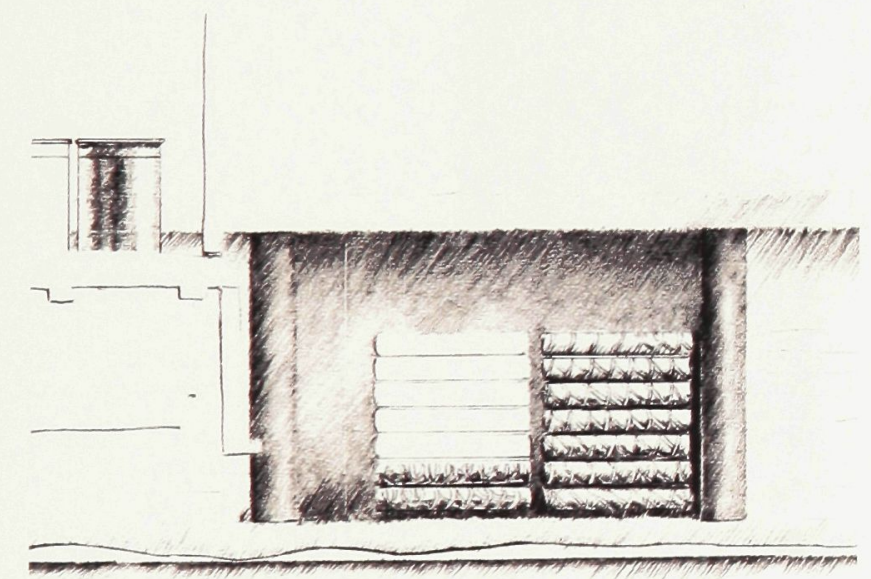

The platform can be built with the open side supported by the same concrete piece as the cross bar at the top of the concrete T's. It is important to have this platform both for storage and to take the weight from the compost bags when they are loaded onto the frame. The top slab can be formed using wood pallets topped with three layers of thin wall panel where the edges can be built up with boards from a wood pallet to hold the form (these wall panels are common as infill material on most shanty homes). The platform, depending on

Drawing of Platform Storage (Author) Figure 35

how much concrete is available, can be economized by only pouring the top slab and using wood poles for support. The back wall is useful to help contain the platform as a storage space however.

When the platform is complete it will be time to begin collecting composting materials. Saw mill shavings should be obtained in bulk from the closest possible 
source, and a stock pile of ground paper and vegetation should be obtained from local markets. The sewn cloth bags, nets, steel hanging arms, and vegetation should all be stored inside the platform until the facility begins the process.

As the construction of the second row begins, it is time to commission the wood pallet toilets from local carpenter shops. The toilet lids are to be purchased at this time and the toilets are to be mass-produced locally. During the household interview and consultation period, several designs will be presented to ensure that residents are comfortable using the toilets.

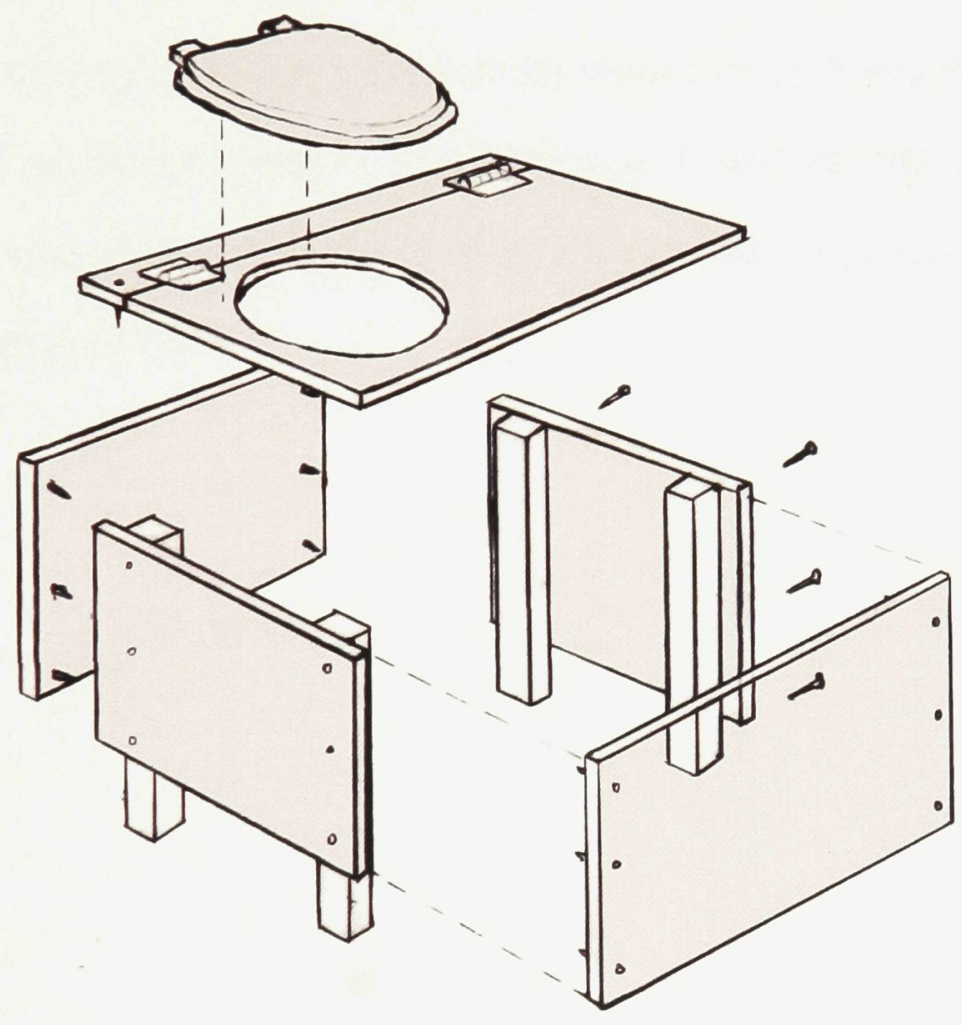


Figure 41 is a standard North American way of constructing a sawmill shaving toilet. Instead of plywood however, a better design would be to build one of wood pallets, (or wood skids) which are the locally available wood source. The carpenters in pachacutec typically use these to construct finished hardwood doors and kitchen tables. Their shop is within a 15 minutes walk from our ideal site location.

There are several benefits to building a site specific toilet. Using smaller pieces allows for a dynamic shape and because the resource is recycled the pallets are very cheap. Constructing wood pallet toilets also allows residents to have finished hardwood pieces of furniture within their homes, which is nicer then a more expensive plywood model. Upon close inspection it is clear that the wood pieces themselves tend to be warped, witch is an inherent property of the material. Taking advantage of this shape creates easy curves, which are useful to make the unit more ergonomic allowing for more leg space (figure 42). 

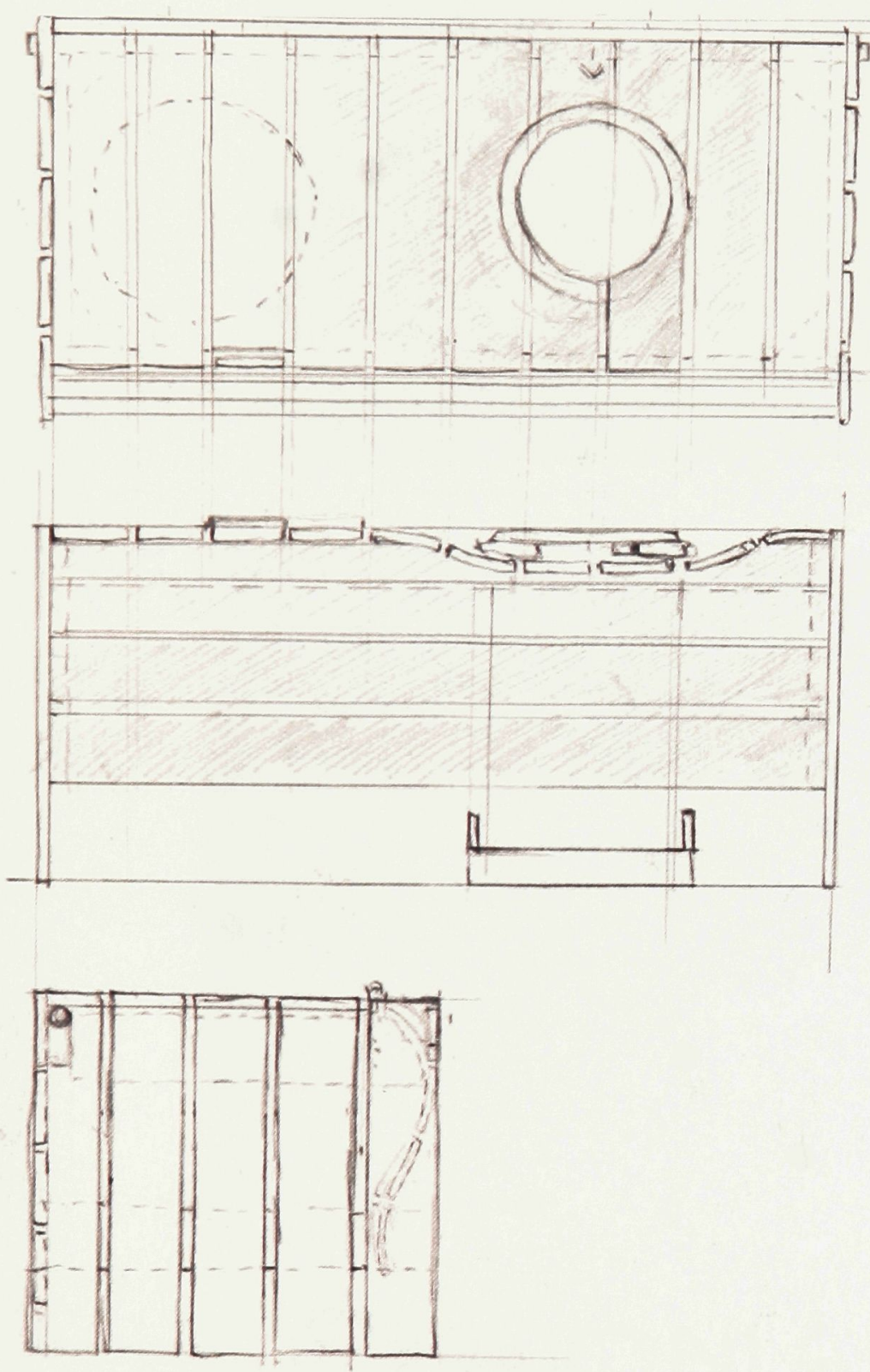

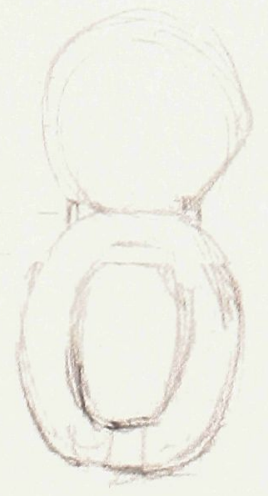

WODEN TOLET COMSTRLICTED FROM WOD PALLETS TO PE INSTALLED IN EVERY PARTICIPAT INIG HOLSHGD WORK TOBE CONIDACTED TO LOCAL PLILIDERS UMIIT DESIGMED TO STORE AM ADDITICNAL
BLCKET 


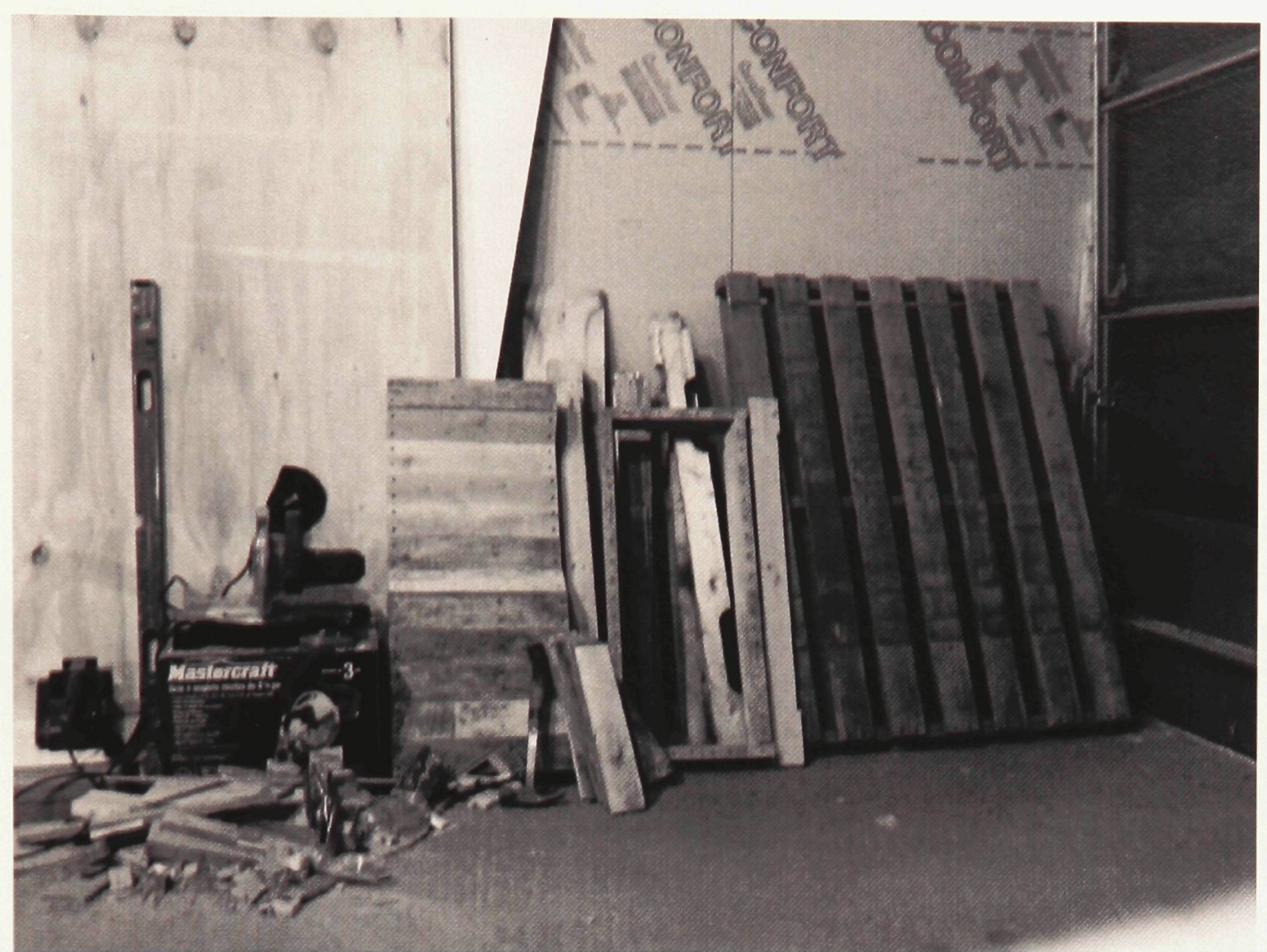

Toilet Construction from Donated Wood Pallets, Mitch's Garage (Author) Figure 39

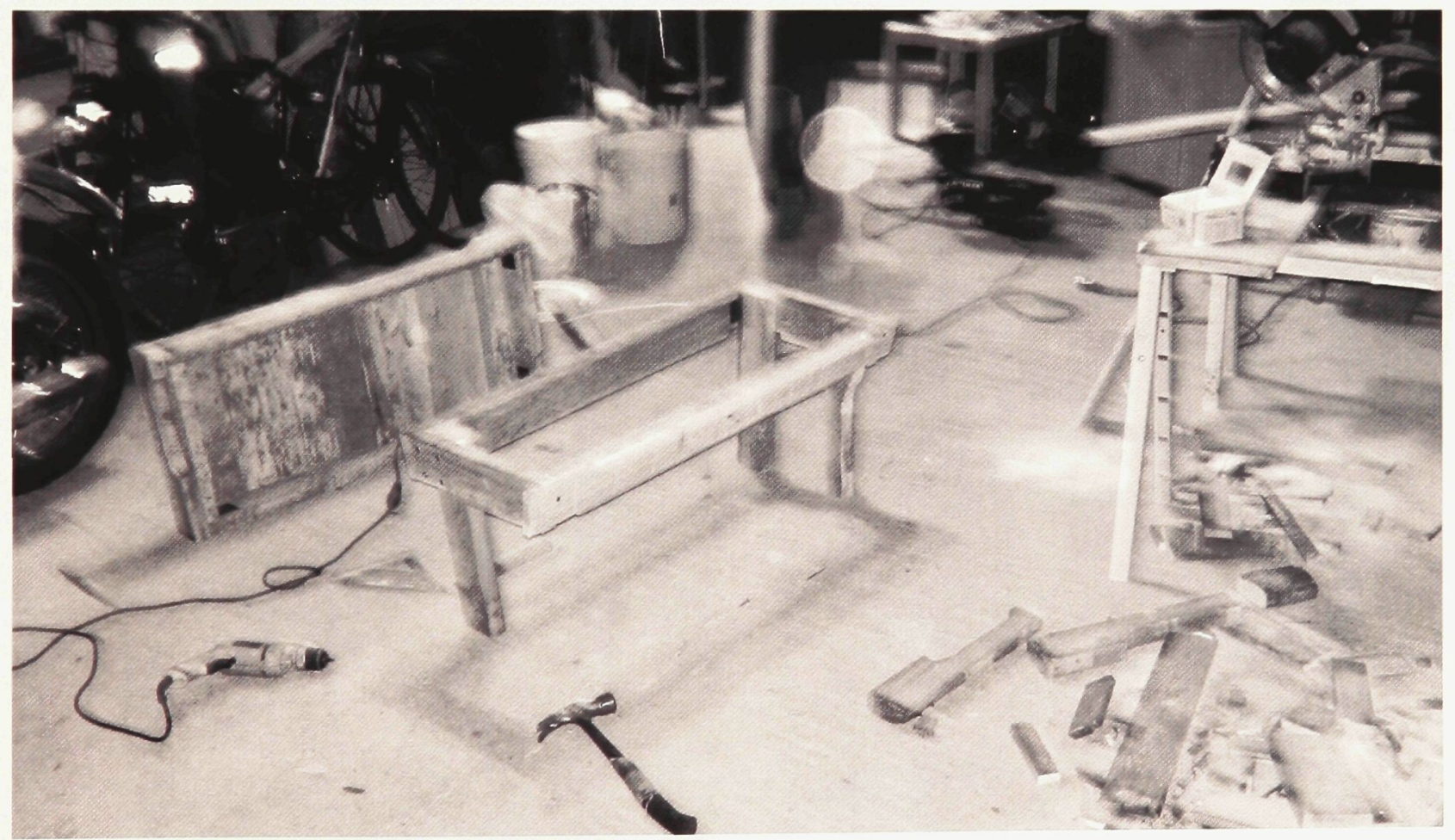

Toilet Construction from Donated Wood Pallets, Mitch's Garage (Author) Figure 40 


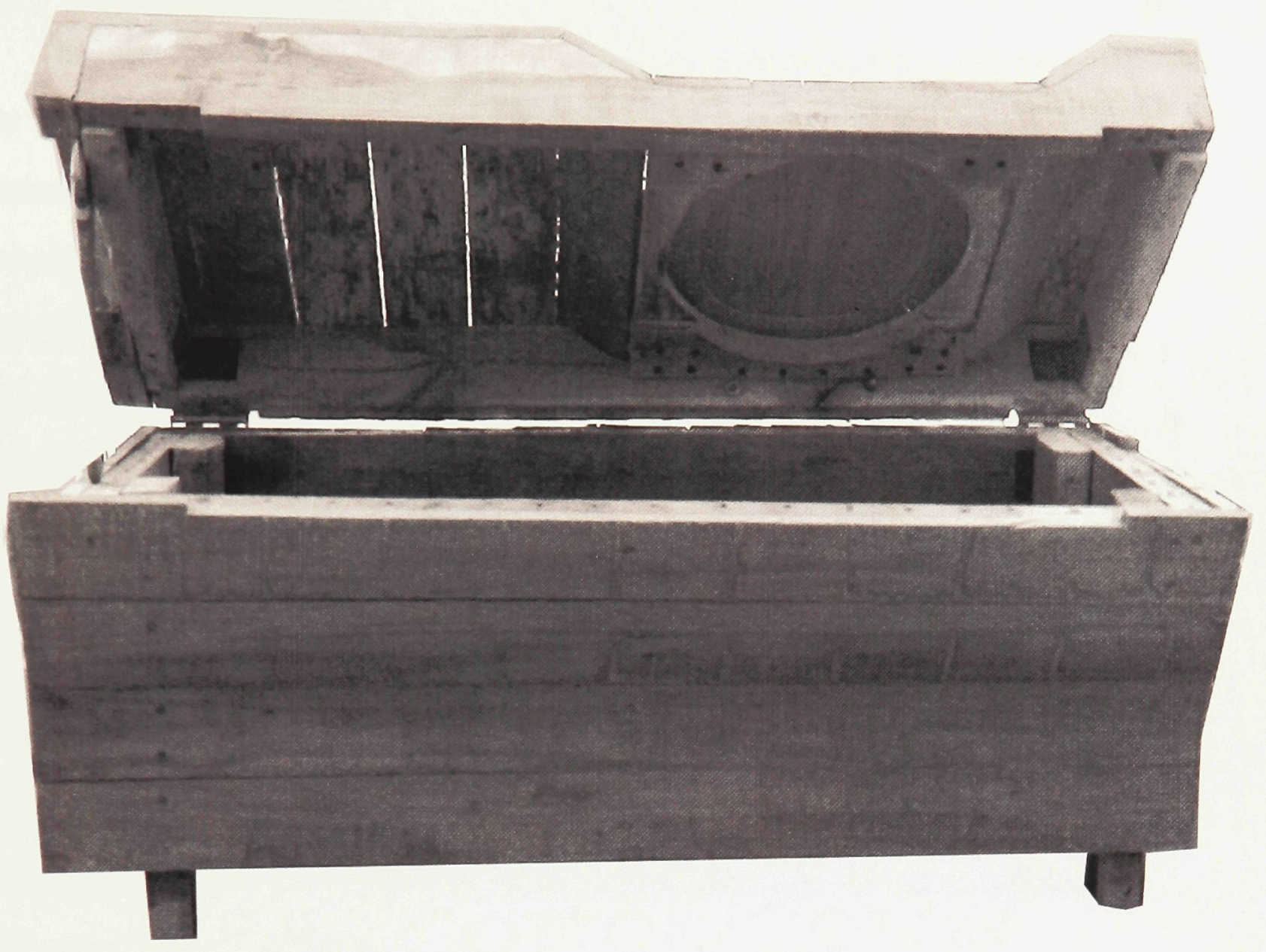

Improved Wood Pallet Toilet with Open Lid (Construction and photo by Author) Figure 42

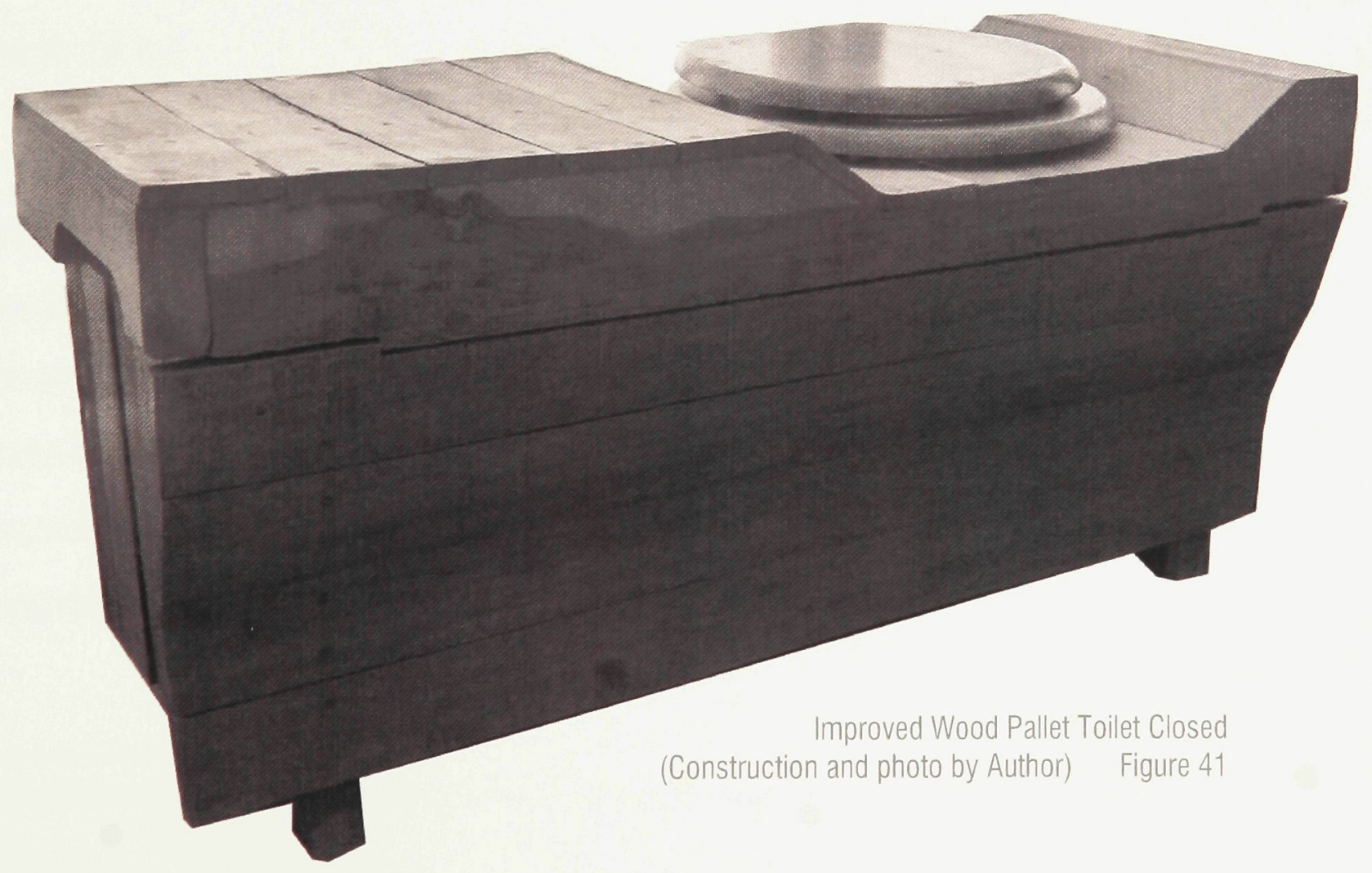


The toilets will be delivered to each participating home accompanied by two yellow 5 gallon pails with lids for human waste disposal. The pails are to be coated with a sawdust and water paste on the inside to help with the bucket cleaning process afterwards. A paper bag filled to the top with sawmill shavings will sit inside each pail, (Residents will use the saw mill shavings as cover material, which will absorb the smell). One green pail for wet waste collection with a lid will also be distributed. Each wood pallet toilet can be used as a storage chest to store the extra bucket. The shape is accommodating because of the change in height, allowing a low seat with higher storage. A small cage will be secured in a level position outside of the home with the capacity to hold three pails and this will help to keep the rats and dogs from disturbing them. When the collection process begins, residents will be expected to bring the bucket to the small roadside cage, sealed with the lid, once a week. A family of three will typically fill one five gallon pail per week. If families are large they can use an additional bucket, sealed until collection day.

\subsection{Filling the facility}

When more than 5 rows are constructed, (figure 47 is one row), the collection process can begin. One worker will drive, while the other workers place the pails onto the truck. When the truck is collecting, the third worker will be laying out the containment nets and preparing a bed of stored vegetation on the platform. Buckets can be dumped onto the cover material, which is resting on the internal bag, which is resting on the structural net, which is resting on the platform. ${ }^{16}$ The green wet waste pails will add vegetation to the system.

\footnotetext{
${ }^{16}$ This vegetation acts as a cover material and insulation to help the thermophilic reaction retain heat explained in appendix $\mathrm{C}$.
} 


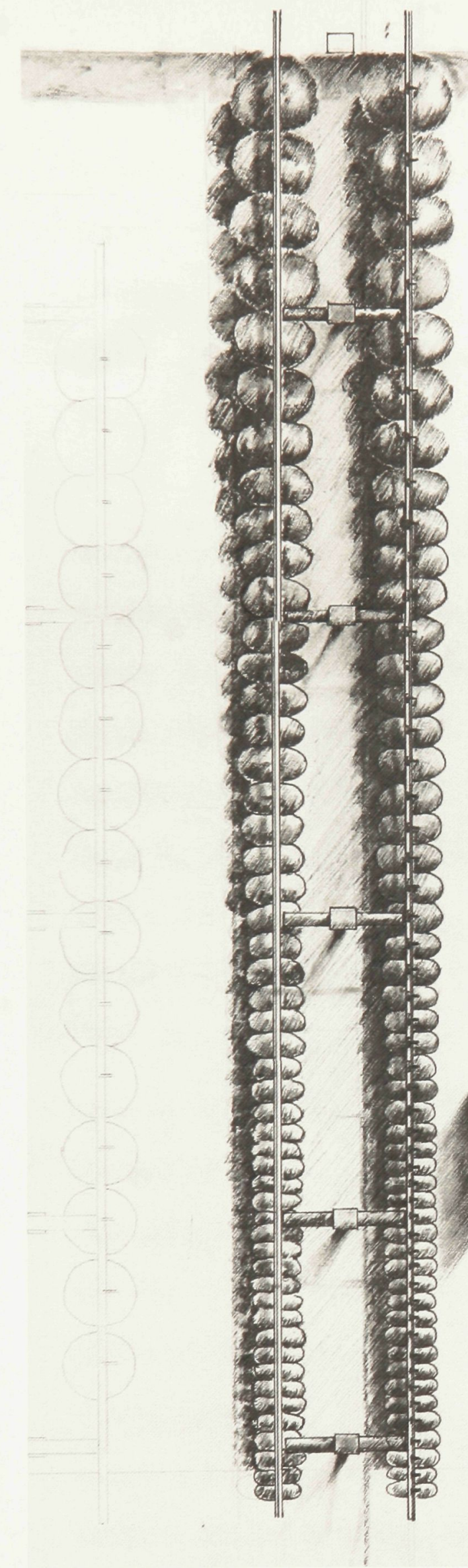

Drawing of Completed Row at Full Capacity (Author)

Figure 43
The facility is designed such that 5 full pails of excreta mix (a mixture of urine, feces and saw mill shavings) will be added on top of the vegetation for each compost bag (refer to figure 26-29). If inorganic matter is discovered in the pails, it will be taken out at this point (a gutter at the edge of the platform will assist removal). The bundle will be brought together when the edges are lifted upward using the steel hanging arms which have hooks for attaching the net. As the hanging arms are placed onto the beams, the majority of the weight in the bag remains on the platform because it is elevated. At this time the bag will be dated with a tag and can be pushed forward. As the bag drops off the platform it will fall into a hanging position. The bags will each hang as part of a larger chain, and these rows will be repeated several times.

The advantage of storing compost by hanging it is that loading and unloading is easier. Loading from one end of the compost chain eliminates the need to load from the side. This method saves space, time and energy. 
The system requires no digging or shoveling because the excreta does not come in contact with the ground. Systematically, new bags are at the top, and old bags at the bottom, (figure 47). The facility drops the finished compost directly onto the truck bed using only gravity resisted by friction to move the chain (figure 49). The plant is essentially powered by bacteria. It requires no electricity or chemicals and produces no waste. Wind helps to naturally aerate the system.

Hanging the compost also allows for several advantages regarding the science of nurturing a healthy thermophilic bacterial environment. Because the bags have a teardrop shape they are ideal for keeping a spherical mass of excreta while the compost shrinks. In a typical bin the material flattens before the thermophilic process is possible if the contents are added all at once. Most human waste compost bin processes prevent the loss due to shrinking by continuing to refill the bin, but the first addition has sat longer then the last addition in such a process and this would be a waste of time on the scale of our facility. Our facility, because of the nets, reduces this time lag which increases the capacity of the system.

Shrinking is a process that is very beneficial to the chain, because the whole chain of bags will shrink, thus increasing the systems capacity. The approach is akin to stacking the compost vertically but separated to prevent cross contamination. The cleaning process is the last step before the pails can be returned to the homes (figure 48). After the contents are emptied onto the platform, the pails will be driven to the small cleaning station. Using a gas boiler and a small water tower, buckets will be sanitized by a steam spray room. The temperature should not be so hot as to melt the plastic but hot enough to kill threatening disease (refer to Appendix C). This steam water will be sanitized, and can be used to irrigate the tree nursery field. 


\section{BLCKET CLEANIITG PROCESS $_{x}$}

(1) DITLOAD THE BUCKETS

(2) CLEAT OFF IHE TRHCK \& BOOTS

(3) PLACE DIRTY BLCKETS INTO STEAMER

(4) PLACE CLEAN BIKKETS ONTO TRLCK

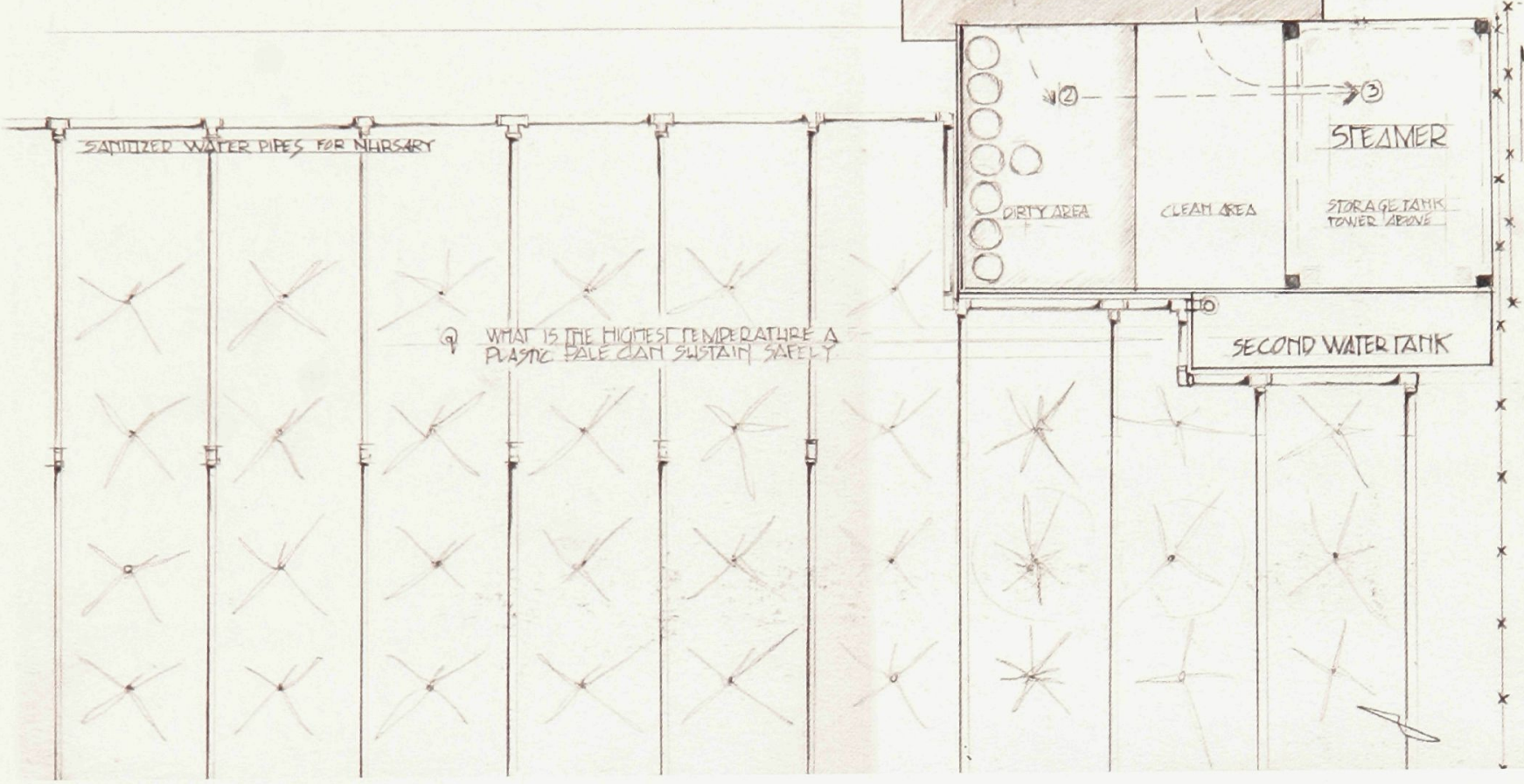

Drawing of bucket cleaning process (Author)

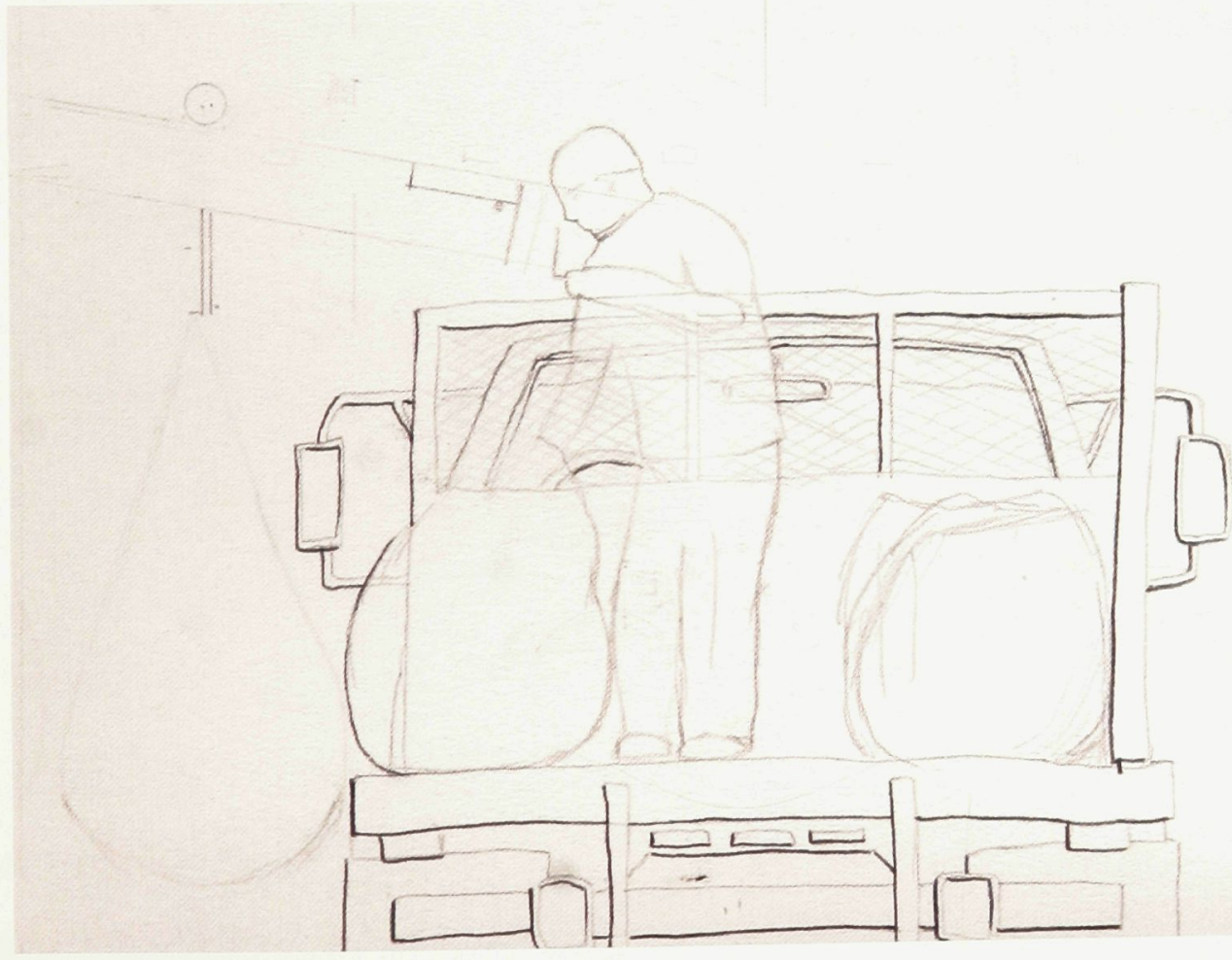

Drawing of unloading process (Author)

Figure 45 
When the buckets are clean, they will be coated in a wood dust paste, so that when they are emptied back onto the platform again the excreta will not stick to the plastic, and thus fall out in one clean organic compost-able shell. The cleaning station is located next to a service road, so that the tower can be filled by the local water truck.

When the compost process is complete, the unloading process will use the Archimedes screw to remove the bags one at a time (figure 50). The bags will more or less fall right into the truck and be ready for delivery to where compost is needed, (figure 49). The structural nets will be brought back to the top to be reused. Initially the compost may take time to be accepted within the community. This is anticipated and if compost sales are not immediate, the product will be applied to the tree nursery grounds to prepare the land for the nursery and to prepare the surrounding perimeter of the facility for planting (figure 52).

In addition to meeting safety requirements of pathogen destruction, which is the minimum requirement of our proposal, the compost sanitation facility must be efficient enough to pay for a large proportion of its own construction by paying back its loans. It should do so using the profit incurred from nursery and compost sales from the small on site compost store (figure 52, 53).

The low tech productivity testing can occur within the nursery and the experiments. As long as they are healthy, trees will be sold from a small sales office built on the facility site. Standards such as ensuring a neutral PH balance and meeting an adequate carbon/nitrogen ratio must be maintained. Worms may even be added after the cool-down period in the chain (refer to Appendix C) to increase compost breakdown. The worms and the trees will germinate in a small tree nursery next to the sales office. This nursery will use old plastic bags for moisture control. When the plants begin to grow they will be transferred to the onsite irrigated field. The roots of these larger trees will be contained in the same inner bags previously used for storage. Some trees will be 
planted and the clippings will be used for further germination. There is also a possibility for varying degrees of fertilizer mixes to be produced at the loading stage, depending on the mixes added.

Lab work will be required for safety to ensure pathogen destruction for the pilot project, but most of the safety testing will only require a thermometer because the science behind heat and pathogen destruction is well researched. One of the ideals of the system is to create a dependable product. That is why the wet waste and excreta are collected in separate containers. The consistency will make testing more reliable and the compost valuable for agricultural application.

\subsection{Pilot Facility Capacity}

Adding 5 full pails per bag is about 25 gallons or 55 liters of 'excreta mix'. ${ }^{17}$ Because the average person is said to produce about 3 gallons of excreta mix each week, each containment bag can hold the capacity of about 8 persons production per week (8.33people) ${ }^{18}$. Each chain has been designed to hold 51 bags per side, and two sides together hold 102 bags per row times 6 rows in total for the pilot project. The facility will therefore have a capacity of 612 bags when each chain is fully loaded ${ }^{19}$

Taking into account its size and rate capacity this collection facility will prevent 106 people from urinating/defecating onto/into the ground. As the facility will use urine as a resource to increase the moisture content of the system it will also prevent $4449 \mathrm{~L}$ of urine pollution from entering the environment in our small participant zone. ${ }^{20}$ More

\footnotetext{
${ }^{17}$ This weight is less than a side of beef that typically hangs from a control arm system in a butcher shop, and less then a load of fish that the nets are designed to hold).

${ }^{18}$ Jenkins, Humanure Handbook page.

${ }^{19}$ This may seem improbable looking at the size of the first bag, if you were to visualize it all the way down the line, (it appears visually that only about 200 bags could possibly fit). Because compost has an incredible tendency to shrink when it is properly breaking down, the volume will decrease by about $30 \%$. This happens over time, however and it works out to hold approximately 3 times the capacity it will appear to be able to hold when the bags move closer together.

${ }^{20}$ Fecal deposit per person is between $135-270$ grams (202avg.) Statistics Source: Humanure Handbook, P.35.
} 
importantly it will prevent an average of $7821 \mathrm{~kg}$ of pathogen filled raw excreta from contaminating the ground and surface soil each year.

\subsection{Conclusion}

It is projected that $20 \%$ of the initial cost of this facility will be covered by the municipality after the pilot proves itself feasible. Alternative funding must be reached through local and international sources, not excluding long term, low interest microloans. As an experimental project, our proposal may have multiple applications in several geographic locations, and resultantly, larger bodies may be interested in funding the pilot as a research and development initiative. It may also be possible to receive environmental funding, as part of the Kyoto protocol offered as credit from countries who continue to pollute.

Compared to water flush toilets each household family would be saving about 30,000 liters of water per year, (refer to Appendix C). In a community of 106, this is a yearly water savings of about $3,180,000 \mathrm{~L} .{ }^{21}$ It is more difficult to take into account the greater savings: to the environment, the fishing industry, the savings in health care treatment amongst the population, the increase of productivity resulting from less illness within the community, the benefit of making the land productive, the savings related to purchasing petroleum fertilizers, the potential increase of foreign investment, an increase in tourism due to a safer, greener environment and a healthier spirit within the community. The remaining chapters of this thesis will act to prove these benefits, and demonstrate such a context through empirical data, development theory and through personal testimonials in Appendix A., B. and C.

\footnotetext{
${ }^{21}$ The municipality spends $\$ 243$ USD per person on the infrastructure to pipe raw sewage directly into the ocean . That's $\$ 25,758$ USD for 106 people. Water expenses are not accounted for in the report but the United Nations in a separate report estimates that the average person in peri-urban Lima spends about \$0.0024 USD per liter for water. This costs 106 residents $\$ 7632$ USD per year in water expenses. That is a total cost of $\$ 33,390$ USD for the first year and $\$ 7,632$ each year.
} 

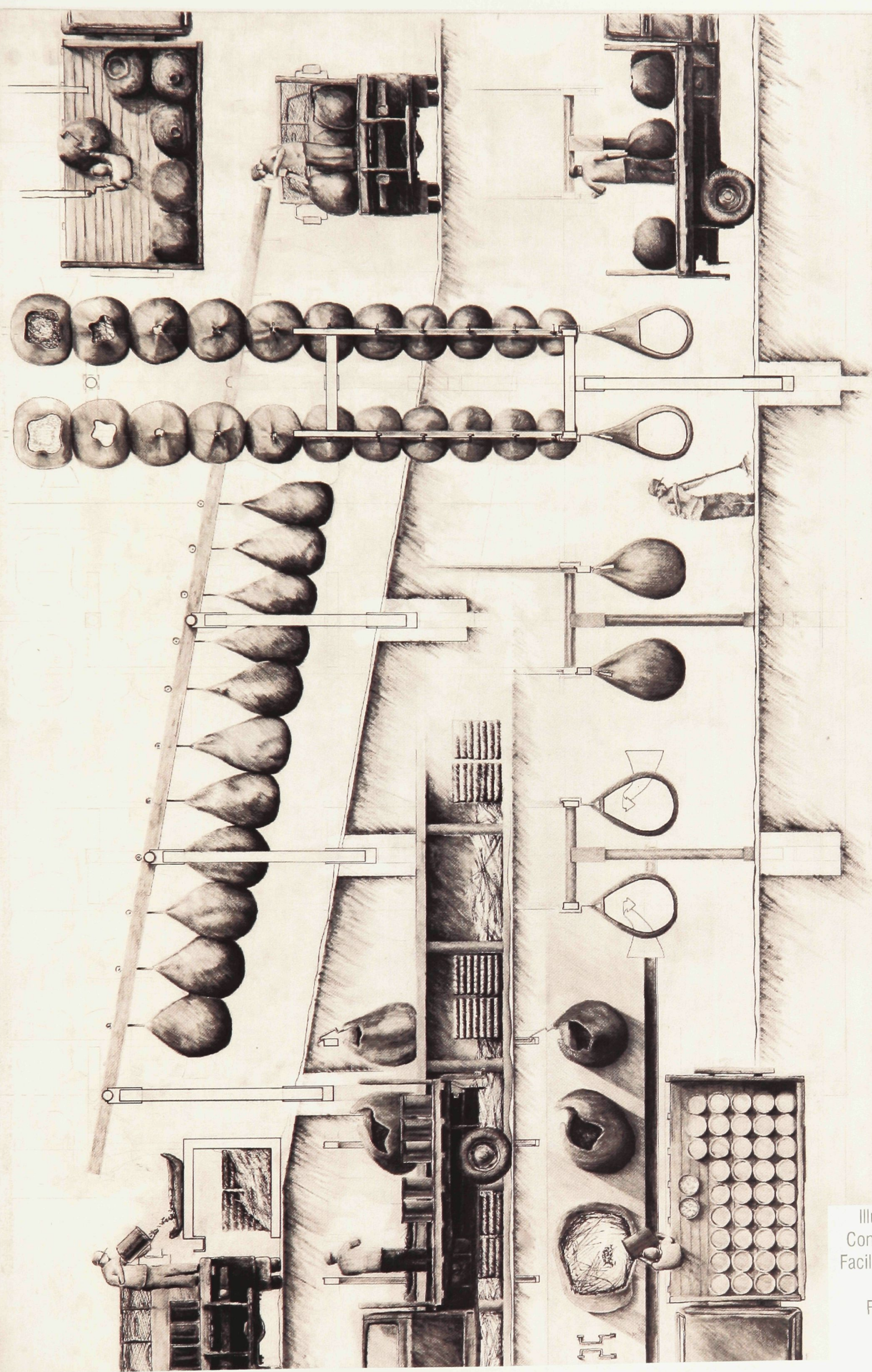


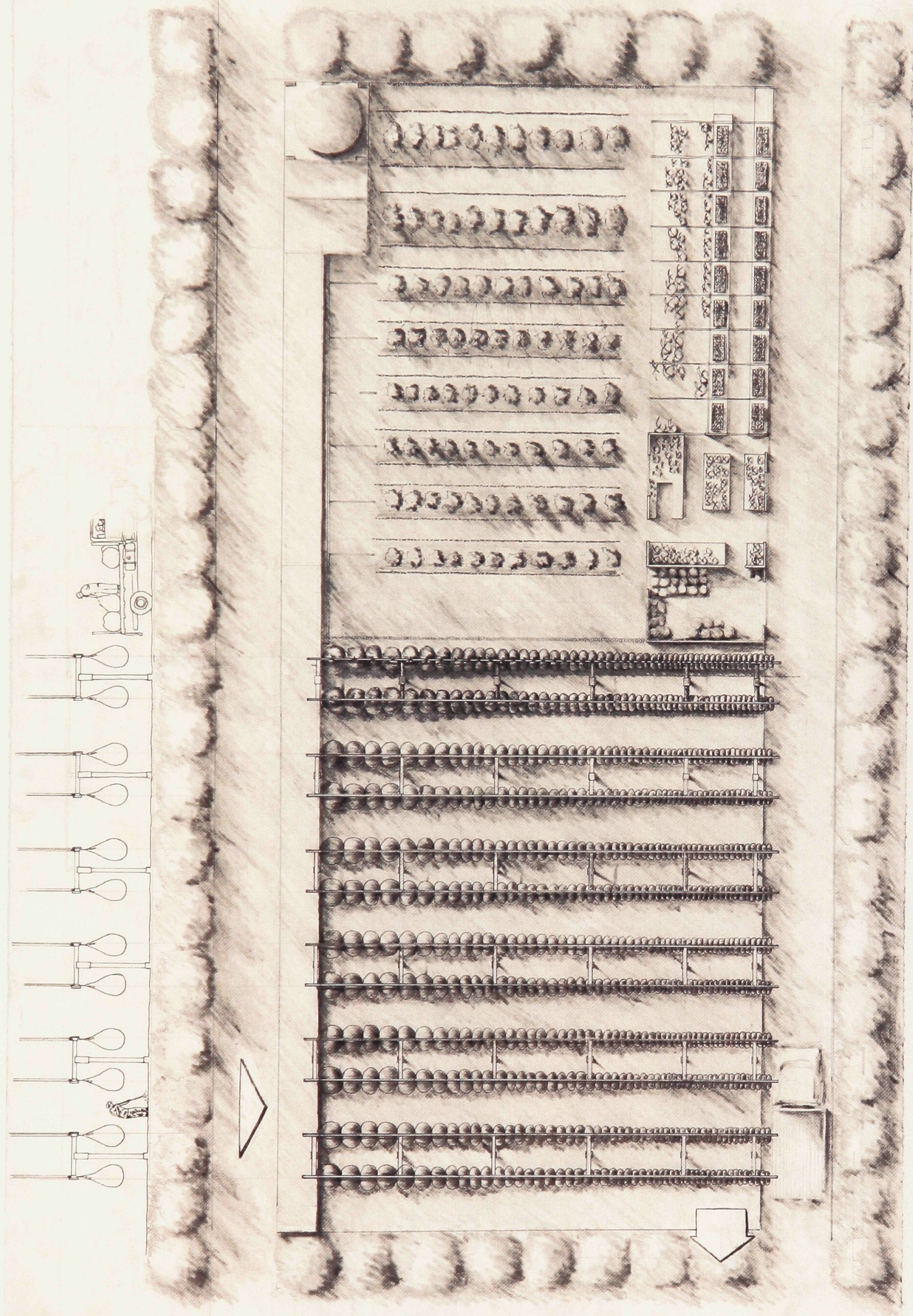

Illustration

Composting

Facility Panel

(Author)

Figure 47 


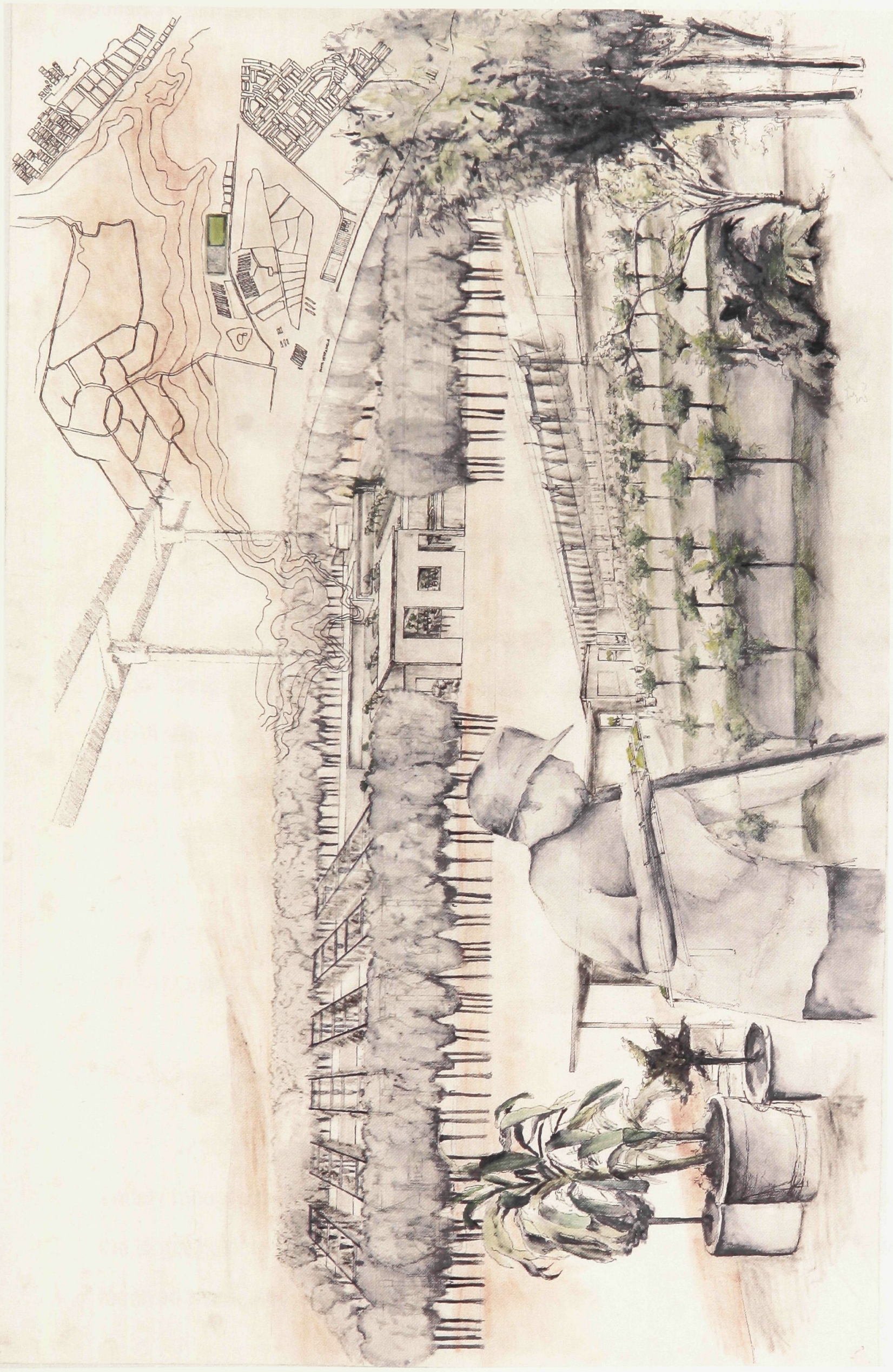

Illustration

Composting

Facility Panel

(Author)

Figure 48 


\section{Appendix A. Invisible Design Context I: Protection of Health and Self-Mobilization}

It is difficult to design for transient and invisible site factors, such as the prevalence of infectious disease, or the forces behind inaction without consulting specialized and expert groups. To validate the implementation of a compost facility, this thesis draws from several publications produced by the UN (United Nations) including the 2000 MDG's (Millennium Development Goals) which were derived from the 1992 publication of Agenda 21 (Agenda for the Twenty First Century), and a CSD (Commission on Sustainable Development) conference titled the 1994 CSD-2. The 2003 Water and Sanitation in the World's Cities report will finally make up the bulk of the chapter.

Publications that lead up to the UN sanitation report identify the context of sanitation ideals as internationally approved targets. The UN sanitation report identifies the transmission pathways and underlying causes of sanitation deficiencies, which make up the invisible design context to which this thesis further responds. The sanitation report will be used to identify the economic benefits of improving sanitation through the analysis of a paper titled Loss in the time of cholera; Peru, 1991. Finally, the private sector sanitation debate and a report on the benefits of community participation conclude the chapter. These publications are relevant both in defining the broad context of Latin/Peruvian development studies, and are critical to the analysis of sanitation in Peruvian slums.

\subsection{Millennium Development Goals}

In 2000, the UN presented to the world eight specific development targets. Widely recognized as the greatest challenges facing our world today and presented at the largest gathering of world leaders in history, the Millennium Development Goals received the signed approval of 191 member states. 
The 8 MDG's include: 1 - Eradicate extreme poverty and hunger, 2 - Achieve universal primary education, 3 - Promote gender equality and empower women, 4 Reduce child mortality, 5 - Improve maternal health, 6 - Combat HIV/AIDS, malaria, and other diseases, 7 - Ensure environmental sustainability, and 8 - Develop a global partnership for development.

Each goal has a further sub-series of more specific targets. Goal 7 (based on chapter seven of agenda 21), Ensure Environmental Sustainability was further defined into three targets that clarified Agenda 21's original structure:

- Integrate the principles of sustainable development into country policies and programs; reverse the loss of environmental resources.

- To halve, by 2015, the proportion of people without sustainable access to safe drinking water and basic sanitation.

- Achieve significant improvement in the lives of at least 100 million slum dwellers, by 2020 .

The first target, and specifically the issue of sustainable construction, produced the greatest impact in Canada, Western Europe and the United States in terms of design research and funding. Ensuring access to basic sanitation and improving the lives of slum dwellers, conversely, has not received significant attention from the developed world. These second and third targets will be the fundamental framework of investigation for this thesis.

Architects who do address these later targets - specifically the third subsection - tend to approach the opportunity for design within slums indirectly. A common approach is to work on low income housing schemes to meet the demands of migrating peoples, with the goal of preventing the overspill that leads to slum creation. Although such an approach is warranted, at some point the actual slums themselves must be 
addressed. From experience, sanitation in these settlements proves to be the greatest design challenge, and this is clarified in the following reports.

Agenda 21 acts as a foundation to the ideological framework of the MDGs, and the CSD-2 (Commission on Sustainable Development Second Session) is a product of the agenda initiative. From the CSD-2 conference lists matters of attention that support foreign involvement and recycling and reuse are called here to attention.

\subsection{Agenda 21 and CSD-2}

The completion Agenda 21-Earth Summit: The UN Programme of Action in December, 1992, at the United Nations Conference on Environment and Development (UNCED), marked a turning point in global awareness of sanitation ideals and acted as a template for the worlds greatest challenges which were simplified as the 2000 MDG's. Agenda 21 is discussed here because it more specifically addresses targets for sanitation that demonstrate the long history of international agreement on sanitation principals.

Chapter 21 identifies four sanitation ideals regarding solid waste management and sewage related issues that this thesis generally responds to. They include:

(a) Waste minimization; (b) Promotion of waste recycling and reuse; (c) Promoting environmentally sound waste disposal; and (d) Extending waste disposal service coverage. ${ }^{22}$

Following Agenda 21, the commission on sustainable development more specifically addressed sustainable goals monitoring Agenda 21's progress, and added to and clarified targets in order to assist governments with structuring their national policies. Held at the UN headquarters in 1994, the Second Session of the CSD called

22 United Nations, "Agenda for the Twenty First Century" quoted by the Secretary General, 31Jan 2007, www.un.org/documents/ecosoc/cn17/1994/background/ecn171994-bpch21.htm 
attention to the needs of impoverished human settlements, listed under "Matters calling for action by the economic and social council or brought to its attention," and of these matters several are listed alphabetically ${ }^{23}$ Of these, several items of matters $C, D$, and $E$, lay out a framework for designing to meet Agenda 21 objectives regarding human fecal waste.

For example, items 82 and 83 of matter $C$ establish the general need for technology transfer from outside sources ${ }^{24}$ Item 90 of matter $\mathrm{C}$ reports on the need for universities to take part in action.

82. The Commission reaffirms the crucial importance of strengthening the capacities, in particular of developing countries, to assess, develop, apply and manage environmentally sound technologies tailored to the countries' own needs and priorities and stresses the need to focus efforts on capacity-building and institutional development. ${ }^{25}$

83. The Commission recognizes that the expertise required for technology transfer and cooperation is being developed in many countries. Therefore, Governments and enterprises are urged to look throughout the world for the best ideas and creative solutions to meet their needs... ${ }^{26}$

90.(k) Calls upon Governments, particularly those of developed countries, to promote the contribution of their universities and research centers in the transfer of available environmentally sound technologies and expertise, including through such mechanisms as university grants and workshops, and encourages international organizations to support those efforts. ${ }^{27}$

\section{Regarding Matter D, the Review of the Sectoral Cluster of Human Settlements,} items: $117,118,121,122,126,127,129,130,132,133,138$ and 139 have laid out an ideological template of principals, upon which this proposal is based. Item 129 most clearly supports the core principals of the proposal and each of the other items can be found on the CSD-2 Website @ www.un.org.28

\footnotetext{
23 A) Cross-sectoral components of Agenda 21 and the critical elements of sustainability. B) Financial resources and mechanisms. C) Education, science, transfer of environmentally sound technologies, cooperation and capacity building D) Review of sectoral cluster: health, human settlements and freshwater E. Review of sectoral cluster: toxic chemicals and hazardous wastes F. Other matters G. Provisional agenda for the third session of the Commission CSD2. E/1994/33 E/CN.17/1994/20 (New York: U.N. Publications, 1994) P.2.

24 CSD2. E/1994/33 E/CN.17/1994/20 (New York: U.N. Publications, 1994) P.18.

25 CSD2. E/1994/33 E/CN.17/1994/20 (New York: U.N. Publications, 1994) P.22.

26 CSD2. E/1994/33 E/CN.17/1994/20 (New York: U.N. Publications, 1994) P.22.

27 CSD2. E/1994/33 E/CN.17/1994/20 (New York: U.N. Publications, 1994) P.22.

28 CSD2. E/1994/33 E/CN.17/1994/20 (New York: U.N. Publications, 1994) P.27-33.
} 
129. The Commission notes, in regard to solid-waste management, that the promotion of waste recycling and reuse provides a unique opportunity in waste management; it helps to solve the problem of environmental degradation and has the potential to alleviate urban poverty and generate income among the urban poor. However, that requires supply-side policies aimed at promoting and supporting resource recovery, and demand-side policies aimed at stimulating markets for recovered materials and products.

\section{Regarding matter E. the Review of Sectoral Cluster Referring to Hazardous Wastes:}

177. The Commission notes with concern that many countries face severe and urgent health and environmental problems due to the production and mismanagement of hazardous wastes by industrial and other economic activities, as a result of: (a) The lack of environmentally sound waste treatment facilities and appropriate technologies;

Each of these concerns regarding 'matters brought to attention' were the byproduct of 35 separate presentations made at the conference by selected papers pooled from the 177 member nations participating. ${ }^{29}$ They are an incredible guide toward a global vision and thus should influence the method of approach to be employed in Peru. ${ }^{30}$

To develop an understanding of how some of these ideals relate to sanitation challenges in Lima, case studies presented in The Water and Sanitation in the World's Cities Report, present rigorously extracted empirical data that further define the social and disease challenges that cannot be understood in any individual site visit. Published by the UN in 2003, the sanitation report is the clearest summary to date of a UN analysis on sanitation in slums. This document is organized by topic and indexed to assist the research of specific case studies in varying cities, and is used to identify our specific site conditions.

29 Not all nations participated in CSD-2 1994, for a complete list of the 177 participants visit www.un.org 30 Continuing to highlight 'the matters brought to attention' and follow them up with UN policy change resulting from CSD-3, the 19th Special Session, CSD-12, and CSD-13,30 is a task the reader may want to continue in greater depth. This would be an exhaustive analysis however, toward just showing a vision as the suggested guidelines have only slowly evolved with the submission of additional case studies. 
10.0 Water and Sanitation in the World's Cities

Water and Sanitation in the World's Cities: Local Action for Global Goals gives an overview of global sanitation struggles and connects the international challenges to Lima specifically.

Globally, Anna Kajumulo Tibaijuka, introduces the text by reminding readers that in 2003, although one billion people still do not have to access to safe drinking water, two billion continue to be "denied access to adequate sanitation". ${ }^{31}$ In a more troubling statement, the text later reports that "more than half of the world's urban households lack a sanitary means for disposing human waste". ${ }^{32}$

She stresses that the "millennium goals may be global in character, but they must be implemented locally, where people live and where shelter and services are required." ${ }^{33}$

There are three general conditions identified in the text that contribute to the lack of water and sanitation provision in Latin America. The three conditions are: "insufficient coverage that excludes an important proportion of the population; deficient quality that has a direct impact on quality of life; [and] serious environmental impacts derived from the fact that the growth of needs has increased persistently quicker than the assigned financial resources and the capacity for provision and planning and regulation"34.

In Peru, as recorded by the World Health Organization in $2000,13 \%$ of urban households had no water service, $11 \%$ had no household connection, but did have access to water, and finally $76 \%$ were reported to have a household connection. ${ }^{35}$ Water resources are intrinsically tied to sanitation because most sanitation provision is water-

31 UN-Habitat Water and Sanitation Report, P.1. (Anna Kajumulo Tibaijuka, Under-Secretary-General, Executive Director of UN-Habitat)

32 UN-Habitat Water and Sanitation Report UN-HABITAT Water and Sanitation in the Worlds Cities, p 79

33 UN-Habitat Water and Sanitation Report, P.1, (Anna Kajumulo Tibaijuka).

34 UN-Habitat Water and Sanitation Report, P.34.

35 UN-Habitat Water and Sanitation Report, P.32. (Phho and Who 2001) 
based. Many of these household connections in Peru function sporadically at best, and commonly the water recovered is not potable. In order for this water to be consumed, it must be boiled for at least three minutes to kill off harmful bacteria. Thus, a proportional requirement for fuel to heat the water is tied to the need for water service.

For sanitation, $67 \%$ of Peru was connected to some form of sewer, $23 \%$ had no sewage connection but had some form of in situ sanitation and $10 \%$ of the entire population of Peru was reported to be completely un-served. ${ }^{36}$

In Lima, the water and sanitation status was reportedly worse than national averages. Metropolitan Lima in 2000 had only $74.3 \%$ of its population connected to the water supply network. This excluded about 549,000 people from an economically priced water service.

Of those who do have water supply in Lima, it was reported that residents only receive an average of 13 hours of regular access per day. ${ }^{37}$ This is no surprise to those who have spent significant time in the capital, as it is quite memorable to experience a half shower, or half flush when the water runs out. Compared to an average of cities polled by the Pan American Health Organization, most cities in Latin America receive 2224 hours of access, on average, per day. To add to the water scare specific to Lima, it was predicted in 1996 that "The aquifer that provides a third of Lima's water is due to run out by 2005 because of over-abstraction". ${ }^{38}$ Water struggle continues to be a major challenge to Lima; the need for water has increased exponentially while the city itself has expanded into dryer and more distant zones.

In informal settlements those inhabitants who receive no water supply can be seen purchasing water from tankers and retail outlets. Unfortunately the poor are often 
forced to pay a higher price per liter than those who have household service after the infrastructure costs. ${ }^{39}$

In addition to the lack of water needed to run a water based sanitation service it was reported in 2000 by the WHO that 1,191,000 people [in Lima] had no access to the city sewer system. ${ }^{40}$ The majority of these people live in informal communities. These communities which are lacking sanitation services face few options. Public restrooms are a poor option because of inconvenient locations, high expense or dubious quality. Unsanitary practices such as hillside defecation or urinating/defecating in public is obviously undesirable (it is not an uncommon option, however) and finally the use of self constructed, uncontained pit latrines are what the majority use. Costs associated with all of these options translate into community health risks, public embarrassment, and an inevitable class separation that divides the contaminated living grounds from cleaner areas.

To understand the breadth of sanitation challenges, it is crucial to understand the health and safety aspect of such practices. There is a range of specific illnesses that result from poor sanitation and polluted drinking water. Pit latrines leach directly into water sources and are the main source of ground water contamination. Internationally recognized diseases associated include: Cholera, typhoid, leptospirosis, scabies, and guinea-worm infection (it was reported that if eliminated internationally these could decrease sanitation related morbidity by $80-100 \%)$. Additional diseases reported include trachoma, conjunctivitis, yaws, and schistosomiasis, (if these are eliminated internationally they can decrease sanitation morbidity by 60-70\%). Finally, tularaemia, paratyphoid, bacillary dysentery, amoebic dysentery, gastro-enteritis, lice-borne diseases, diarrhoeal diseases, ascariasis, and skin infections are reported to result from

\footnotetext{
${ }^{39}$ The average cost of a water truck liter of water in Lima is 0.0024 (US\$).
}

${ }^{40}$ UN-Habitat Water and Sanitation Report, P.36-37. 
polluted drinking water and poor sanitation, (if these were eliminated they could decrease sanitation morbidity internationally by $40-50 \%$. $)^{41}$

To compare our site challenges with similar issues internationally, charting both the percentage of lives lost, and DALY's (disability-adjusted life years) allow epidemiologists to further asses the damage incurred internationally from these illnesses. It is explained that world-wide risk factors for water, sanitation and hygiene in terms of diarrhea and selected parasitic diseases accounted for 5.3 per cent of all deaths and 6.8 per cent of all DALY's. ${ }^{42}$ The global burden of disease from water, sanitation and hygiene report explains that "this exceeds the disease burden of many major diseases including malaria and tuberculosis." ${ }^{43}$ For comparison, in Latin America and the Caribbean a report identifies that diarrhea and selected parasitic diseases account for $4.8 \%$ of all DALY'S. The percentage is only lower than international averages because Africa's loss due to sanitation accounts for $21.7 \%$ of all DALYs. ${ }^{44}$ It is important to acknowledge the global impact to demonstrate the potential value of this compost facility proposal for Pachaqutec.

\subsection{Design Context lists: Transmission pathways, underlying and direct causes}

Acknowledging the opportunity to change some of these statistics, a new proposal offering provision to counter such statistics must address the root causes of the lack of provision, moving beyond such general objectives as being economical, practical or socially acceptable. It has been identified that lowering the percentage of loss due to the prevalence of these illnesses requires approaching the specific 'transmission pathways' leading to infection.

\footnotetext{
${ }^{41}$ UN-Habitat Water and Sanitation Report, P.62. (Table 2.2)

${ }^{42}$ UN-Habitat Water and Sanitation Report, P.61.

${ }^{43}$ UN-Habitat Water and Sanitation Report, P.61. (Box 2.1)

${ }^{44}$ UN-Habitat Water and Sanitation Report, P.62. (Figure 2.1)
} 
Regarding sanitation, some international transmission pathways include:

- Transmission through ingestion of water such as drinking water and to some extent bathing (includes diseases from fecal-oral pathogens and diseases from toxic chemicals)

- Transmission caused by lack of water linked to inadequate personal hygiene (including trachoma and scabies)

- Transmission caused by poor personal, domestic or agricultural hygiene (includes personto-person transmission of fecal-oral pathogens, food-borne transmission of fecal-oral pathogens as a result of poor hygiene, or use of contaminated water for irrigation or cleaning)

- Transmission through contact with water (through bathing or wading) containing organisms such as schistosoma

- To a certain extent, transmission through vectors proliferating in water reservoirs or other stagnant waters or certain agricultural practices

- Transmission through contaminated aerosols from poorly managed water resources (eg legionellosis)

These pathways present the challenge to which a compost facility must be geared to respond. As they are broad in scope however, it is important to narrow them with case studies more relevant to our site.

Identified 'fecal-oral' pathogens cannot contaminate people if feces are prevented from contacting both the subsoil that leads to contaminated water, and the surface soils associated with playing, working and areas for growing food. The sanitation report urges that "the only safe sanitation methods are those that eliminate all possibility for contact with excreta" 45

It seems that public defecation and the use of uncontained pit latrines are the main contributors to contact with excreta in informal parts of Lima. During time spent conducting research in these communities it was frequently requested of me to advise residents of possible sanitation alternatives. Their self-built pit latrines were so poor that

\footnotetext{
${ }^{45}$ UN-Habitat Water and Sanitation Report, P.79.
} 
it became clear they were the underlying cause of outdoor defecation. The related problems are blatantly self-evident. The pits overfill, they are not easy or bearable to clean, their construction is poor, and they can be dangerous to use. A special report entitled "Managing children's feces in Lima" gives more insight into the underlying pathways and resultant complexities of such systems. The report uses children's activities to narrow the design context that is important for creating an appropriate alternative. In addition, the site conditions are almost identical to Pachaqutec.

Research in Lima, Peru looked at the various ways that small children's feces were dealt with in a densely populated shanty town, where water for the most part was purchased from tankers and where only some house-holds had latrines. Almost all children under one year were kept in diapers, which were washed daily because of limited stocks and rinsed at least three times to avoid diaper rash. The cost in terms of both water and time were a strong motivation for getting children out of diapers as soon as possible. Potties were considered the most hygienic solution at this point, and in some cases training began as early as six months. But because mothers were busy, potty training was generally inconsistent, and it was common for children to defecate in their clothes-a transgression most commonly greeted with shouting or slaps. As in the case of diapers, feces from potties were emptied into latrines in those households that had them, but otherwise onto a rubbish dump or a nearby hillside commonly used for defecation. Most mothers felt that potties should be emptied and washed as soon as possible-but acknowledged that they were generally too busy to do this. Because of the time commitment involved in training children and keeping potties clean, only 20 per cent of small children actually used potties, and in most cases mothers simply allowed them to defecate directly onto the ground-although defecation away from the home area, and especially near a neighbour's home was considered unacceptable. Feces were sometimes left on the ground, and sometimes scooped up and disposed of in latrine or dump. Although children were generally cleaned up with paper, 30 per cent were found to retain some fecal matter on their clothes or bodies. Latrines were considered an unrealistic solution for children under the age of four because of flies and bad odors, but also because of the large openings and the need for small children to be accompanied. Although some learned to manage latrines independently over time, most children over three used the hill side, looking for a spot that was free of feces and trash. ${ }^{46}$

The report is extremely useful for identifying social pathways in the context of communities like Pachaqutec. The importance of identifying the circumstance of children is paramount. The report urges that "sanitation-related illnesses affect young children most, in part because of their lower immunity to pathogens, but also because of their behaviour. Small children have a drive to play, and explore, they are closer in contact with the ground and they have less appreciation of hygiene." 47

\footnotetext{
${ }^{46}$ UN-Habitat Water and Sanitation Report, P.80. (Box 2.3 Managing children's feces in Lima Box 2.1)

${ }^{47}$ UN-Habitat Water and Sanitation Report, P.79.
} 
It has been suggested that public facilities would be a better solution but studies in the report show otherwise. It has been stated that "the higher incidence of intestinal parasites in urban children... has been repeatedly associated with shared toilets or a lack of connection to city sewer systems" ${ }^{48}$. This would suggest that house-specific solutions have a better safety record than the use of public facilities. Both this proposal and water based sewage systems promote provision within the home. A personal testimony from India entitled "The difficulties of getting to public toilets" explains in more detail the necessity for at-home service comparable to services in Peru.

We have no toilets: we use two toilets in Ambedkar Nagar. It is outside our settlement, five minutes away. People from two settlements use the four toilets - two for men and two for women. We have to stand in a queue for half an hour. That is why the men all go under the bridge and only the women use the toilets. Children also go out in the open. ${ }^{49}$

Testimonies like this are common throughout these reports and serve to remind us of the opportunity for improvement and the necessity to expand upon our efforts with the hindsight we now have. Sanitation strategies are so important in certain circumstances that it has even been reported "improvements in sanitation had more of an impact than did improvements in water provision; in fact the benefits from improved water only occurred when sanitation was also improved" 50

Continuing to narrow the pathways of infection it is important to identify the specific causes reported. Thus we refer to the UNISEF 2002 report entitled "Examples of the range of proximate, contributory and underlying causes for the prevalence of diarrhoel diseases in a squatter settlement".

\section{UNDERLYING CAUSES}

Low priority given by international agencies to providing funding for urban water and sanitation

Limited funding available for investment in water and sanitation nationally because of debt burdens and poor economic performance

\footnotetext{
${ }^{48}$ UN-Habitat Water and Sanitation Report, P.79.

${ }^{49}$ UN-Habitat Water and Sanitation Report, P.85.

${ }^{50}$ UN-Habitat Water and Sanitation Report, P.79.
} 


\section{CONTRIBUTORY CAUSES}

Weak and ineffective local government, lacking funds to invest in water and sanitation and overwhelmed by rapid population growth

Low transfers of funds to local government; centralized government structure unwilling to support development of competent, effective local governments in urban areas

Illegal status of the settlement with the local government not wanting to allow piped water supply and sewers to illegal squatters

Shallow wells the only readily available source of water for the settlement, and are contaminated PROXIMATE CAUSES

Use of drinking water and cleaning foods contaminated with human excreta ${ }^{51}$

Ground soil contamination is the technical design problem. Pathogens leach into the ground water because pit latrines do not allow the excreta to decompose. Over time these pathogens creep into water sources, onto backyard playgrounds and into the preparation of food. Public avoidance is the architectural problem beyond the technical failures of the system and must be dealt with by designing a more approachable unit.

A similar report by UNISEF entitled: "The Range of Causes Contributing to Inadequate Water and Sanitation in Urban Areas", gives a list of causes that contribute to diarrhoel diseases. This list of causes relate more specifically to towards the proposed solution:

UNDERLYING CAUSES ACTING AT THE REGIONAL, NATIONAL AND INTERNATIONAL LEVEL

National governments not providing support (political choice, debt burden, etc) and International agencies not providing support

CONTRIBUTING CAUSES ACTING AT THE CITY OR MUNICIPAL LEVEL

Water shortages, Rapid population growth overwhelming agencies or utilities responsible for provision, Ineffective local institutions (including city and municipal government), Refusal of water and sanitation agencies to work in informal settlements

${ }^{51}$ UN-Habitat Water and Sanitation Report, P.102. 
PROXIMATE CAUSES ACTING AT HOUSEHOLD AND NEIGHBORHOOD LEVEL

Limited household capacity to pay, Illegal status of many settlements, Constraints on 'do it yourself' provision for households or communities (including absence of water locally) ${ }^{52}$

Causes vary between cities. Each of those identified here are not guarantees to a lack of sanitation provision. For example, some cities experience rapid population growth and still manage to meet provision adequately as only some conditions presented here apply to them. Similarly, some have water shortages while still managing to find ways of providing water to residents. Pachaqutec experiences every one of those identified causes.

In addition to this urban range, Pachaqutec experiences the most causes identified locally for deficient sanitation amongst informal settlements. In the third and final list the UN identifies additional causes:

PRIMARY CAUSE OF DEFICIENT SANITATION IN PERI-URBAN AREAS

No formal property rights

\section{SECONDARY CAUSES}

The distance between informal settlements and existing sewer networks; the irregular urban layout that characterizes many of the settlements; the cost of construction in zones below the water table; and the utilities lack of confidence that costs would be recovered and regular payments for services made by inhabitants. ${ }^{53}$

The cost of construction below the water table is not a concern in Pachequtec as the site is high up from the ocean. Each of the other complications of informality do, however, present a problem on our site.

Many sections of Pachequtec still await legal land tenure. The photograph taken at night in October 2005 (figure 53) is a visual cue to the divide between formality and informality. Typically the zones using florescent light 'borrow' electricity. The sections using low sodium lights (orange lights) have usually received land tenure. In this

\footnotetext{
${ }^{52}$ UN-Habitat Water and Sanitation Report, P.103. (Table 3.1)

${ }^{53}$ UN-Habitat Water and Sanitation Report, P.104.
} 
particular case, however, the low sodium lights represent a failed development project that was planned by the city to lure residents from the core. Rural migrants quickly and illegally re-settled it.

Regarding the distance from sewer networks, there were none in evidence of being reasonably close. Residents are using pit latrines that can be seen in almost every back yard and are easily identifiable.

Regarding the complexity of the grid, the territory is patchy with both imposed order and areas of more 'evolved' space. These irregular spaces are much more organic and spatially interesting, but do not support (typical) sanitation provision. This sanitation proposal would require a clear path for its main collection route but constitutes a more accommodating system for complex spaces. The collection process identified can occur using a variety of methods (motorized rickshaw or 'moto-taxi', people powered rickshaw, hand carried etc) and brought to a major street for small truck transport. The spaces that have an imposed order however, will be very accommodating to both systems.

Regarding finances, it is possible for residents to pay for the services provided by the municipality through taxes. However, this can present a difficult circumstance as many residents already pay without receiving adequate provision. This proposal recognizes the potential for the system itself to provide a return. Financially, there is unique opportunity here to privatize the service as a 'community-run' business. This can be run formally, in partnership with the municipality, as well as informally due to the low infrastructural costs and the simplicity of the technology. 


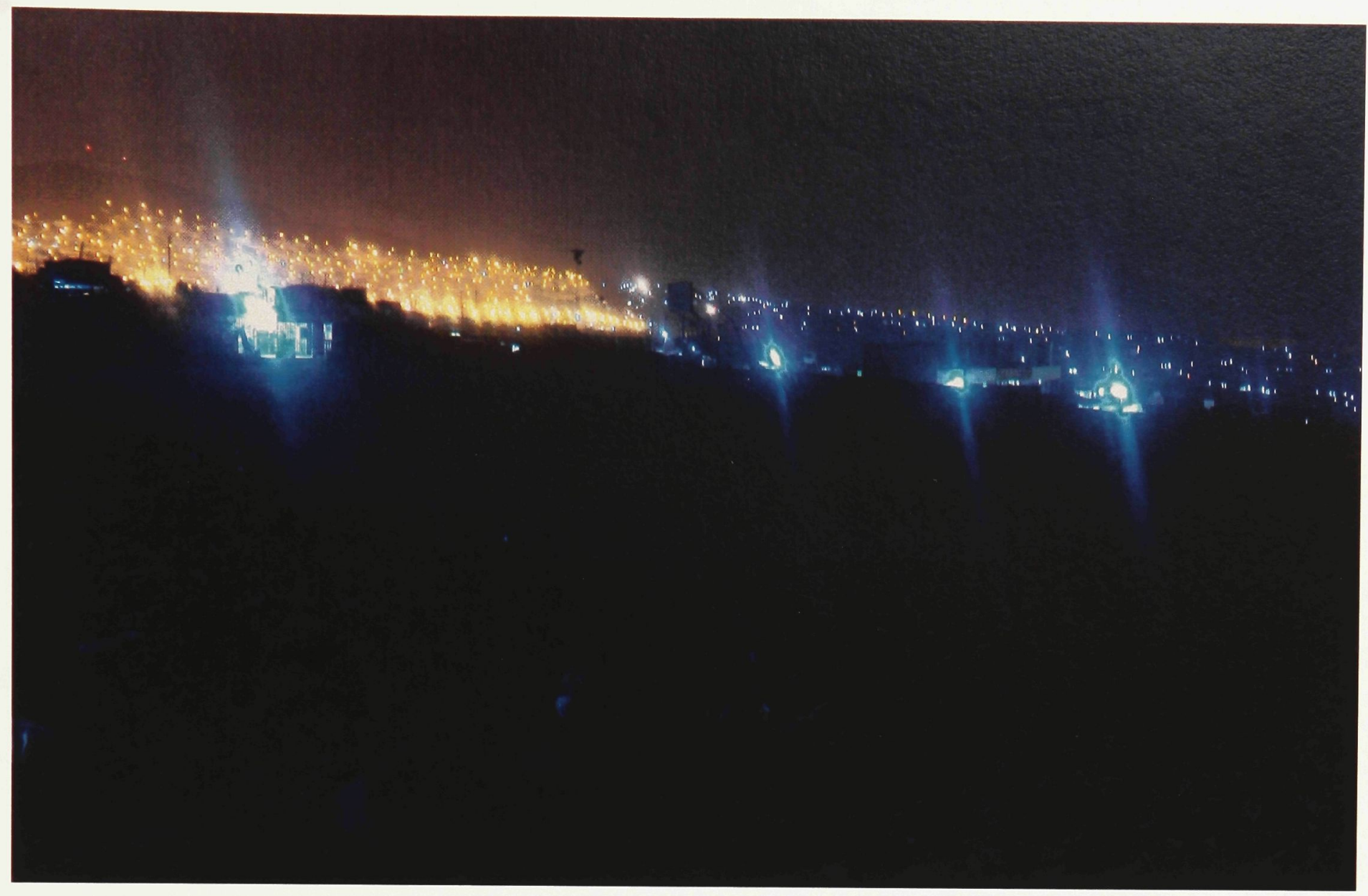

Informal divide Pachecutec at night (Author) ${ }^{54}$

Figure 49

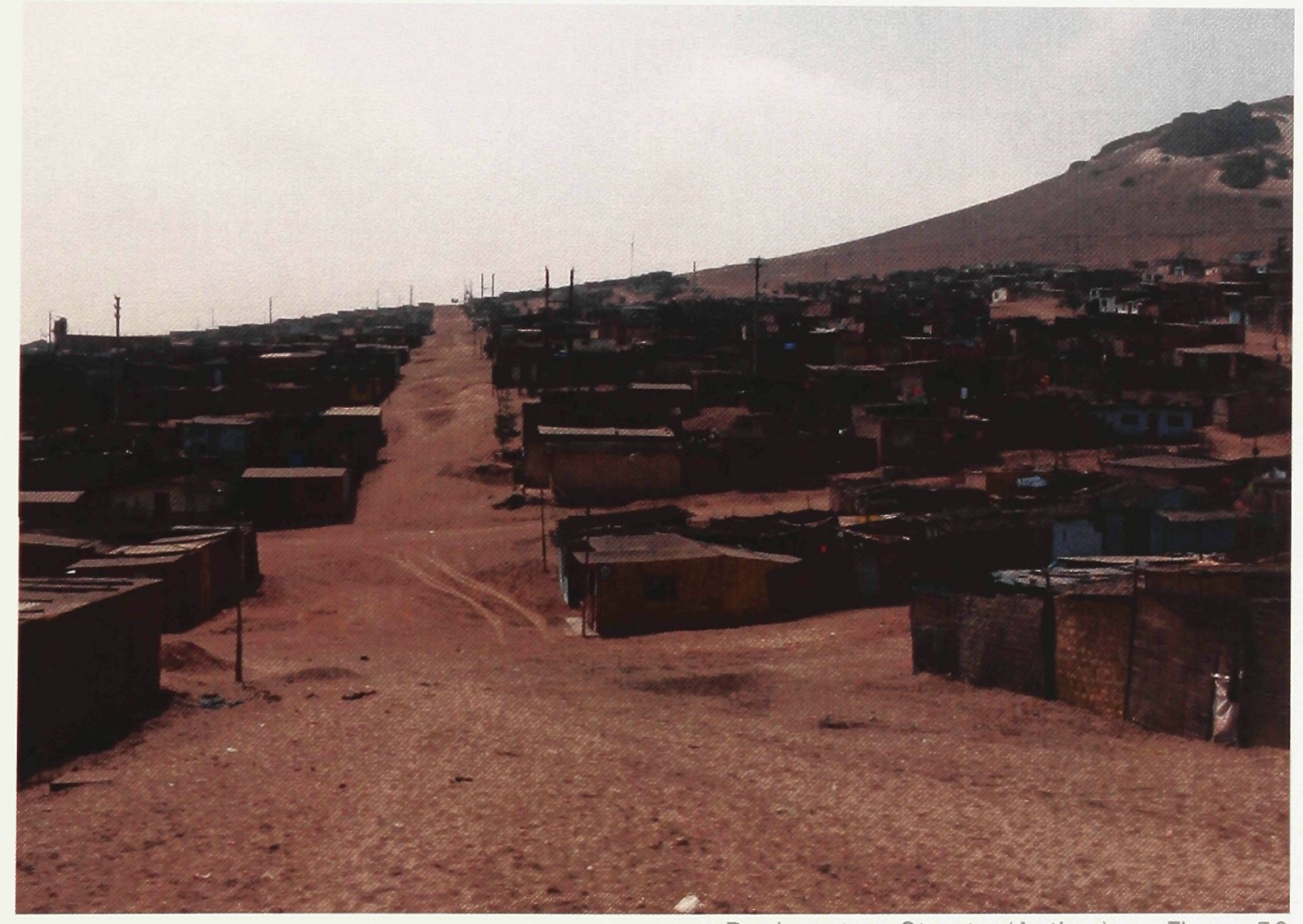

Pachacutec Street (Author) Figure 50

${ }^{54}$ Observing these communities at night is an easy way to distinguish the legal zones from the zones still awaiting legal status. The zones that are well lit, have received electricity as a formal service, the often florescent zones, which use electricity more efficiently, often 'tap into the formal grid' 


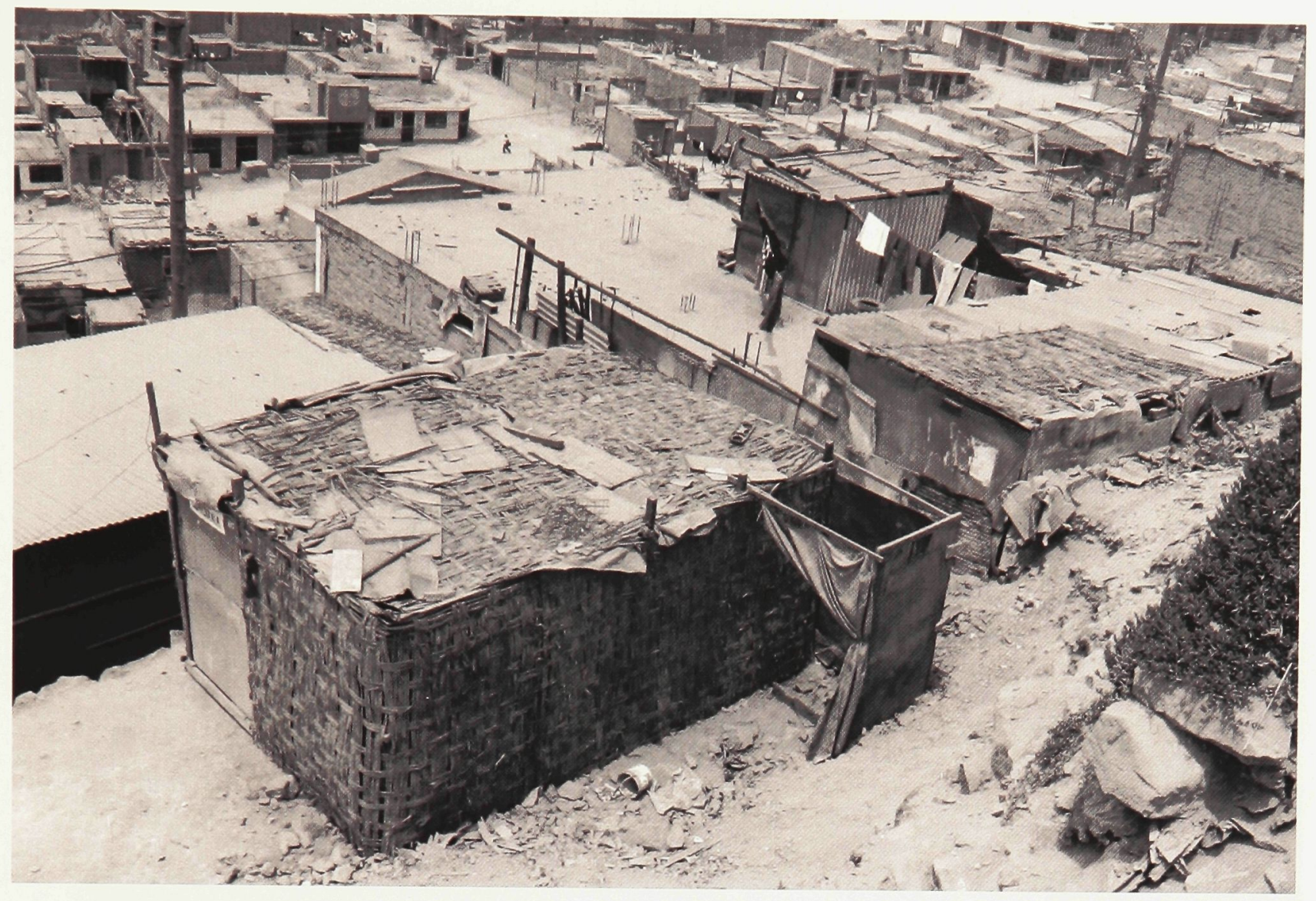

Bathroom addition (Author) Figure 51

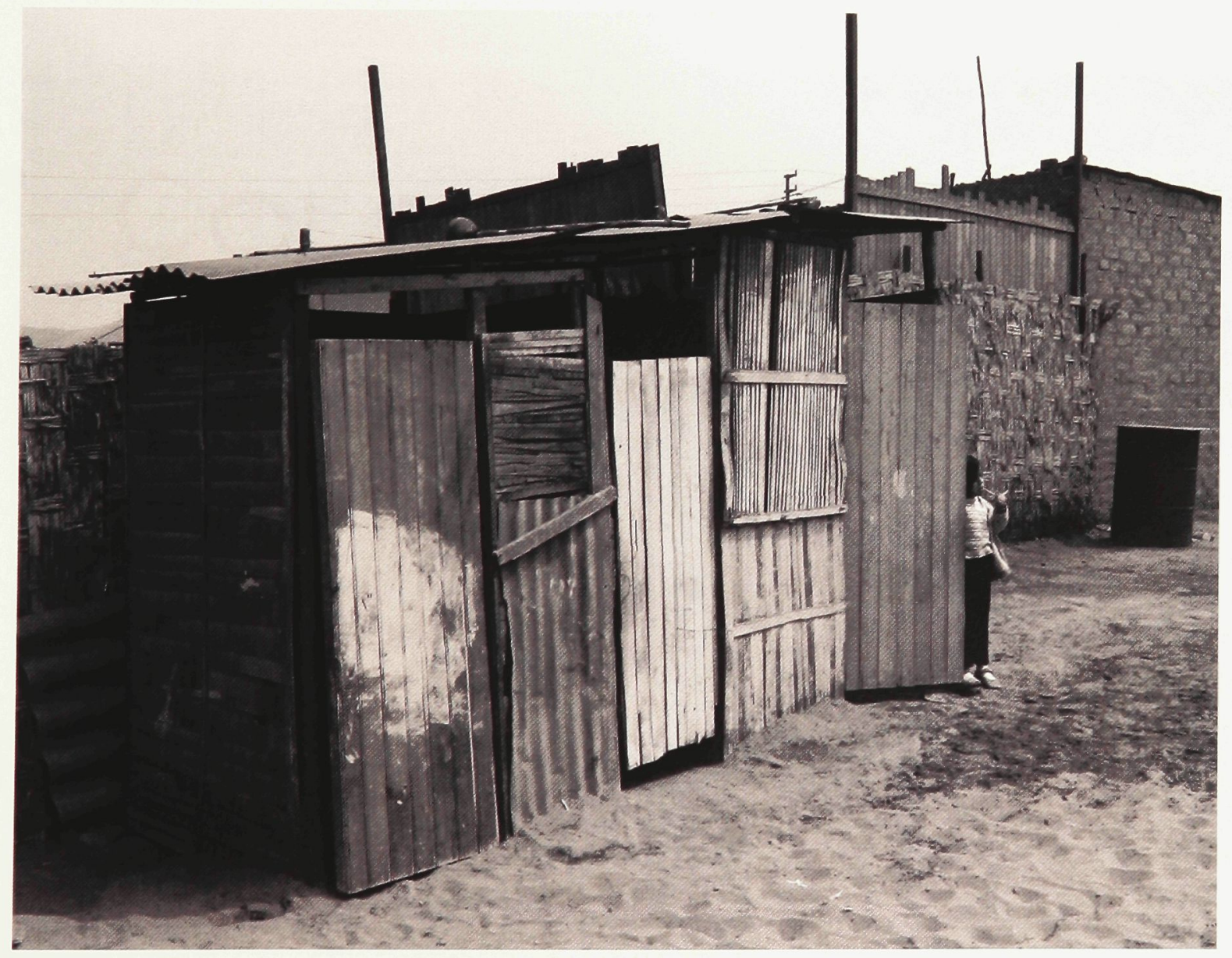

Boys and girls pit latrines (Author) Figure 52 


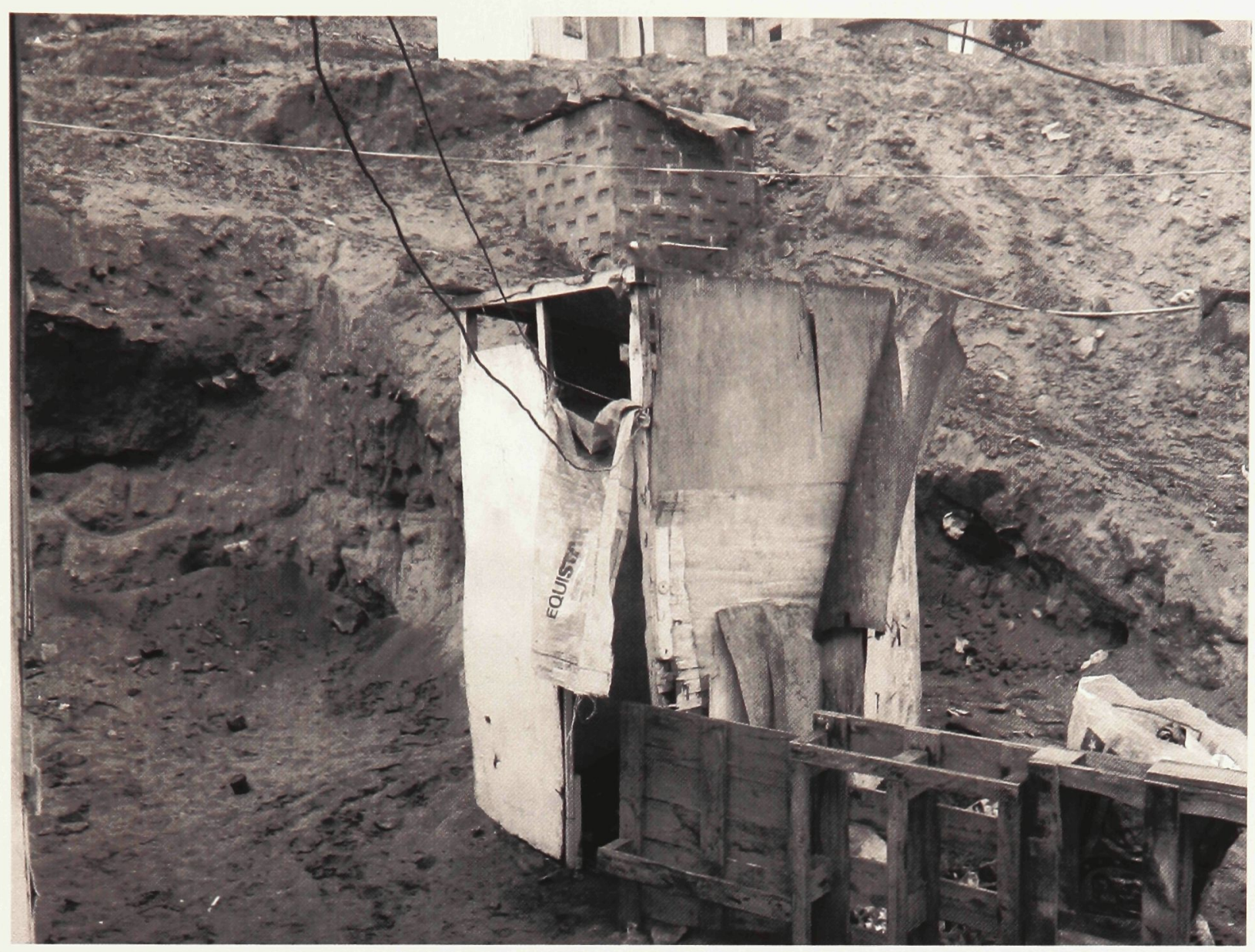

Pit latrine (Author)

Figure 53

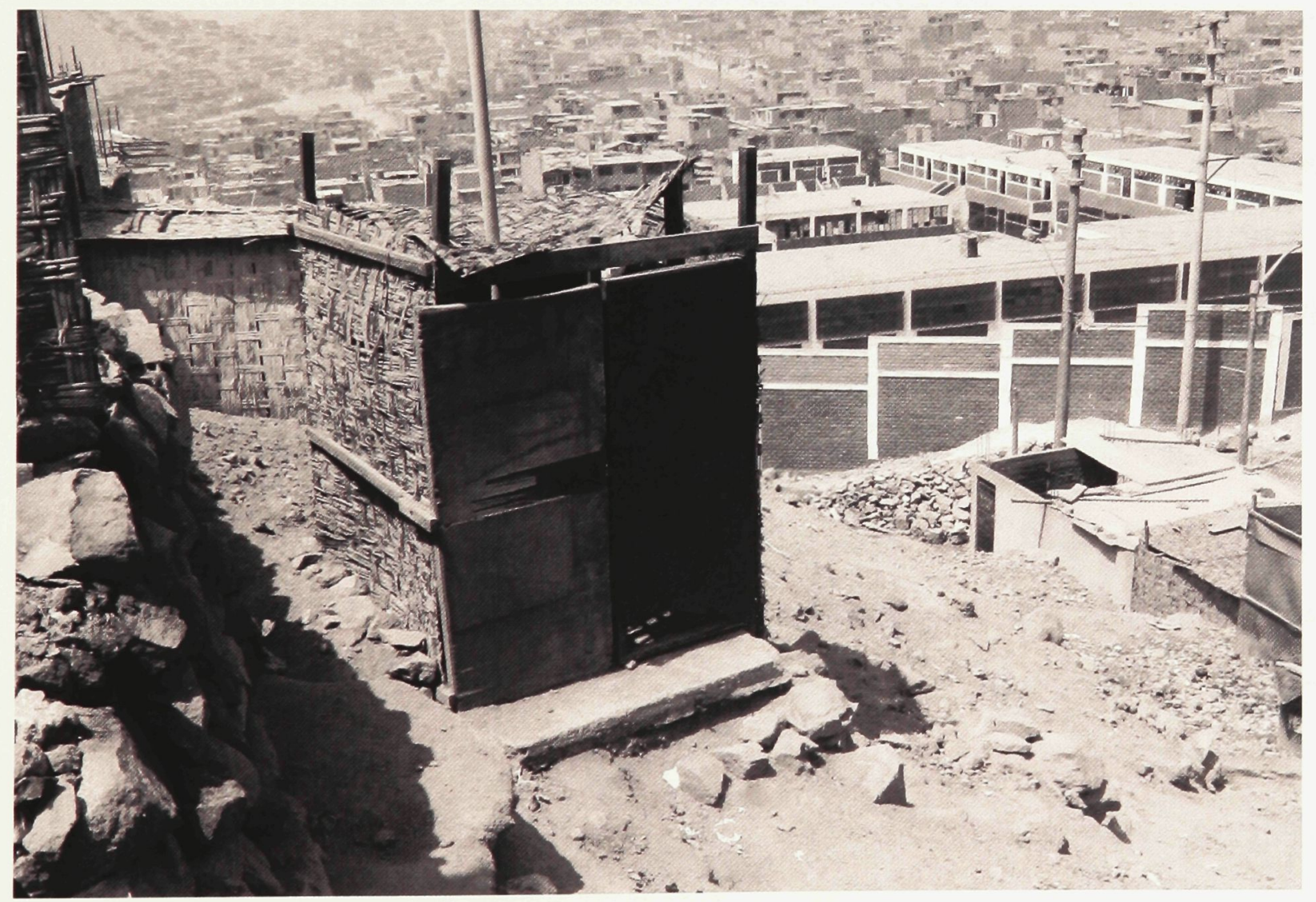

Pit latrine (Author) Fiqure 54 
12.0 Economy Report: Loss in the time of cholera; Peru, 1991

This brings us to the economic benefits of providing sanitation in Pachacutec. Clearly adequate water and sanitation provision acts to attract business and tourism, while the lack of services deters investment. Communities where adequate service is introduced typically experience a surge of new business creating more jobs and tax funding. A resultant surge in funding can be used toward increasing water provision and other investments into the community. This in turn may attract more business. The reciprocal benefit from improved service constitutes one of the more obvious economic benefits.

Economic benefits which are less obvious include the productivity increases resulting from a healthier community. In a special report by Sandy Cairncros, entitled "Loss in the time of cholera; Peru, 1991", demonstrates that after the loss of time in exports, imports, tourism, fisheries, street food vendors, Cholera patient care, absence from work due to illness, absence from work due to death, future absence from work due to death, and taking into account the benefits gained from the pharmaceutical industry and international donations: a total net loss of approximately US $\$ 232$ million was incurred in Peru. The total cost of providing stand-post water supplies for the 5.9 million who constitute Peru's un-served population; at a mean cost of US\$41 per head, totaled at US $\$ 242$ million. ${ }^{55}$ Continued lack of provision is an economically draining factor for our site. Treating the symptoms in this respect is an inadequate solution.

Many efforts to improve sanitation internationally are guilty of not boosting the smaller economies over the long term. The resultant economic and health loss has lead to an embarrassing standstill in poverty reduction. The report takes note: "There has been a tendency among many governments and international agencies to focus on relieving the symptoms- for instance, on ensuring the availability of oral re-hydration

${ }^{55}$ UN-Habitat Water and Sanitation Report, P.92 (Table 2.11). 
salts for the rapid treatment of diarrhoel diseases- rather than addressing the causes...Curative responses, effective as they are, do not prevent re-infection." ${ }^{56}$ The need for both relief work and resolution proposals from local and international groups will continue, but only proposals that offer lasting assistance, such as projects that support prevention of illness, will retain investments". ${ }^{57}$

Land tenure is another informal circumstance of lost economy effecting poverty reduction on our site. For those still awaiting land tenure, the adoption of this proposal should increase their chances of receiving it; sanitation provision will help prove an ability to survive independently, which is the main criteria for receiving title. The borrowing potential of the community is strengthened as a result and housing investments are made in return which boosts local material supplier businesses and creates more jobs in the community.

Concerning startup investment, one of the most relevant aspects of the compost proposal is that household to household no permanent infrastructure is required. This means that the system is easily adaptable in situations of rapid change. The economic investment for the compost facility in Pachacutec is also not permanent, given that the kit-of-parts structure can be disassembled. A relevant social aspect that relates to economy is that reducing ground contamination in the participation zone should not require changes to the social networks, which must grow if they are to be made use of. Social networks are not destroyed because the infrastructure is very light and requires no household renovations. Finally, the beautification of the streets through planting has great potential to make the environment more productive.

\footnotetext{
${ }^{56}$ UN-Habitat Water and Sanitation Report, P.101.

${ }^{57}$ Such as proposals that reduce deep ground and surface soil contamination. UN-Habitat Water and Sanitation Report, P. 101.
} 


\subsection{Private Sector Sanitation Debate}

The sanitation report recognizes both the positive and negative aspects of using private companies for utilities such as sanitation, a strategy our facility must employ as a service run within the capacity of its community. As with all non-government run services, our proposal must fit within national health and environmental regulations, though it is autonomous.

The benefits for this proposal of making the community itself the direct benefactor of company profits is clear. In similar projects the sanitation report urges:

The growing interest in small-scale private providers has also been accompanied by a growing awareness of the need to develop models of community-managed services that place considerable emphasis on self-regulation. In part, this reflects a pragmatic response to the inadequacies of public provision-although it also reflects a much more widespread recognition of the importance of more participatory development models... In such models, users have a voice and choice in aspects such as technology, level of service, service provider, financing arrangements and management systems, in exchange for making contributions in cash or in kind... Such models often seek to engage community members from the beginning of the service delivery process, in order to build community ownership. " ${ }^{8}$

The sanitation report adds, "When allowed to flourish, the small scale entrepreneurs are efficient, competitive and replicable - requiring no subsidies or monopolistic conditions. ${ }^{59}$

Many negative conditions have affected public perception of using private companies, such as the dramatic turnaround that sometimes occurs when the government privatizes an entire industry with insufficient time for responsible transition. The way in which private companies have been invited to participate varies across Peru and there have been many instances of both success and failure related to management ability more than technology. In our case, however, there is no service to replace, but proper management will be the determining factor.

${ }^{58}$ UN-Habitat Water and Sanitation Report, P. 184.

${ }^{59}$ UN-Habitat Water and Sanitation Report, P.184. 
One strong caution to this proposal is that the expense of provision was shown to be the dominant decision maker and if a choice between public and private is possible, the poor will often choose the cheaper solution even if it is providing a poorer service.

14.0 Participation: International Institute for Environment and Development

A 1995 report by the International Institute for Environment and Development identifies several typologies of encouraged community participation in water and sanitation provision. Although all are considerable candidates for the informal communities of Pachaqutec, the seventh level is found most desirable:

\author{
1. passive participation \\ 2. participation through information giving \\ 3. participation through consultation \\ 4. participation through contribution \\ 5. participation through collaboration \\ 6. participation through partnership \\ 7. participation through self-mobilization
}

Minimal levels of participation such as the passive type are discouraged by the UN for provision attempts in low-income areas. ${ }^{60}$ Passive participation involves: "residents participate by being told about water and sanitation initiatives" which are delivered to them by private groups. The seventh level alternatively describes: "residents work together to demand and/or implement water and sanitation improvements.

Participants develop contacts with external acting forces, some of whom may contribute organizational as well as technical skills, but resident groups retain control over how the resources are used." ${ }^{61}$

${ }^{60}$ For low income settlements the UN encourages community participation.

${ }^{61}$ UN-Habitat Water and Sanitation Report, P. 215. 
It was further reported that "even water and sanitation engineers, economists, utilities and others not predisposed to take community-level organization seriously have come to accept the importance of engaging with local groups in deprived areas, and not treating water and sanitation as simply a service to be delivered or a product to be sold"62

The UN unanimously supports participatory systems of sanitation provision, urging the use of even the passive type over no participation. For governments to address the needs of low income groups, it was reported "it must seek the most appropriate way to achieve this, and this will be much influenced by local circumstances including local resource availabilities and local capacities within government and civil society". This argument continues stating that "this may sound like a plea for high-cost public sector piped provision to each home, but low-income households also want reliable, sustainable systems, and high-cost systems that fail to generate the revenues needed to maintain them are not sustainable and are rarely reliable". ${ }^{63}$ 


\section{Appendix B. Invisible Design Context II: Peru’s National Sanitation Policies}

A strong dichotomy tends to exist between what the UN recommends and the position that national policies take. A 2004 report entitled The Evaluation of Peru's National Sanitation Policies serves to highlight the deficiencies in current peri-urban ${ }^{64}$ and rural sanitation projects. This report serves to outline the governmental policies which have prevented sanitation in Pachacutec. The sanitation report identifies changing government responsibilities, funding strategies aimed at meeting provision, technology gaps and finally a plan for expanding provision which extends to 2011. Finally, the sanitation report highlights the roles which service providers, institutional tiers of regulatory bodies and stakeholders play in informal settlements which demonstrate how a compost facility can contribute to filling the provision gap. ${ }^{65}$

A summary of the report identifies that "capacity and resources appear to be the critical elements of most conflicts involving sanitation". ${ }^{66}$ Ultimately, this document demonstrates how the 'capacity and resources' policies currently in place act as a guiding structure; setting the design constraints within which this proposal operates ${ }^{67}$.

\subsection{The evolution of sanitation policy}

The government has made significant strides towards forming regulatory bodies; a progressive step to organizing sanitation efforts at a national level. These steps demonstrate that the government is initiating positive change. The sanitation report notes that:

\footnotetext{
64 The term peri-urban refers to what is known as the urban fringe, or the urban periphery typically occurring outside of the urban core.

${ }^{65}$ Many of these groups are not directly involved sites like Pachacutec, but work within neighboring locations

${ }^{66}$ Evaluation Report, P.2.

${ }^{67}$ Sponsored by the U.S. Agency for International Development, the document was prepared in collaboration between the Environmental Health Project (EHP/USAID), The Pan-American Health Organization (PAHO/CEPIS) and the World Bank Water and Sanitation Program (IBRD/WSP).
} 
The Ministry of Housing, Construction and Sanitation was created in 2002 and includes the Vice-Ministry of Construction and Sanitation (VMCS), under which the National Directorate of Sanitation (DNS) is responsible for policy development for both safe water supply and sanitation. This is an important indicator of political will that is absent in many other countries of the region. More than US $\$ 2$ billion has been invested in water supply and sanitation projects over the past 12 years, and a total investment exceeding that amount has been projected for the next 10 years. A large part of the initiatives resulting from said investments however, have been unsustainable. ${ }^{68}$

Current sanitation policies in Peru only address sanitation provision as a method of excreta disposal. There is little in the way of policy aimed at developing more sustainable approaches to sanitation which take into account the larger cycles of health and the environment. ${ }^{69}$

It has been reported that "The issue of technical norms presents a large gap in Peru. Currently existing norms date to the 1940s, 1960s and 1970s, thus providing evidence that one of the fundamental functions in managing the sanitation sub-sector, i.e., the normative function, is extremely precarious." 70

Funding has thus far been disproportionately allocated towards water provision over sanitation and the poorest communities continue to be underrepresented. The report estimates that "Investments in rural sanitation works are projected at US\$67 million between 2002 and 2011 , with $83 \%$ of the budget allocated to the water subsector and $17 \%$ to the sanitation sub-sector". ${ }^{71}$

This is in spite of the knowledge that an increase in water has shown to increase health standards only when sanitation is equally improved. ${ }^{72}$

The report goes on to state "The team finds little evidence in the Strategic Plan that small cities or the urban poor constitute a priority for the Ministry. Investments in these areas are left to the discretion of the water and sanitation enterprises." 73

\footnotetext{
${ }^{68}$ Evaluation Report, P.vii.

${ }^{69}$ The World Bank technical report \#57 has identified many possible partial composting approaches, several UN texts have also recommended more sustainable approaches.

${ }^{70}$ Evaluation Report, P.67.

${ }^{71}$ Evaluation Report, P.67.

${ }^{72}$ Water and Sanitation Report, P.80.
} 
As little economic advantage results from injecting sanitation services into the poor or rural areas, many communities which do not meet national standards remain self-reliant. The report goes on to indicate that governing bodies which do offer assistance only offer funding in peri-urban (the urban fringe), poor communities for initial investment. Informal policy states that "In order to receive financial support, communities must be formally organized and in addition demonstrate their ability to cover operating and maintenance costs." Initial funding is not offered in every case however, and the start-up support from municipalities is only a fraction of needed funding. Furthermore, communities which are more informal than others can require more funding as they are more challenging to service.

As previously mentioned, the poor do not constitute a priority for the ministry, however the report goes on to identify that "One of the many challenges faced by sanitation work planners in Peru is that approximately half of Peru's population lives in poverty." The National Statistics and Informatics Institute classified 55\% of families as living below the poverty line in 2001 . Of these, $44 \%$ (i.e. $24 \%$ of all Peruvian families) were classified as living in "extreme poverty." The highest poverty rates are found in rural areas, particularly in the mountains. Assuming a household size of five, $20 \%$ of the country's poorest families earn an average of US\$234 per capita per annum (approximately US $\$ 1,170$ per year (Table 4.2.1)). Income amounts vary considerably between districts, as well as between urban and rural communities. Of these groups, it is reported that "Approximately one third of the country's urban poor live in Greater Metropolitan Lima."

${ }^{73}$ Evaluation Report, P.67. 
16.0 Local stake-holders, and regulation groups for the peri-urban.

The Target Group Table below shows some of the roles that ministries and private groups have taken in different urban and rural communities throughout Peru. The table also identifies local stakeholders that our facility proposal would involve. It is clear that our site in greater metropolitan Lima, or the urban fringe referred to as 'peri-urban', has very few regulatory bodies and oversight groups.

Roles of institutional stakeholders in the sanitation sub-sector, by target group (peri-urban section indicated in bold for clarity).

\begin{tabular}{|c|c|c|c|c|}
\hline \multirow[t]{2}{*}{$\mathrm{N}$} & \multirow[t]{2}{*}{ ROLE } & \multicolumn{3}{|l|}{ TARGET GROUPS } \\
\hline & & Rural & Peri-urban & Small cities \\
\hline 1 & Sector planning & VMCS / MINSA+ & MINSA + & MINSA + \\
\hline 2 & Normative & $\mathrm{NE}$ & NE & $\mathrm{NE}$ \\
\hline 3 & Regulatory & NE & NE & $\mathrm{NE}$ \\
\hline 4 & Financing & $\begin{array}{l}\text { VMCS / FONCODES / RG / } \\
\text { LG / ICA / NGO }\end{array}$ & EPS / ICA / NGO & VMCS / LG \\
\hline 5 & Implementation & JASS / NGO / SP & NGO / SP & SP \\
\hline 6 & Oversight & NE & NE & $\mathrm{NE}$ \\
\hline 7 & Supervision & LG & NE & $\mathrm{NE}$ \\
\hline 8 & Monitoring & MINSA & MINSA & MINSA \\
\hline 9 & $\begin{array}{l}\text { Operation and } \\
\text { maintenance }\end{array}$ & JASS & PS & LG \\
\hline 10 & Training & MINSA / NGO & NGO / ICA & $\mathrm{NE}$ \\
\hline 11 & $\begin{array}{l}\text { Advisory } \\
\text { assistance }\end{array}$ & MINSA / ICA / NGO & MINSA / NGO & $\mathrm{NE}$ \\
\hline$+: 0$ & olementary roles & NE: Not in evidence & & \\
\hline
\end{tabular}

Source: Evaluation Report, P.64 Figure 55

Pachacutec is classified under the peri-urban target group, with several bodies responsible for overseeing different aspects of its provision. Sector planning and monitoring involves MINSA, (Ministerio de Salud or Ministry of Health), to which the 
facility will have to prove itself as a service that does not adversely affect health. Sector planning involving the Ministry of Health for peri-urban sites is indicated to only serve a complimentary role, indicated by the + sign. As the table identifies, there are no normative or regulatory bodies to oversee sanitation in places like Pachacutec. Financing in peri-urban areas is not controlled by VMCS (Vice Ministerio de Construcción y Saneamiento or Vice-Ministry of Construction and Sanitation) as is the case in the urban core. Instead independent organizations such as EPS (Sanitation Service Provider Entities), the ICA (International Cooperation Agencies) and NGO's are the groups who are financially contributing. Financing from these groups typically amounts to about $20 \%$ of what is required, and the rest is up to the general public. This includes paying for maintenance, operational costs and startup fees, depending on the area. The implementation of service is provided by $\mathrm{SP}^{74}$ (Local Service Providers) who are responsible for collaborating with NGO's, who in turn connect to community leaders on sites like ours.

There is also no oversight committee or supervision group for peri-urban areas. Operation and maintenance is paid for by users but is not carried out by the public sector. Instead various and competing groups of the Private Sector (PS) are responsible for operation and maintenance. Finally, training and advisory assistance is the responsibility of the NGO's, ICA's, and Ministry of Health.

The Ministry of Health, although not directly involved with private sanitation projects on the ground, acts to oversee standards such as those involving water re-use. The report offers a good example of water reuse that fits within similar regulations which may be used to oversee composting excreta.

Article 111 is worthy of particular note as it affirms that the State encourages the treatment of wastewater with a view toward its reuse, provided that such treated water satisfies the qualitative requirements

${ }^{74}$ Local Service Providers are undefined groups and therefore vary between districts. 
established by the appropriate authority with no adverse effects on public health. In this case, the competent authority is the Ministry of Health, according to both the Water Law and the Health Law. ${ }^{75}$

This thesis proposal must also be compliant with National environmental policy:

Law No. 26410 created the National Council on the Environment (CONAM), an agency charged with directing national environmental policy and whose purpose is to plan, promote, coordinate, control and exercise stewardship over the country's environment and natural treasures. Compliance with national environmental policy as formulated by CONAM is mandatory. ${ }^{76}$

As the full compost of excreta is not a system used for government provision, is on a community scale and is an experimental application, CONAM may have to study our facility for full approval. Sufficient literature, however, is available on the environmental benefits of individual compost to prove the merit of extending such a service to an entire community

\subsection{Policy Driven Technological Gaps}

Although a range of sanitation systems exist which could be tailored to specific communities, the official policies in place dictate that financial support will continue to be directed towards standardized systems. This is due to the limited capacity of regulation bodies. In an example of urban investment "The VMCS has budgeted US\$713 million for urban sanitation works during the 2002-2011 period, an amount that represents $30 \%$ of its programmed investments. Of this total, $17 \%$ (US\$123 million) is earmarked for the rehabilitation of existing sewerage systems, 75\% (US\$535 million) for extension of sewerage networks; and 8\% (US\$55 million) for the construction of latrines." 77

An admission of reducing provision to standardized systems has been reported:

Historically, sanitation programs implemented by government agencies have installed conventional sewerage systems and, in rural areas, latrines that are likewise conventional. Recent evaluations of such programs have found low rates of connection to piped networks (on the order of $20 \%$ ) in both poor urban

${ }^{75}$ Evaluation Report P.42.

${ }^{76}$ Evaluation Report P.59.

${ }^{77}$ Evaluation Report, P.34. 
and rural communities (CENCA, 2001). The VMCS has responded to these disheartening results in its Strategic Plan by limiting all investments in rural sanitation works to onsite technological options (i.e., latrines) until the year 2011. It appears that there is no support at present for the idea of offering a range of options, each with its own costs and associated obligations for beneficiary families. ${ }^{78}$

For our proposal it is very important to note that this approach does not restrict technological options that stray from the norm. The report offers that:

Given the lack of large-scale microcredit or targeted subsidy programs for investing in sanitation works in Peru, the Vice-Ministry of Construction and Sanitation (VMCS) might consider promoting alternative (and low-cost) technologies as a means of facilitating access by poor families to improved services. To date, the development of such technologies has not been hampered by the national level-of service norms. The Ministry of Health, in collaboration with the national regulatory agency (SUNASS), which serves only urban communities, has established norms for water and wastewater but has not issued regulations related to allowable levels of service for either water supply or sanitation; nor has the VMCS proposed, in its Strategic Plan, the establishment of such norms. ${ }^{79}$

CENCA (Center for Social Research and Popular Education) for example, has experimented in Lima's peri-urban areas to install "ecological toilets," which include the treatment of wastewater and the reuse of greywater for landscaping public areas. For such projects, the potential benefits of reuse are obvious. The report however offers up some of the drawbacks of introducing new technologies to a standardized system. These issues will pose challenges to our proposal. It has been reported that:

Although there is no doubt that these projects have contributed to expanding sanitation coverage and to broadening knowledge of appropriate service levels, this diversity of innovations can also pose challenges for the enterprises, the municipalities and the Sanitation Service Administration Boards (JASS), which are required to support the operation and maintenance of installed systems. While these institutions are clearly anxious to support projects that extend coverage in their areas of service, they are possibly poorly equipped to handle new technologies. In Lima, for example, SEDAPAL has only recently established construction standards that provide for the use of shallow "condominial" sewers. Indeed, in its Coverage Expansion Program (PAC), SEDAPAL is considering for the first time a range of sanitation technologies. With support in the form of a loan from the World Bank, this program installs conventional systems, condominial systems (costing some $40 \%$ less than conventional systems) or progressive systems (on-site sanitation), depending on both technical considerations and the ability of the community to maintain and co-finance the installations. It is likely that other enterprises, as well as municipalities and the JASS, have a much lesser capability than SEDAPAL to manage the construction and operation of a wide variety of sanitation systems.

Introducing variants to standard technologies could potentially overwhelm sanitation enterprises. Our project, however, is proposed for an area that has no

${ }^{78}$ Evaluation Report, P.37.

${ }^{79}$ Evaluation Report, P.37. 
provision or regulatory bodies currently allocated. Because this proposal is designed for the implementation capacity of its community, it can be run independently of local sanitation enterprises.

This waterless proposal does not necessitate experience beyond that of a layman, as working with soils productivity, running a tree nursery or participating in the vehicular collection process would require new training that the sanitation sector does not provide.

It is assumed that the Ministry of Health would support preventing ground contamination and stopping the ocean dumping of fresh excreta, but the pilot would additionally have to prove that excreta can be safely sanitized through composting, before it can be sold as a resource. The ideal strategy is to provide sanitation with steady and progressive steps through a tiered approach.

Initially compost should be restricted to the nursery, where the application is internal. Secondly, non fruit-bearing trees sold for beautification can raise funds to pay for additional testing. In time, testing can be performed for agricultural uses, such as with fruit-bearing trees which do not readily absorb water and bacteria in the same way that vegetables do. Testing for use in growing vegetables can then be conducted using donated farming plots and applied to infertile portions of farmland. These tests will serve to indicate the best practices for initial treatment.

This proposal is not intended to burden or hinder the efforts of other sanitation enterprises and as reported, there are drawbacks to innovation in a context of standards. Because Pachacutec has the potential to earn a profit in addition to meeting provision, the benefits will hopefully out-weigh the regulatory challenges of introduction.

To avoid complications, similar initiatives in the past which deviate from official norms (such as the 'ecological toilets' project), have relied upon funding from sources 
other than the government. This is necessary until a new system can prove itself as a viable option, as the research and development areas are under-funded.

\subsection{Funding comparisons}

A common challenge when offering conventional services is the expense of servicing communities far from the proximity of the urban core. The following table shows the budget allocation where funding is promised for the following areas:

Projections of sanitation coverage expansion, 2002-2011

\begin{tabular}{|l|l|l|l|}
\cline { 2 - 4 } \multicolumn{1}{c|}{} & Projected investment & $\begin{array}{l}\text { Cost per person } \\
\text { served }\end{array}$ & $\begin{array}{l}\text { Projected \# of } \\
\text { persons served }\end{array}$ \\
\hline Network rehabilitation & US $\$ 123$ million & US $\$ 12$ & 10.250 .000 \\
\hline Network expansion & US $\$ 535$ million & US $\$ 209^{*}$ & 2.559 .809 \\
\hline Latrine construction & US\$122 million & US $\$ 22$ & 5.545 .455 \\
\hline
\end{tabular}

(VMCS, "Strategic Plan for the Sanitation Subsector) *The average of two VMCS estimates for expansion of sewerage networks (\$185 and \$233), depending on the inclusion or exclusion of primary works. Table source: Evaluation Report P.52. Figure 56

If latrine construction costs $\$ 22 \mathrm{USD} /$ person, and does not include any service such as connection to the larger network, our system must be more economical per unit (even though it is possible to recover funds in the larger process). For the toilets proposed it is estimated that they can be constructed and finished as a hardwood piece for $\$ 5$ USD per unit. As our compost provision toilets are designed to be constructed of wood pallets, a readily available resource, the majority of funding will go directly to labour.

19.0 Issues with International Collaboration

Regarding international collaboration, "Discussions with SEDAPAL (Castilian acronym for Water and Sewerage Service of Lima) and the Cusco enterprise indicate 
that, although they welcome international cooperation activities, of which there are several, these areas are not profitable for the enterprises and there is no national policy supporting the investment risk or the use of subsidies in these areas." ${ }^{80}$ Micro finance proposals are required where provision cannot be met by government or by private industries. Failing to financially support international assistance may suggest that such enterprises could be threatened by independent and community run sanitation projects. Where no provision has occurred however, potential earnings are not comparable to earnings that are guaranteed.

The poor cannot afford to be speculated on until investment in them becomes profitable.

Traditionally, these thresholds of investment are defeated only by self-help. Creating a community enterprise involves investing money directly into the community it serves. The report acknowledges the potential for increased self-sufficiency reached through international support. It is written that:

International cooperation with the World Bank/WSP (Water and Sanitation Program) currently supports efforts to develop management options for small cities, and the international cooperation provided by Switzerland, Germany and others is supporting efforts in peri-urban areas, in some cases with condominial arrangements... it will be important to take advantage of, and expand, these efforts if the VMCS (Vice-Ministry of Construction and Sanitation) is to establish and emphasize strategic objectives and support efforts in these areas. At present, the above constitutes a significant gap in the policy framework. ${ }^{81}$

It was further reported that:

The issue at stake here is that the capacity to enforce remedial environmental actions and controls is lost between overlapping jurisdictions. For example, if a municipal wastewater treatment plant violates the regulations and pollutes rivers or streams, effective enforcement requires that the Ministry of Health identify the problem and issue a citation (which is not done because MINSA has no enforcement capacity). The body with oversight with regard to rivers is CONAM [National Council on the Environment], but the latter does not have enforcement capacity, and the body with executive oversight to the municipal level for policy is MVCS [Vice-Ministry of Construction and Sanitation], which does not have enforcement capacity. In order to address the problems and issues, measures must be taken to clarify legal responsibility and, short of that, an effective delegated mechanism from the three authorities to act in

${ }^{80}$ Evaluation Report, P.67.

${ }^{81}$ Evaluation Report, P.67. 
coordination will be required. In the meantime, many acts of environmental degradation and wastewater violations go unaddressed. ${ }^{82}$

SEDAPAL struggles with a lack of oversight capacity and legal empowerment to intervene in cases of environmental degradation, thus the services they do provide with sanitation have significant gaps in their provision to the urban poor. In addition, services from SEDAPAL as a policy don't offer service to informal settlements, "For example, in Lima SEDAPAL requires families to show evidence of tenancy prior to approval of a network extension project. This is an area in which the VMCS could facilitate dialogue between sector institutions with a view toward consolidating and standardizing policies related to land tenancy and investments in infrastructure." ${ }^{13}$

\subsection{Compost Provision and Peruvian Law}

Inserting a compost proposal into an area that is not serviced by the government of Peru, SEDAPAL, MVCS, Provider Entities, Private Groups, internal organizations or NGOs will require in the least permission and approval from many of these groups. This may seem like more of a courtesy as stated, as they have little or no enforcement capacity. Regardless, these groups will be helpful for gaining approval from the municipality and thus the research is geared toward offering each of them an alternative approach.

In case of failure to secure funding from any of these bodies, a secondary approach might be to present a case before the municipality, explaining the dangers of ground contamination involved with the use of pit latrines. The municipality may then consider funding the cleanup and removal of the pits where all other provision is met through micro loans. Two legal articles which support this are:

Law No. 26842 ... states that health is an essential condition of human development and a fundamental means for achieving individual and collective well-being, a concept which includes sanitation, inasmuch as

${ }^{82}$ Evaluation Report, P.72.

${ }^{83}$ Evaluation Report, P.37. 
the latter is an effective and substantive means for contributing to public health. In addition, the law stipulates that public health is the primary responsibility of the State. ${ }^{84}$

As regards sanitation... Article 106 states that, when environmental contamination implies a health risk or is harmful to individual health, the national-level health authority shall establish essential prevention and control measures to ensure that the acts or situations creating such risk and harm will be halted, something that the EPSs have done on many occasions. ${ }^{85}$

This proposal could be classified as a research and development project towards creating a new service provider entity. The following Peruvian law supports this:

Article 6 of Law No. 26338 stipulates "that sanitation services are to be provided by public, private or mixed entities, hereinafter referred to as 'provider entities,' constituted for the exclusive purpose of providing such services, with such entities required to have their own capital and to be endowed with both operating and administrative autonomy. ${ }^{86}$

In the event that this proposal cannot be classified as an autonomous provider entity, it could be transmuted into a private facility, in which a community has the option to contribute. This option is further demonstrated in the following law:

Legislative Decree No. 613, Code Governing the Environment and Natural Resources, was approved in 1990. This Code is the result of an environmental trend that was occurring both in Peru and at the international level, and is the principal legal framework for matters concerning the environment. As regards environmental protection, In most sanitation programs and projects currently in operation in Peru, families are required to contribute between 10 and $30 \%$ of the initial capital costs. (Frequently these contributions can be made in either labor or in kind.) Families not formally enrolled in sanitation projects can also invest in private facilities. ${ }^{87}$

One objective of this proposal is to demonstrate the legal pathways by which one may secure the permissions required to run the pilot program. To expand its coverage within the legal framework seems entirely possible within Peruvian law.

\subsection{Chapter Conclusion}

In summary, the government is looking for complete autonomy with new service provider groups in the peri-urban and informal areas. As opposed to integrating a

\footnotetext{
${ }^{84}$ Evaluation Report, P.41.

${ }^{85}$ Evaluation Report, P.41.

${ }^{86}$ Evaluation Report, P.62.

${ }^{87}$ Evaluation Report, P.53.
} 
compost proposal amongst the regulatory bodies of Lima, areas further from the city core are encouraged to be more self sufficient in an effort to decentralize sanitation provision.

Regulation and standards enforced by the municipal authorities and national programs such as the Ministry of Health act to ensure that no extreme health violations occur. Sanitation service is otherwise run by independent groups, sometimes international. A heavy dependence on NGO's and private enterprises is also common for informal areas. This pilot project should then receive little resistance from government, the municipality or provider groups during its trial. Stakeholder groups of innovation such as CENCA may be a legislative point of reference for validating the initiative. As Pachacutec is an informal settlement and awaiting land tenure, there may be no other option. Along with the greater ideal of meeting adequate provision, serving the needs of the community is the chief objective. The larger adoption into policy is not expected to be integrated into the plan until 2011, as funds have already been directed towards meeting provision through standard, albeit unsustainable forms. 


\section{Appendix C. Building on Innovation: Technology and Potential}

The Evaluation Report discussed in Appendix B summarizes three recommended strategies for improving service to the poor in Peru: "The three principal strategies for improving access to sanitation services by poor families include offering lower-cost technical options; lowering the financial burden of initial costs through subsidies and/or credit programs; and keeping services affordable by applying cross-subsidized rate structures. ${ }^{88}$

Offering "low-cost technical options" was one of the driving forces behind the technical design of our facility. Two texts in particular have been instrumental during the design process. Technical Paper \#57, produced by the World Bank, has acted as an implementation guide for new sanitation proposals and was instrumental in recommending a process of approach in addition to exhibiting a range of large scale composting options. Secondly, the Humanure Handbook, produced by Joseph Jenkins has acted to identify small scale composting options and in addition, the tested health benefits and bacterial processes involved. Jenkins' text mainly promotes the use of a personalized bin system where the Technical paper promotes a larger, mechanical method. Our community facility would fit somewhere between the two.

\subsection{World Bank Technical Paper}

Technical Paper \#57 The Co-composting of Domestic Solid and Human Wastes (written in 1987), outlines a general strategy for introducing sanitation systems to lowincome settlements. The site conditions addressed in the document are applicable to the economic, cultural and informal challenges faced in Peru. In addition, the sensitivities to

${ }^{88}$ Evaluation Report, P.68. 
approach in the World Bank text have critically acted as a framework for our design. Its many recommendations act to fortify an argument for composting.

Technical Paper \#57 makes 5 specific recommendations for introducing a sanitation system. The first recommendation is to identify 'information on the waste material'. ${ }^{89}$ The World Bank further describes, "It is important to determine the nature and composition of the wastes to be composted. Such basic information will be of use later when the time comes to choose an appropriate composting system. Furthermore, it is useful to know how the collection of these wastes would fit into the overall waste management system (e.g., land filling and incineration) and if there are already wasterecycling activities to which this could be added, such as organized sorting of garbage for recyclable or scavenging and biogas operations." 90 The nature of the waste in our case is $100 \%$ organic, and has not been mixed with heavy metals, chemical or medical pollutants. Also, until further testing is possible, its intended use is limited to beautification projects. Regarding the effort to fit services into a common system; water and gas are delivered to the site via truck, which will suffice for our model. Water containers for example are depicted in the image above at an Aldeas Comunitario in Wascar, near Pachacutec. Using plastic containers for human waste collection would integrate smoothly with systems currently in place.

The second recommendation was to ensure that a market existed for compost. The report asks:

"Is there a market for any compost that might be produced? Perhaps there are crop farmers or horticulturalists in the city outskirts who would use it to improve the quality and productivity of their crops. Maybe the public or private sector is involved in a landscaping program, or perhaps there is badly eroded topsoil or sandy and/or clay soils that could be reclaimed for productive use. The financial viability of cocomposting garbage and human waste is dependent on a well-developed market that is willing to pay at least for the costs of production". ${ }^{91}$

${ }^{89}$ Obeng and Wright, P.72.

${ }^{90}$ Obeng and Wright, P.72.

${ }^{91}$ Obeng and Wright, P.72. 
Pachacutec is located in the desert, and its sand can not readily retain water ${ }^{92}$, thus little to nothing grows without added soil and irrigation; one would actually be pressed to find less productive land ${ }^{93}$. Tree nurseries in arid places, however, are often still successful, especially when compost becomes economically available and waste water is used for irrigation. ${ }^{94}$ All of the municipalities surrounding Lima are consistently making efforts to landscape traffic islands and parks in an effort to cover the dusty sand. ${ }^{95}$

The third recommendation is to describe the type of plant or facility in our case and the details of its operation. The paper describes:

"next, we ask about the type of plant, taking into consideration possible location, availability of trained technical staff and manual labour, and financial resources to cover capital and operating costs, in order to determine which system would be most appropriate for the city. Economic and financial feasibilities will be of importance in considering the costs involved for a specific system."

\section{The report continues to suggest that,}

"a simple windrow or forced aeration system [may most likely]... suit the capabilities of the establishment... [and] the potential for manufacture nationally, thus reducing the requirement for foreign exchange components."

The windrow approach is typically used for treated sewage and is not encouraged for composting untreated excreta. Our system requires little foreign exchange components, as aeration is the result of individual containment, thus negating the need for forced air machines. Our system is heated through a thermophilic bacterial

${ }^{92}$ Compost is said to hold nine times its weight in water (900\%), as compared to sand which only holds $2 \%$ - Humanure Handbook, P. 28.

${ }_{93}$ The dessert hills are very arid, Lima is second only to Cairo as the driest capital city. Only in flooded plains adjacent to the ocean does water saturate the soil in Pachacutec.

${ }_{94}$ Anne Griffith interview, University of Toronto graduate, B.A. Agricultural Studies in International Development.

${ }^{95}$ When I first arrived to Peru I worked in a park landscaping project planting a garden near Pachacutec. Arnan, a local gardener by trade and myself dug several meter deep holes using shovels and pick axes. We replaced the rocky sand with fertilizer, and planted a few small trees. The experience was educational.

${ }^{96}$ The windrow approach will be discussed in more detail shortly. Obeng and Wright, P.72. 
process and does not require industrial heating. ${ }^{97}$ This was found to be more economical than an electric process. Regarding the availability of trained staff; the local concrete block producers are employed for the facility structure, the local wood shop for toilet construction, the local fisherman for net weaving of the containment baskets and hired non-expert locals for the general employees who would use a local flatbed truck for waste collection.

The fourth recommendation is to set up a pilot based project.

Once the waste materials and composting systems have been identified, it is useful, if a large-scale operation is being planned, to start with a pilot plant. This will serve two purposes: first, the prospective operators will become familiar with the process; second, it will serve as a good public relations exercise to produce small amounts of compost for sale or as samples for the potential market. ${ }^{98}$

This approach was adopted and found necessary not only for public relations and experimentation, but also because little finance will be available beyond the system paying for itself. In other words, the pilot requires a startup loan but may eventually generate a small profit and that will go towards funding its own expansion. If this is not possible or takes too long, additional loans will be needed for expansion purposes after the first loan is paid off.

Finally, technical paper \#57 suggests that the 'benefits and justification' be properly addressed.

There are those [benefits] that can be readily quantified, such as reducing the need for sanitary landfill of garbage and recovering materials for industry, which often obviate importation or mining of similar industrial materials. For specific waste management activities, the careful integration of composting operations should allow for more efficient collection networks, the savings of which can be easily quantified and used to offset the cost of composting. In addition it should be relatively simple to demonstrate the benefits of compost in terms of improved soil productivity, measured as increased yields and/or reduction of other inputs (fertilizers and water), and easier tillage. This can easily be carried out in a controlled trial using compost produced locally on a trial basis for two or three cropping seasons perhaps at the pilot compost plant. Other benefits, such as the effect of compost on the quality and longevity of the soil, the reduced health risk of having pathogenic material in the environment, and the improved aesthetic quality of the

\footnotetext{
${ }^{97}$ Thermophilic bacteria occur naturally in hot springs, tropical soils, compost heaps, in your excrement, in hot water heaters (both domestic and industrial), and in your garbage, to name a few places... These bacteria are said to be found in the sands of the Sahara Desert, but not in the soil of cool forests: Humanure Handbook P.37.

${ }^{98}$ Obeng and Wright, P.72.
} 
surroundings, are difficult to quantify but are of importance in ensuring adequate maintenance of the environment. ${ }^{99}$

The justifications presented in this last recommendation effectively sum up the benefits our facility should bring to Pachacutec

23.0 Technical Options: World Bank and Joseph Jenkins

Joseph Jenkins is well accustomed to using compost to treat human waste. In his text, The Humanure Handbook -Third addition: A Guide To Composting Human Manure, Jenkins explores a whole range of composting options, many of which are also addressed in the World Bank technical paper. The Humanure Handbook is a useful guide to the bacteriological processes, health concerns, and soil productivity associated with composting excreta. Many of the UN sources cited earlier in this thesis are also referred to in his text. The main distinction is that where the technical paper promotes aerated systems and double vault pit latrines, Jenkins advocates a simple wooded bin system, a process he and his family have relied on for 20 years. Jenkins also suggests the possibility of a larger collection process at the end of his text. ${ }^{100}$ The Communitario design for Hogar adapted Jenkins system in part because of its resourceful and homemade nature, which makes it an ideal fit for families that cannot participate in the larger community facility. The compost facility draws on the composting concepts Jenkins explored as a basis for the community design. Both texts adamantly advocate the importance of composting in poverty stricken areas.

Highlighting the broken chain of what he calls 'the human nutrient cycle', Jenkins compares the options of returning excreta to the soil versus the energy involved in discarding, polluting and producing chemical fertilizers. Technical Paper \#57 also

\footnotetext{
${ }^{99}$ Obeng and Wright, P.72.

${ }^{100}$ Refer to Figure 57. A rendering of a cargo van is placed at the end of the Humanure Handbook to suggest that a larger collection facility could be employed in North American Suburbs.
} 
addresses these environmental issues to promote compost. The World Bank urges that "the recycling of human waste has been an accepted practice throughout the world for many years... One method of reusing human waste is composting, which means converting it into a material that is safe to use, usually on land." It is further stated that, "Urban areas are finding it increasingly difficult to safely dispose of human waste and domestic solid wastes. It is also becoming increasingly important worldwide to improve the nutrient and physical qualities of agricultural soils. This is especially true in the food production areas surrounding growing urban centers in developing countries" 101 Technical Paper \#57 also highlights the inefficiency of water-based transport: "the advantage of night soil [human manure] over sludge [mixed sewage] is that it does not contain heavy metals" among other contaminates. Such additions are detrimental to the composting process. For the purposes of this study, water based technologies will not be explored further in the text, although they are visually depicted on the following pages for visual comparison.

Of the many composting approaches, 'Night soil' is the term introduced in Technical Paper \#57 for human waste that is not mixed in a sewage system and often contained before use on land. The report identifies that "it [night soil] is [commonly] deposited into buckets, pits, or vaults". ${ }^{102}$ Reviewing night soil techniques, the WB mentions that in regulated versions, "there has been little experience in night soil composting". ${ }^{103}$ Treated sewage co-composting approaches are more common than night soil systems, and both techniques share a similar process. Pre-treated sewage, however, is typically pre-sanitized and the mix is chemically and industrially treated. An important distinction therefore is made between a range of compost methods that require expensive or electric machinery versus those which do not. Both machine driven

\footnotetext{
${ }^{101}$ Obeng and Wright, P.vii.

${ }^{102}$ Obeng and Wright, P.1.

${ }^{103}$ Obeng and Wright, P.2.
} 
and thermophilic bacterial processes are documented as safely destroying harmful diseases and their associated hazards (previously identified), in human waste. In both cases, heat acts to expedite the sanitation process, and both systems work better in warmer climates.

\subsection{Pit Latrines}

Pit latrines are not sanitary. In addition to the cultural, epidemiological, and environmental violations previously identified with using them at community scales, it is important to point out some further problems. Jenkins identifies that "Outhouses create very real health, environmental and aesthetic problems. The hole in the ground is accessible to flies and mosquitoes which can transmit diseases over a wide area. The pits leak pollutants onto the ground even in dry soil. Outhouses will transmit pollution three meters (10 feet) below the outhouse hole and one meter ( 3 feet) sideways in dry soil. They can be expected to leak pollution 50 feet sideways in wet soils, following the direction of groundwater flow." 104

The critical flaw with pit latrines, is ground contamination. They are one of many unsustainable disposal methods common to our site. They do not properly decompose, and transmit disease as readily as defecating on open ground. During the warmest months in Pachacutec the smell of these pits cannot be ignored. One could argue that the discomfort factor of pit latrines is a destructive force to the human spirit in places like Pachacutec. Chemicals dumped into the pit latrines in attempts to sanitize them only pollute the subsurface further. In addition, as they fill they cannot be emptied and require new pits to be dug. ${ }^{105}$

${ }^{104}$ Humanure Handbook, P.87.

${ }^{105}$ Note the pile of excreta is exaggerated in the image, in reality it would be flatter. Humanure Handbook, P.86. 


\subsection{Direct Dumping}

One method common in some parts of the world is to apply night soil (fresh excreta) directly onto farmers fields. This method is not recommended and described more here as an example of what not to do. Throughout Asia the detriments of this process are well documented. Pathogens and various diseases residing in fresh excreta can survive for a long time outside of the human body and present a strong risk of infection. As long as fresh excreta is continually spread, pathogens are continually present in the surrounding environment. These diseases reside in surface soils that get onto clothing, and are absorbed agriculturally into water-retaining foods. They can also survive in subsurface soils long enough to contaminate underground water reserves which are either directly consumed or used to wash food, thus resulting in further infection. Insects can spread infections even further. Jenkins reports additionally that "Americans who have traveled to Asia tell of the horrible stench of night soil that wafts through the air when human excreta is applied to fields". ${ }^{106}$

\subsection{Large Scale Machine-Ventilated}

Raising the temperature of excreta using a mechanical forced air industrial process typically takes less time than a self-aerated composting approach but requires continued investment and a power source. Although these systems are far more advanced then dumping fresh excreta onto farmland, most versions still involve dumping treated sewage, which is not entirely sanitized, onto the ground. Uncontained, disease can spread in the same way as with fresh dumping, albeit to a lesser extent. In this approach (which is recommended by the World Bank), a mechanical aeration system draws air from outside of large piles, using a suction pipe inside the pile. These systems are tailored to handle large scale treated sewage piles. The air pipe is necessary

\footnotetext{
${ }^{106}$ Humanure Handbook, P.21.
} 
because the piles suffocate under their own weight. ${ }^{107}$ More advanced versions of forced air systems contain sewage using concrete floors. Some large-scale processes referred to as batch composters even occur indoors in pole barn type structures. One mechanical approach involves a forced heating process. A heat process could potentially destroy night soil pathogen in a matter of minutes but requires intense amounts of energy and such a process would not be beneficial for creating compost. Most large composting operations take advantage of the thermophilic process encouraged in various forms through aeration systems. A disadvantage beyond the expense and containment issues of the mechanical aeration processes is the resulting loss of soil productivity due to nitrogen depletion, which is a direct of result of artificial aeration. ${ }^{108}$ Some windrow systems are used in developed countries such as Canada, where in Nova Scotia sewage sludge is applied to the ground. The waste is pre-sanitized however before it is applied outdoors. It is important to note that the mechanical aeration accelerates the composting process only, and sanitation has yet to occur before the material is released into the environment.

Double pit vaults are an example of more manageable methods that are not water dependant. While they are not the most ideal system for meeting provision in Pachacutec they are far better than uncontained pit latrines. Double vaults are encouraged in the World Bank technical paper because they allow for a regulated amount of time to pass before collection. Jenkins recognizes time control to be a middle benefit approach somewhere between direct dumping and thermophilic compost. Once the first pit is full it can be left alone for a pre-determined amount of time (typically two years depending on climate) while the second pit is in use. For full provision however, each house would require the complete system. These pits must be placed in a location which makes them accessible for emptying, usually away from the home, and two pits

\footnotetext{
${ }^{107}$ Humanure Handbook, P.233.

${ }^{108}$ Obeng and Wright, P.52.
} 
must be dug. Construction is usually concrete to allow for containment, although portable systems in plastic do exist. They are an intensive undertaking for one household, thus it is common in poverty stricken areas for a unit to be shared amongst several families. As identified earlier, shared outhouse systems do not address the social implication of having to wait in line for service or the difficulty associated with having to clean the waste of others. Double vault pits can also be intimidating to children and may require parental accompaniment. Furthermore, the waste sits on site for years before emptying. Finally, most models do not allow proper oxygen exposure, a vital factor in reducing odor.

An evolution on the double pit vault ${ }^{109}$ is the carousel system. This system shares the same problems associated with the double pit, but it has the exception of being lighter, more manageable and having more storage areas. The carousel latrine would be an interesting addition to our facility in Peru, and a welcome participant to our larger facility. Our sawdust toilet, however, is a much simpler way of collecting the waste, more applicable on a community scale, is less complicated to build, and can be used readily within the home. To use the carousel latrine, users have to climb a set of steps to defecate, which is how users avoid digging pits. To use the carousel latrine, users have to climb a set of steps to defecate, which is how users avoid digging pits. Typically they are used to compost on-site. (Figure 51)

In selecting a proper system it is advantageous to remove the waste in smaller increments, as it is better to remove garbage in smaller increments then to let it pile up before removal. For large pits, the report offers that: "emptying of these pits is often hazardous because full pits contain fresh excreta." ${ }^{110}$ Nothing was found in the text regarding more manageable containment systems. In our proposal there is no large 'pit'

${ }^{109}$ Refer to Compost Systems Image.

${ }^{110}$ Obeng and Wright P.1. 
to empty, and our collection process transports the material in sealed buckets to the facility before opening them so the feces is brought away with the pail. The facility is self-contained and the steam used to clean the buckets is reused as irrigation for the nursery; sanitized because of the heat. The organic baskets employed require no further cleaning, as the storage device is sold as a part of the final compost and additionally tailored to the size required for planting a tree, thus the whole bag can be planted right into the ground so no waste is produced. Finally, having a nursery onsite makes transport of compost unnecessary.

Better designs usually involve a higher expense. The key challenge for this thesis was to develop a system that was advanced enough to

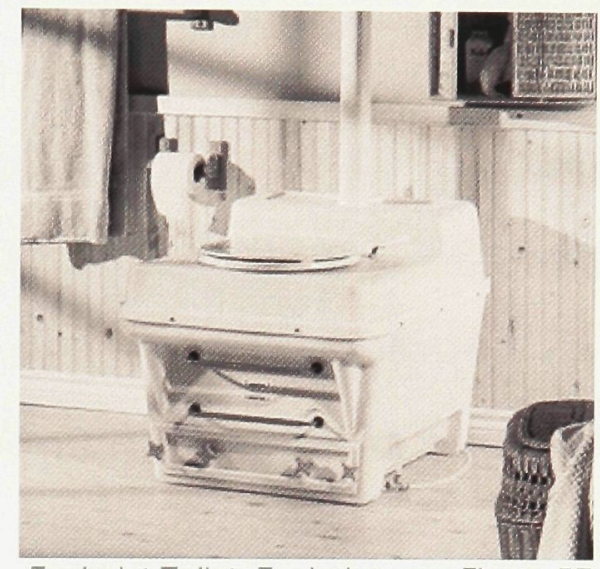

Envirolet Toilet: Envirolet.com Figure 57 provide culturally acceptable sanitation without using foreign commercial production, or a middleman that absorbed investment outside the community. Many commercial toilets take advantage of on site compost, but do it within the home in recognition of the advantages. Depicted in the following pages such commercial brands as the Solar Toilet, the Vera Toga, the Clivus, the Sven Linden, the Biolet, the Sun Mar, the Dowmus, the Phoenix, the Aquatron, etc. all can be used with varying degrees of structural alteration to households. Many require ventilation pipes. Some of these systems allow for solar energy to accelerate the compost process with added heat, others like the Envirolet offer a range of fan drying options. Envirolet is a Canadian company that offers windmill, battery powered or fully electric forced aeration components. The Envirolet is an important system to discuss as it demonstrates a common technique for maximizing the capacity of most on site systems: whereas windrow composting uses aeration to activate heating for compost Envirolet uses forced 
air to shrink the waste for capacity. Separating each deposit does not allow room for bacterial composting. A deposit sits isolated on a perforated tray where it dries, you then push and pull handles until it drops reduced in mass. The commercial advertises that approximately $90 \%$ of the human waste is moisture, (the World Health Organization reports $66-80 \%{ }^{111}$ ) and so removing the moisture is its main approach. Envirolet is arguably not a composting toilet because the compost process is not possible if the 'deposit' is dried before the 'good bacteria' can take over. It does however help to make the waste inert. The "Composting" actually occurs when the product is applied to flowerbeds. The themophlic bacteria process will not occur using this method however, unless the waste is applied to a proper composting bin. This system also uses added microbes (found unnecessary by several WB texts), for the windrow processes. Envirolet is thus not applicable to providing a sanitation solution for our site, especially for the scale that is proposed.

${ }^{111}$ Humanure Handbook P.35. 


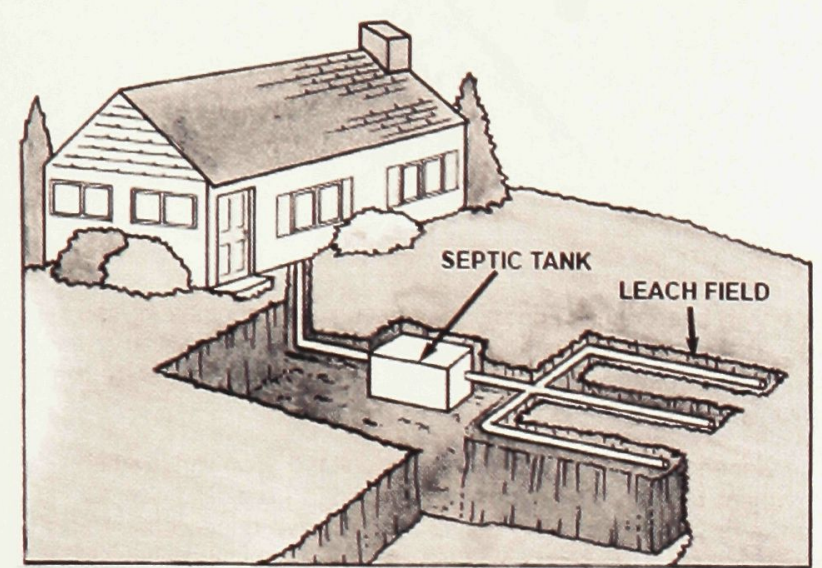

STANDARD SEPTIC TANK GRAVITY DISTRIBUTION SYSTEM
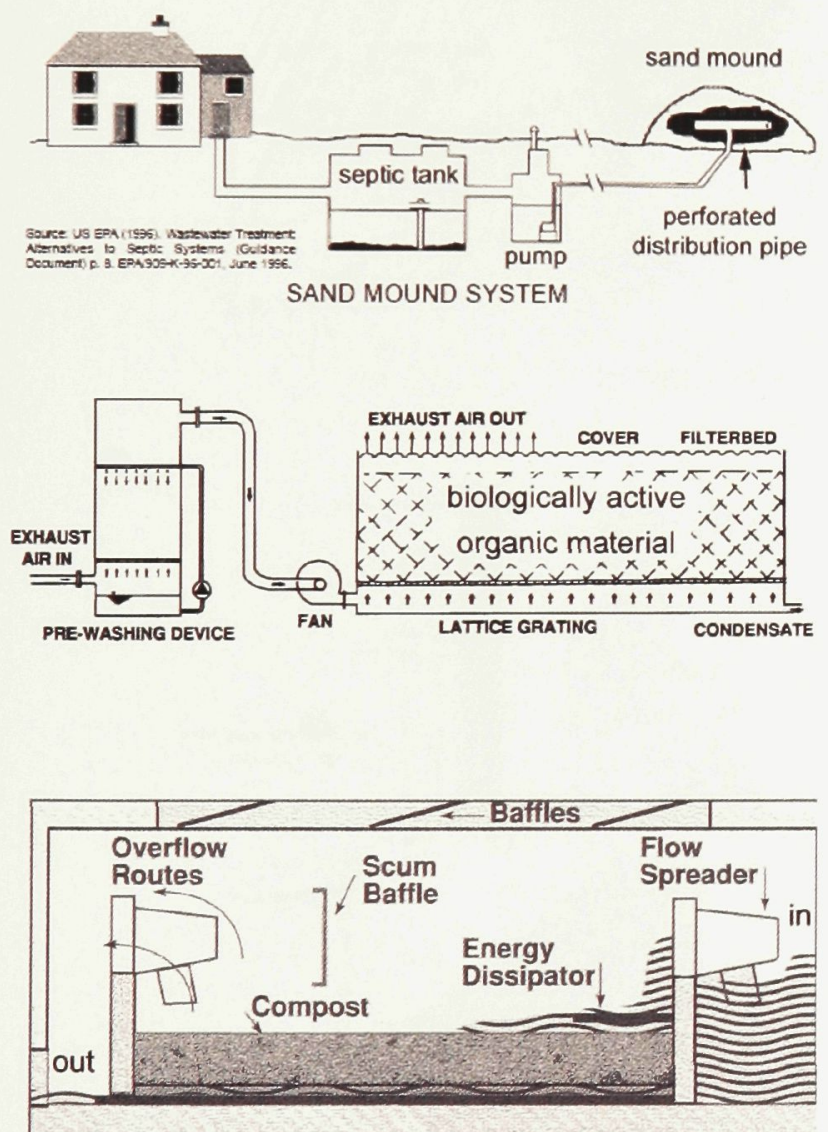
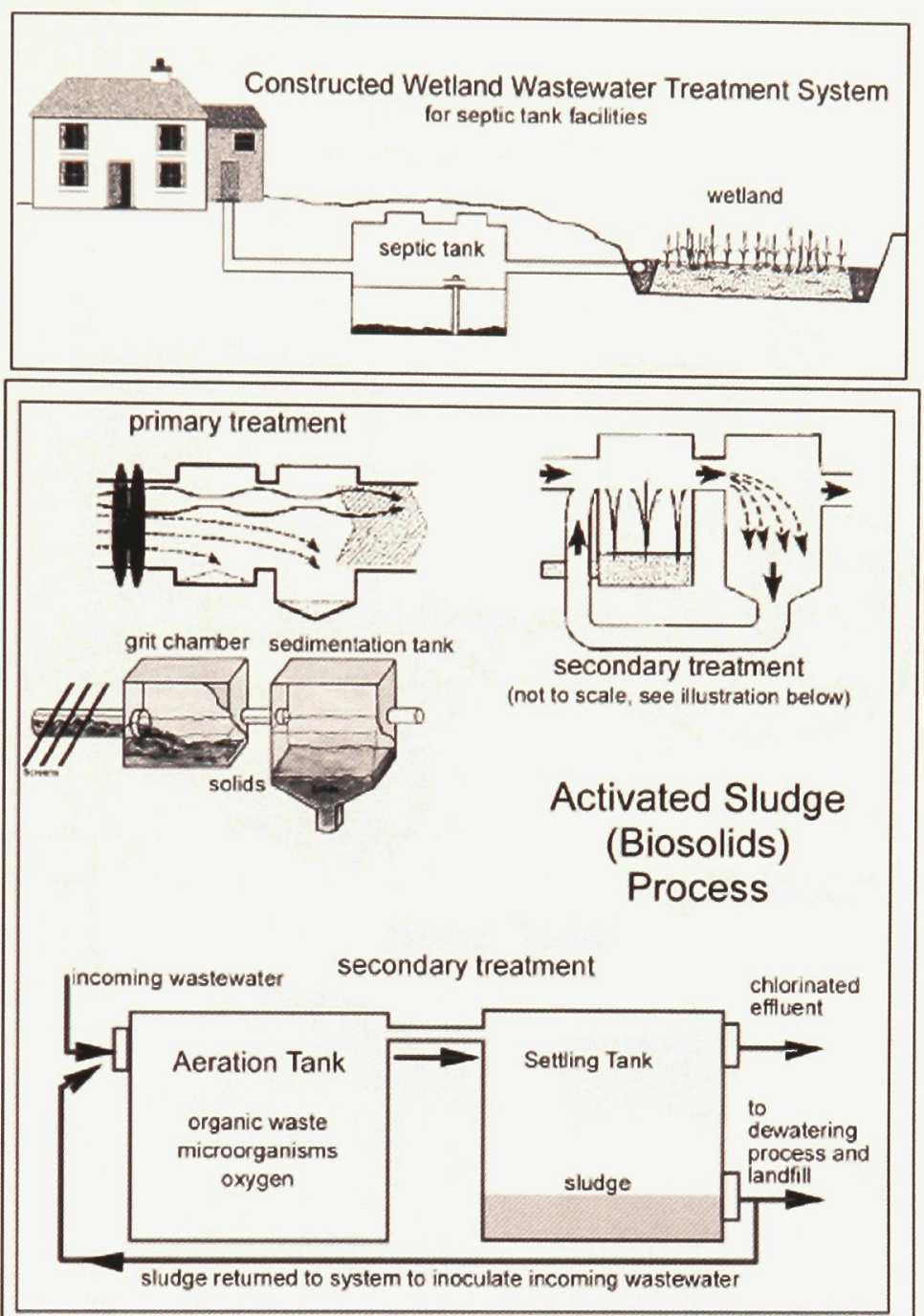

Typical Three Cell Lagoon System

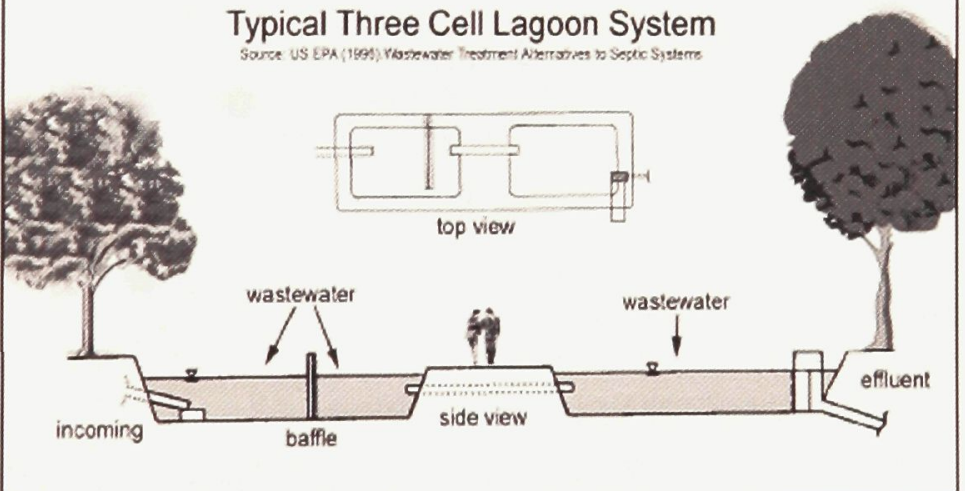

Source: Humanure Handbook- Appendix C Composting Toilet Systems P. 87-88 Figure 58 

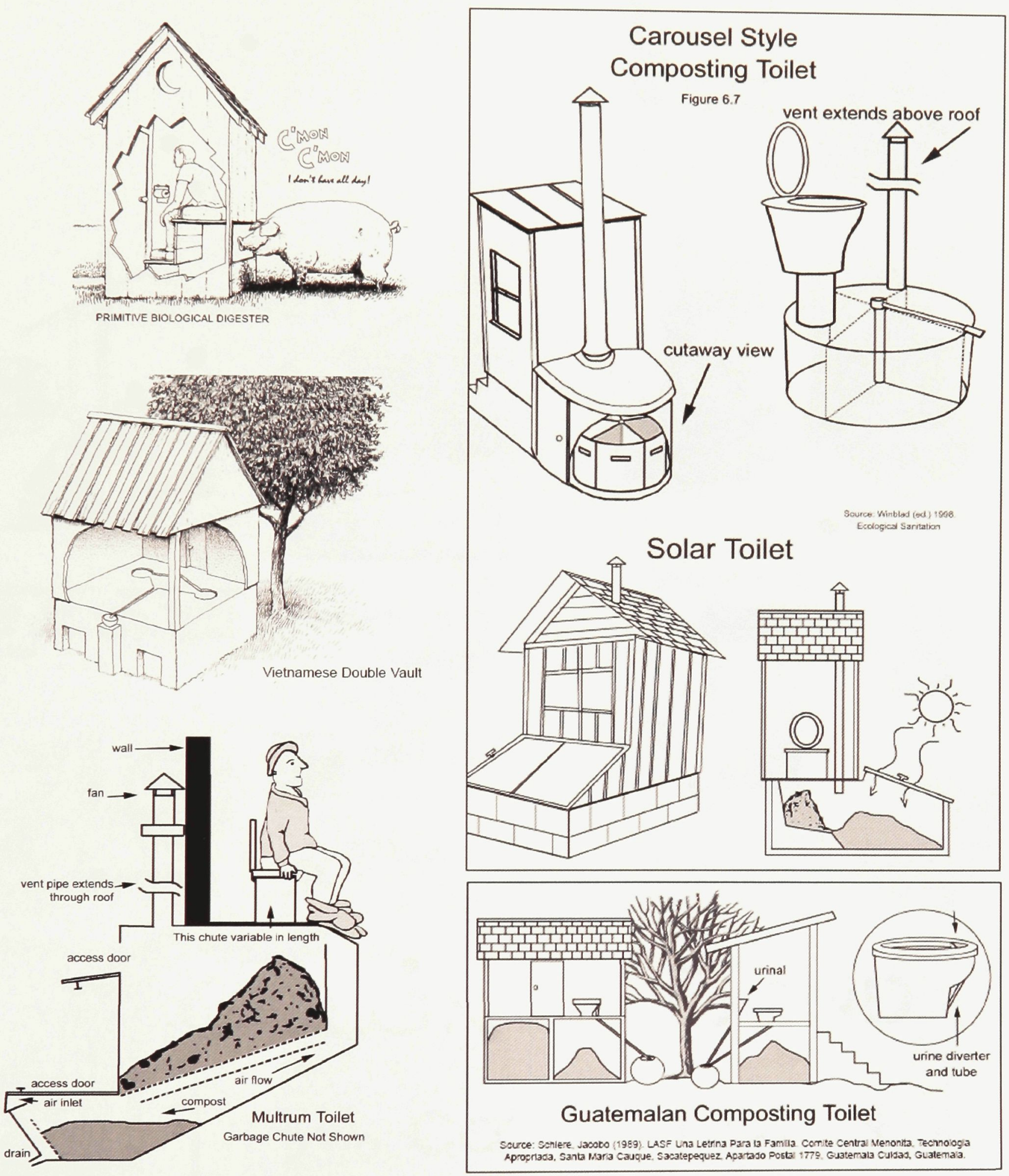

Source: Humanure Handbook- Appendix C Composting Toilet Systems P. 102-108 Figure 59 

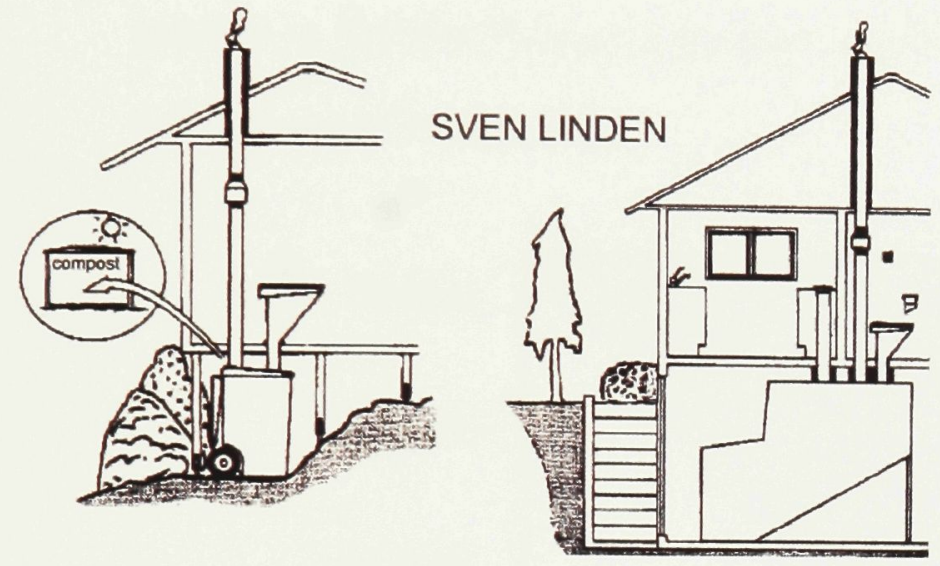

Clockwise from top left: Sven Linden, Sven Linden, Aquatron, Dutch Hamar, Alascan, Bio-Sun, Sun-Mar.
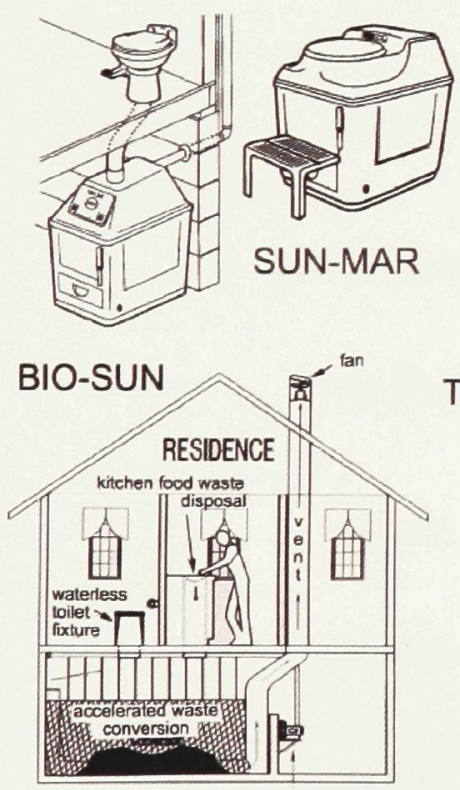

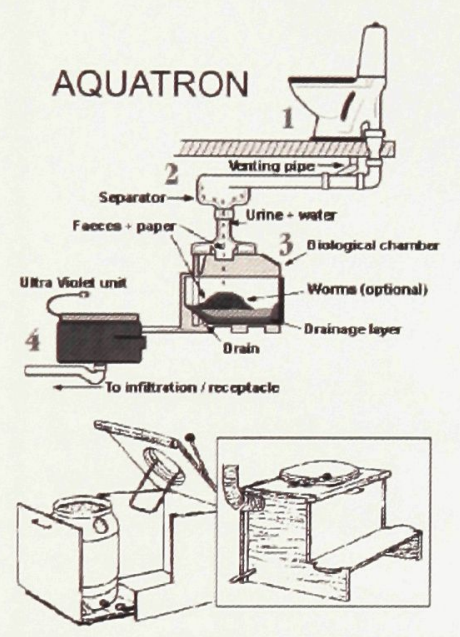

TECHNISCH BUREAU HAMAR

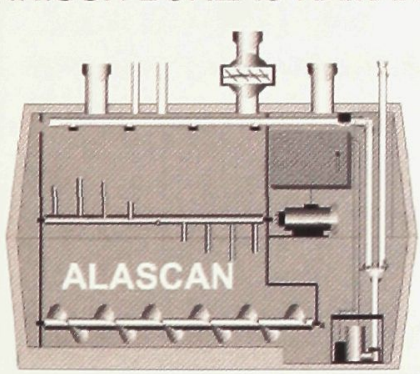

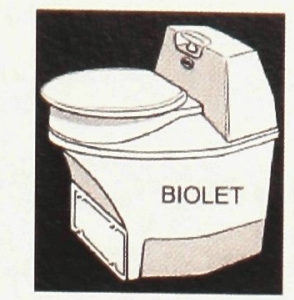

Clockwise from top left. Biolet, Vera Toga, Clivus, Carousel.
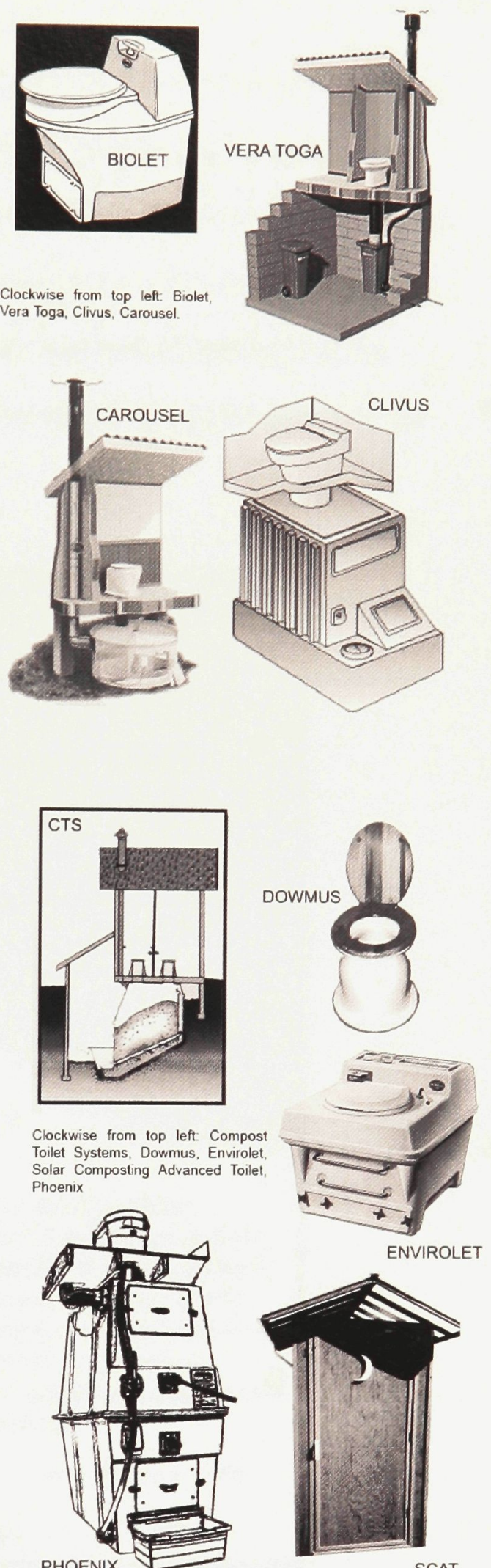

SCAT

Source: Humanure Handbook- Appendix C Composting Toilet Systems P. 102-108 Figure 60 
A natural approach to sanitation involves storing excreta in a contained space for a regulated amount of time in an environment that nurtures a process of self-heating using a scale that permits self-aeration. Using a multiple of smaller storage units permits aeration to occur between airspaces, while piles are individually contained to keep track of the time they have sat for. Taking advantage of proper ingredient layering, natural aeration is assisted, allowing the thermophilic bateria to reproduce, which sanitizes the waste in a self heated way.

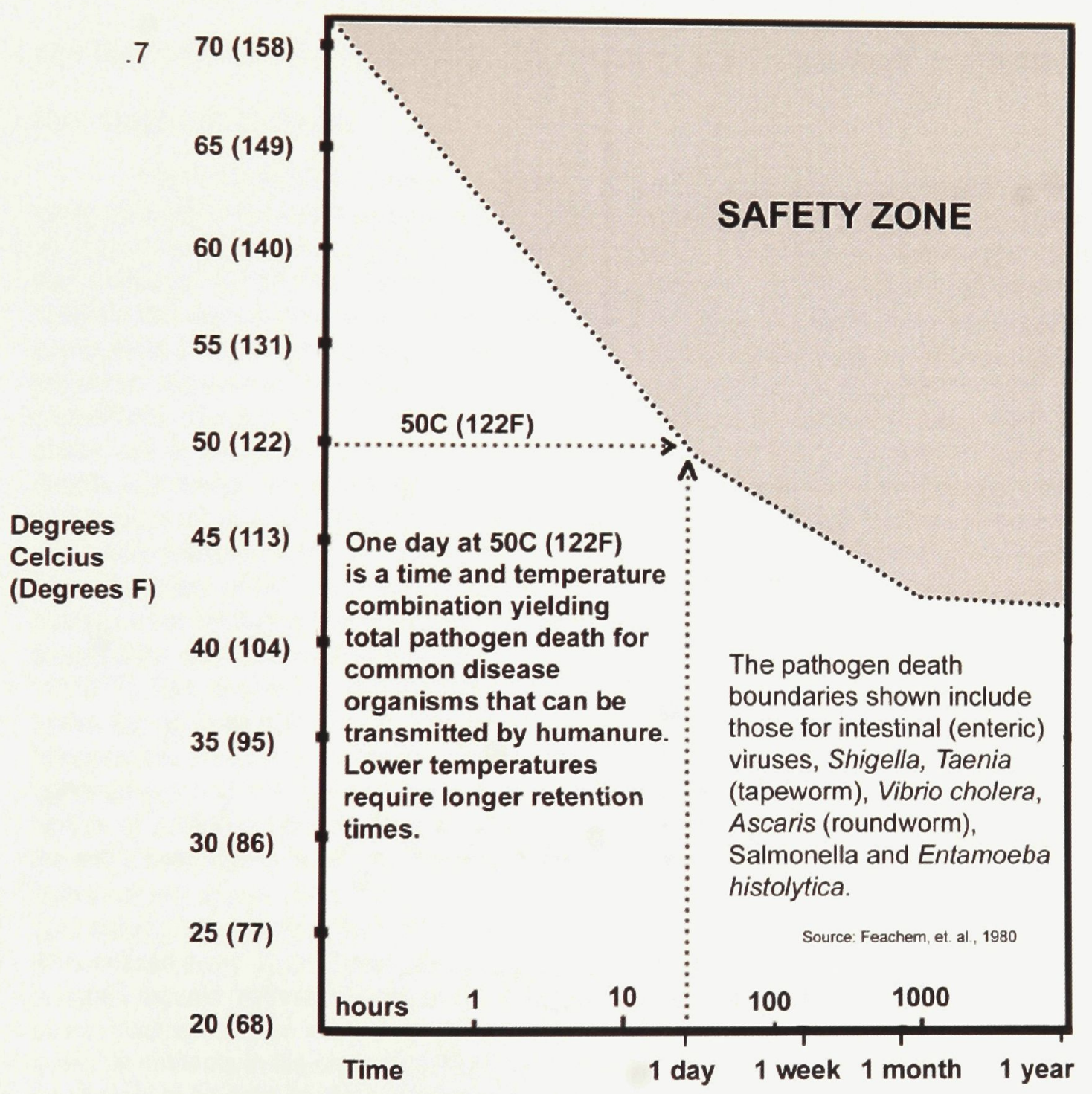


Our system was design to respond to the accepted thermophilic bacterial science behind Jenkins bin system. Generally, two keys to killing pathogens are required using a thermophilic process. Employed by our system, these are: 1) achieving appropriate temperature; and 2) achieving an appropriate passing of time; while making sure the waste is contained. These keys are often employed by safer composting systems, some of which take composting to the level of rigorous pathogen destruction. The following chart displays the temperatures required to destroy pathogens, most of which present threats to our community. It is reported that proper thermophlic stage temperatures in compost average at $44^{\circ} \mathrm{C}-52^{\circ} \mathrm{C}$. It is further reported that: "This stage can then continue to about $70^{\circ} \mathrm{C}$ ". This process is best explained in Jenkins text on the four stages of compost.

FOUR STAGES OF COMPOST: There is a huge difference between a backyard humanure composter and a municipal composter. Municipal composters handle large batches of organic materials all at once, while backyard composters continuously produce a small amount of organic material every day. Municipal composters, therefore, are "batch" composters, while backyard composters tend to be "continuous" composters. When organic material is composted in a batch, four distinct stages of the composting process are apparent. Although the same phases occur during continuous composting, they are not as apparent as they are in a batch, and in fact they may be occurring concurrently rather than sequentially. The four phases include: 1) the mesophilic phase; 2) the thermophilic phase; 3) the cooling phase; and 4) the curing phase. Compost bacteria combine carbon with oxygen to produce carbon dioxide and energy. Some of the energy is used by the microorganisms for reproduction and growth; the rest is given off as heat. When a pile of organic refuse begins to undergo the composting process, mesophilic bacteria proliferate, raising the temperature of the composting mass up to $44^{\circ} \mathrm{C}\left(111^{\circ} \mathrm{F}\right)$. This is the first stage of the composting process. These mesophilic bacteria can include $\mathrm{E}$. coli and other bacteria from the human intestinal tract, but these soon become increasingly inhibited by the temperature, as the thermophilic bacteria take over in the transition range of $44^{\circ} \mathrm{C}-52^{\circ} \mathrm{C}\left(111^{\circ} \mathrm{F}\right.$ $125.6^{\circ} \mathrm{F}$ ). This begins the second stage of the process, when thermophilic microorganisms are very active and produce a lot of heat. This stage can then continue to about $70^{\circ} \mathrm{C}\left(158^{\circ} \mathrm{F}\right)$ although such high temperatures are neither common nor desirable in backyard compost. This heating stage takes place rather quickly and may last only a few days, weeks or months. It tends to remain localized in the upper portion of a backyard compost bin where the fresh material is being added; whereas in batch compost, the entire composting mass may be thermophilic all at once. After the thermophilic heating period, the humanure will appear to have been digested, but the coarser organic material will not. This is when the third stage of composting, the cooling phase, takes place. During this phase, the microorganisms that were chased away by the thermophiles migrate back into the compost and get to work digesting the more resistant organic materials. Fungi and macroorganisms such as earthworms and sowbugs also break the coarser elements down into humus. After the thermophilic stage has been completed, only the readily available nutrients in the organic material have been digested. There's still a lot of food in the pile, and a lot of work to be done by the creatures in the compost. It takes many months to break down some of the more resistant organic materials in compost such as "lignin," which comes from wood materials. Like humans, trees have evolved with a skin that is resistant to bacterial attack, and in a compost pile these lignins resist breakdown by thermophiles. However, other organisms, such as fungi, can break down 
lignin, given enough time; since many fungi don't like the heat of thermophilic compost, they simply wait for things to cool down before beginning their job. The final stage of the composting process is called the curing, aging or maturing stage, and it is a long and important one. Commercial composting professionals often want to make their compost as quickly as possible, usually sacrificing the compost's curing time. One municipal compost operator remarked that if he could shorten his compost time to four months, he could make three batches of compost a year instead of only the two he was then making, thereby increasing his output by $50 \%$. Municipal composters see truckloads of compost coming in to their facilities daily, and they want to make sure they don't get inundated with organic material waiting to be composted. Therefore, they feel a need to move their material through the composting process as quickly as possible to make room for the new stuff. Household composters don't have that problem, although there seem to be plenty of backyard composters who are obsessed with making compost as quickly as possible. However, the curing of the compost is a critically important stage of the compostmaking process. A long curing period, such as a year after the thermophilic stage, adds a safety net for pathogen destruction. Many human pathogens have only a limited period of viability in the soil, and the longer they are subjected to the microbiological competition of the compost pile, the more likely they will die a swift death. Immature or uncured compost can produce substances called phytotoxins that are toxic to plants. It can also rob the soil of oxygen and nitrogen and can contain high levels of organic acids. So relax, sit back, put your feet up, and let your compost reach full maturity before you even think about using it. ${ }^{112}$

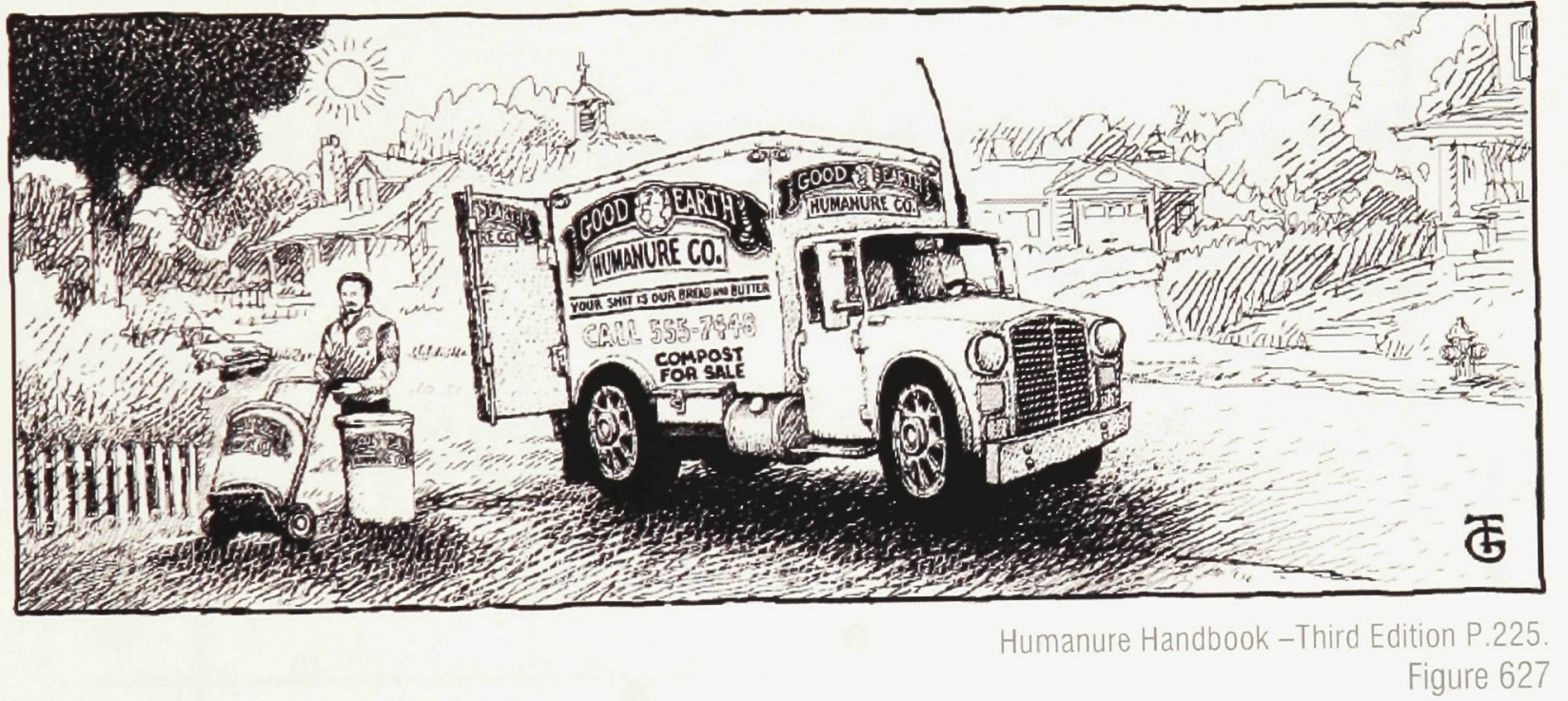

${ }^{112}$ Humanure Handbook P. 152. 


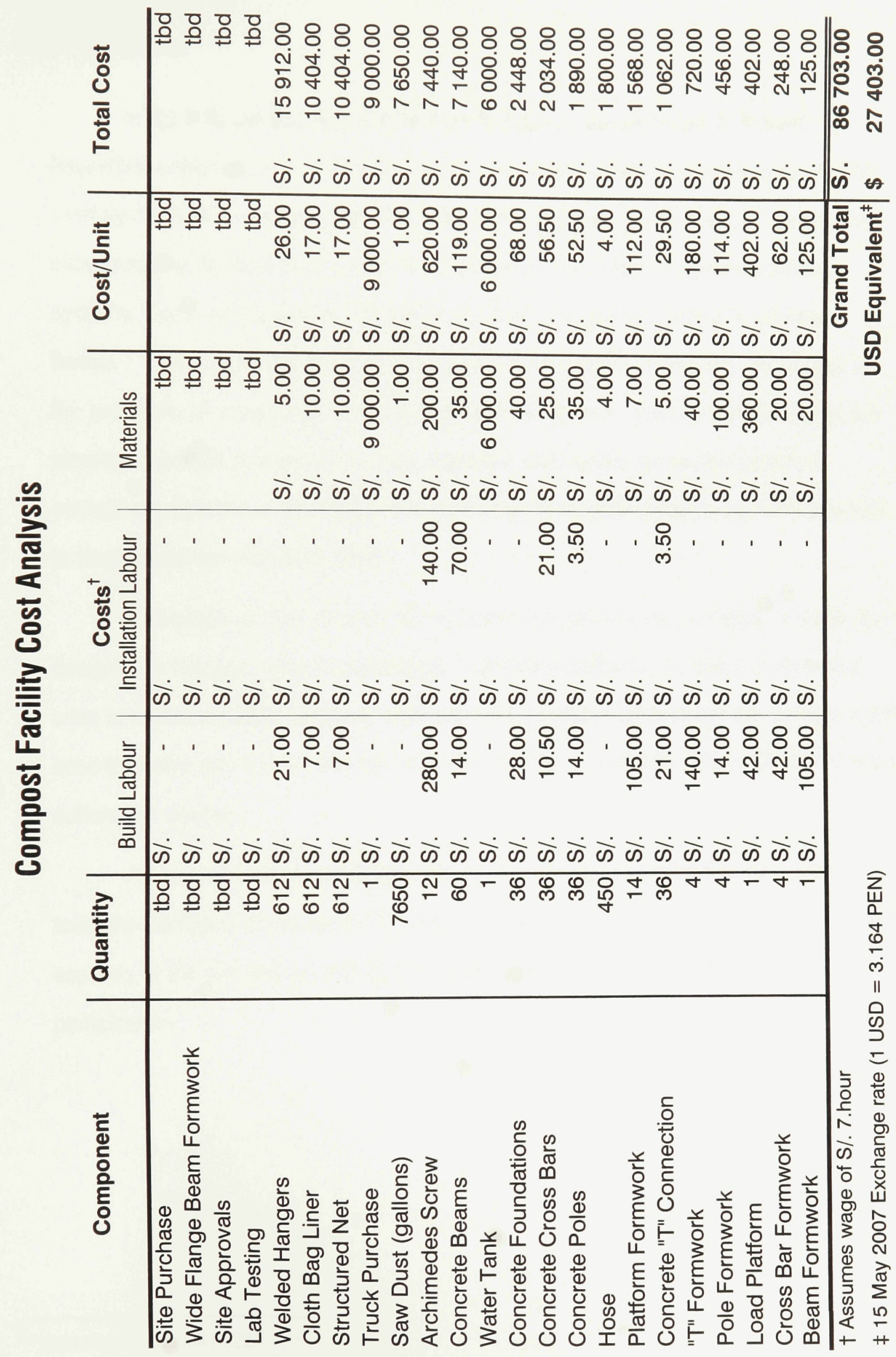




\subsection{Conclusion}

In the final chapter of the Humanure Handbook, Jenkins hints at expanding household compost into a community scale. He predicts that, "composting toilets and toilet systems will continue to be designed and redesigned in our lifetimes. Eventually, entire housing developments or entire communities will utilize composting toilet systems. Some municipalities will eventually install composting toilets in all new homes." ${ }^{113}$ By suggesting the larger design for North American suburbs, he alludes to the possibility of integrating large-scale compost collection where water resources are abundant and soil productivity is high. Arguably, the system for private compost collection presented in this thesis has more value in an informal desert community than in North American suburban homes.

This proposal, like Jenkins' bin system, also has its own economy of scale. It is designed to function within a community 100-600 inhabitants. If Lima's government were to embrace sanitation using compost for hundreds of thousands the solution would need to evolve into a more appropriate system as the community, the resources and the culture will change.

As a mediator between ideals and opportunities, this thesis was designed to meet the sanitation challenge in Pachaqutec. It was sculpted by the economic and social capacity of the site and not intended to be possible without community support and participation.

${ }^{113}$ Humanure Handbook P. 227. 
AGENDA 21. Agenda for the Twenty First Century, New York: UN Publications, 1992.

(31Jan2007, www.un.org/documents/ecosoc/cn17/1994/background/ecn171994-bpch21.htm)

CSD-2. Review of the Sectoral Cluster of Human Settlements. Article E/1994/33

E/CN.17/1994/20, New York: UN Publications, 1994. (5 Feb 2007, www.un.org)

Davis, M. Planet of Slums. London: Verso, 2006.

De Soto, H. The Mystery of Capital: Why Capitalism Triumphs in the West and Fails Everywhere Else. New York: Basic Books, 2000.

Edwards, Davis, Bellido. Joint Publication 12E Evaluation of Peru's National Sanitation Policies. Washington: EHP/USAID, PAHO/CEPIS, IBRD/WSP, 2004.

Fathy, H. Architecture for the Poor: An experiment in Rural Egypt, Chicago: the University of Chicago Press, 1973.

Herz, Khander, SR. Women's Work, Education, and Family Welfare in Peru: World Bank Discussion Papers. Washington: The World Bank, 1991.

Jenkins, J. The Humanure Handbook Third Edition: A Guide to Composting Human Manure. Grove City PA: Published by Joseph Jenkins Inc., 2005.

Kulbhushan, Minakshi, J. Architecture of the Indian Desert. Ahmedabad: AADI Centre, 2000.

Mitchell, Long, Bellassai EC. Recycling from Municipal Refuse: World Bank Technical Paper Number 30. Washington: The World Bank 1984.

Obeng, Wright FW. The Co-composting of Domestic Solid and Human Wastes: World Bank Technical Paper Number 57. Washington: The World Bank 1987.

Schreiber, H. SOS Children's Villages - Tracing the Roots, SOS-Kinderdorf International. Austria: Innsbruck, 2003.

Smith, A. The Wealth of Nations. London: J.M. Dent and Sons Ltd., 1778.

UN-HABITAT. Water and Sanitation in the Worlds Cities: Local Action for Global Goals. London: Earthscan Publications Ltd, 2003.

UN-HABITAT. The Challenge of Slums: Global Report on Human Settlements. London: Earthscan Publications Ltd, 2003. 